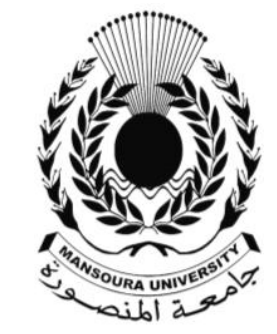

جامعة المنصـورة المانفة

$$
\text { كليـة الآداب }
$$

\title{
المدن الذكية ودورهل في علاج هشكلات النقل الحضري- حالة المدينة المنورة-دراسة جغرافية
}

\author{
إعـــ/د \\ دكتور/ شوهلدي عبدالحميد عبد القادر الخواجه \\ استاذ الجغرافيا المساعد \\ قسم الجغرافيا - كلية الآداب - جامعة المنصورة \\ والاستاذ المشارك بجامعة طيبة بالمدينة المنورة
}




\title{
المدن الذكية ودورهل في علاج مشكلات النقل الهضري - حالة المدينة المنورة-دراسة جغرافية
}

\section{د/ شوهلي عبدالحميل عبد القادر الخواجه}

\author{
ملغص الببحث \\ يعالج هذا البدث الدور الذيّ تؤديه تطبيقات الددن الذكية لإيجاد حلول لمشكلات النقل الحضري، والتتيّ نتجت عن الندو المستصر والمتزايد فيّ \\ أعداد السكان والمركبات، وذلك بالاعتماد على آليات نظم النقل الذكية مثل نظم تحديد المواقع العالميّ GPS، ونظم الموقع الأوتوماتيكي للمركبات \\ AVL \\ ويناقش البحث تطبيقات نظم النقل الذكية والمتمثلة فيّ: النظم المتقدمة للتحكم والسبيطرة وإدارة المرور، النقل العام و معلومات المتنقلين، التحكم \\ بالمركبة وسلامتها، نظم عمليات أساطيل المركبات التجارية، و متطلبات تطبيق نظم النقل الذكية فيّ الددينة المنورة، و أهعية كل منها، ودىى \\ ملاءمتها لواقع المدينة وظروفها الخاصة. مع التركيز على أهمية تطوير خريطة هيكلية لنظم النقل الذكية، والخيارات المتاحة للددينة لتطوير \\ خارطتها الهيكلية، ودوها فيّ ايجاد حلول لمشكلات النقل الحضريّ كتخفيض الضغط المروريّ على شورعها، وتحسين الحركة المرورية، ورفع \\ مستوى السلامة المرورية، والتقليل من الوقت المهر فيّ رحلات النقل الداخليّ، والحد من التلوث البيئيّ واستهلاك الوقود والحوادث المرورية التيّ \\ تمثل تكلفة اجتماعية واقتصادية، بالإضافة إلى زيادة التحكم والسيطرة على النقل وإدرته بفاعلية كبيرة. ومن هنا تأتيّ أهمية هذه الدراسة والتيّ تعد \\ بثثابة تحليل جغرافيّ ديناميكيّ يسلط الضوء على هذه المشكلات وكيفية علاجها فيّ المدينة المنورة.
}

\section{Abstract}

This research addresses the role played by Smart Cities applications to find solutions to urban transport problems resulting from the continuous and growing population and vehicle growth, based on intelligent transport systems such as GPS, AVL automatic location systems, the traffic .

The research discusses the applications of intelligent transport systems: advanced systems for control, control and traffic management, public transport and mobile information, vehicle control and safety, fleet systems of commercial vehicles, and the requirements of the application of intelligent transport systems in Medina, the importance of each, The city has its own conditions. With emphasis on the importance of developing a structural map of intelligent transport systems, options for the city to develop its structural plan, and its role in finding solutions to urban transport problems such as reducing traffic pressure on its streets, improving traffic, improving traffic safety, From environmental pollution, fuel consumption and traffic accidents, which represent a social and economic cost, as well as greater control, control and management of transport. Hence the importance of this study, which is a dynamic geographical analysis that highlights these problems and how to treat them in Medina.

التقنيات المتقدمة. مما انعكس بشكل مباشر على

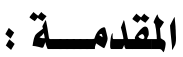

شكل المدينة وتخطيطها، والذيّ يظهر بصور

أدى التقدم التقنيّ الكبير الذيّ واكب العقود

جلية فيّ تقنيات الاتصالات والمعلومات، والذيّ الأخيرة من القرن الماضيّ وبداية القرن الحاليّ،

انعكس على شكل الحياة، وعلى طريقة أداء الأنشطة المختلفة، مؤدياً إلى ظهور مجتمعات جديدة تعتمد اعتماداً كبيراً على المعرفة والتقنيات إلى تطورات سريعة وعديدة فيّ المدن الكبرى، نتيجة التطور فيّ الأنشطة الاقتصادية وزيادة الاعتماد على وسائل النقل، وظهرت اتجاهات الرقمية، ، فظهرت المدن المتطورة التيّ تعتمد على تقنيات المعلومات والاتصالات والذكاء

جديدة للتنمية الحضرية بهدف تحديث المدن القديمة بواسطة تكامل الاستراتيجيات الجديدة مع 
البلدان دون تامين احتياجات تلك القطاعات من

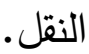

ولقد اهتمت الجهات المعنية بشئون النقل والمواصلات فيّ المدينة المنورة بتأسيس البنية الأساسية لشبكة النقل الداخلية والخارجية، ورفع مستويات الكفاءة والفاعلية بهما ولاسيما شبكة النقل الحضري، ويُعزى ذلك لأن المدينة المنورة تُعد من أهم مناطق الجذب السكانيّ للإقامة فيها، وتوافد الهجرات الريفية عليها، وتوافد ملايين الزائرين من الحجاج والمعتمرين سنوياً، وقد وصل

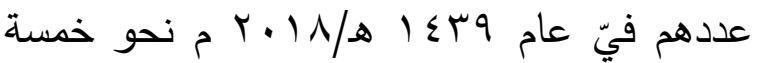
ملايين زائر ( هيئة تطوير المدينة المنورة،ه ( • (Y)، ومن المتوقع أن يزداد هذا العدد ليصل إلى 0, ب

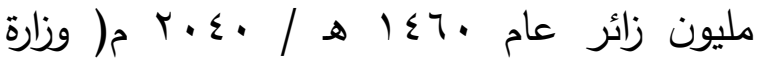
الاقتصاد والتخطيط ، مصلحة الاحصاءات العامة والمعلومات، ابr| الثبكة النقلية فيّ المدينة المنورة باتباع معايير تقنية عالية مرورية

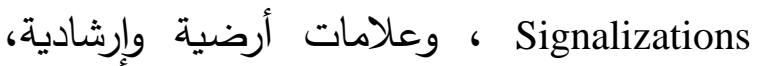
وتقنيات ذكية، وغيرها لتحقيق الأمان على الطرق والتيّ ستساهم فيّ تطوير البنية التحتية لشبكة Total الطرق بشكل فعال وتحقيق الجودة الثاملة -Quality Management وعلى الرغم من أهمية دور النقل الحضريّ فيّ عمليات التتمية بالمدينة المنورة، إلا أن له تأثيرات سلبية على البيئة الحضرية، فع تزايد عدد سكان المدينة، و سرعة ايقاع الحياة بات الطلب على السيارة فيّ تزايد مستمر، ومع تزايد أعداد المركبات والتتوع فيّ استخدامها والاعتماد شبه
الصناعيّ، يطلق عليها المدن الذكية، والتيّ تؤثر مرافقها وخدماتها على صنع السياسات وأساليب التخطيط الحضريّ. وتشكل المدينة المنورة واحدة من المدن الرائدة فيّ المملكة العربية السعودية التيّ تُطبق تكنولوجيا المعلومات ونظم المعلومات الجغرافية وانترنت الأشياء بإمكاناتها القصوى، لاستتباط مفاهيم التخطيط الحضريّ المتكامل للمدن الذكية. وذلك من خلال رؤية تتموية حضرية تنظر وتدمج مختلف التقنيات لإدارة أصول المدينة - بما فيّ ذلك - على سبيل المثال لا الحصر، نظم المعلومات المحلية، والمؤسسات التعليمية، وأنظمة النقل، والمستشفيات، وإمدادات الطاقة، والمرافق، وإدارة النفايات، وتطبيق قوانين الخدمات المجتمعية الأخرى. مما أسهم فيّ التغلب على تحديات التخطيط الحضريّ للمدينة. و يُعد الارتقاء بمستوى قطاع النقل والمواصلات فيّ العصر الحديث من المؤشرات الدالة على التحضر المستمر ، وتعد البنية التحتية لشبكة النقل عنصراً رئيساً من التنمية الثاملة Comprehensive Development ، ولها العديد من المؤشرات حيث يُقاس تقدم الدول بتقدم وسائل ونظم النقل السائدة فيها، وخاصة إذا اعتمدت على تطبيقات تكنولوجية وأنظمة ذكية حديثة، وهيّ تساهم بشكل فعال فيّ تطوير مقدرات المدن في مختلف المجالات. حيث يعد قطاع النقل أحد الركائز الرئيسة للاقتصاد، ودعامة أساسية من دعائم التقدم، ولا يمكن أن يتحقق النمو المتوازن بين قطاعات الاقتصاد الوطنيّ لأي بلد من 


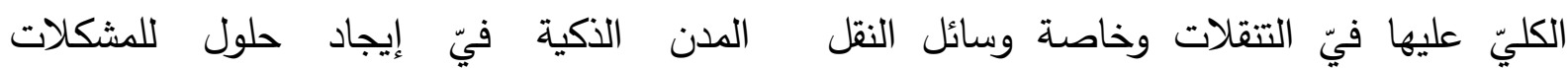
الحضرية، ولأن تلك المشكلات تمس حياة الإنسان الخاص الأمر الذيّ أفضى إلى مشكلات مرورية مباشرة، فإنه من الضروريّ دراستها، والتصديّ لها

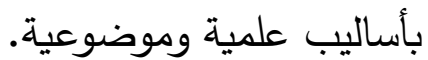
وتمثل نظم النقل الذكية تطوراً طبيعياً للبنية الأساسية للنقل، وذلك بتحديثها لمسايرة التقدم التكنولوجيّ والتقنيّ فيّ عصر المعلومات، وهذا ضروريّ لتزايد الطلب على النقل وخاصة فيّ المدن الكبرى مثل المدينة المنورة، حيث تساعد نظم النقل الذكية على توفير طاقة استيعابية أكبر،

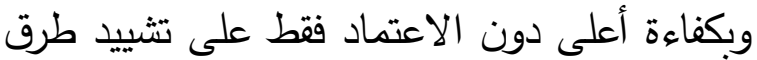
جديدة، كما تمثل إحدى الأدوات الحديثة فيّ تنظيم وتحسين حركة المرور عن طريق اعتمادها على لئ تقنيات الاتصالات والتكنولوجيا الحديثة، وتتكون نظم النقل من عمليات متعددة تتمثل فيّ جمع البيانات بواسطة أدوات الطريق المختلفة، و معالجة البيانات وتحليلها فيّ مراكز السيطرة والمتابعة والتحكم ، ثم نقل المعلومات ونشرها فيّ المدينة عن طريق وسائل مختلفة منها اللوحات المرورية الاككترونية والتيّ تعمل على إعطاء التعليمات للسائقين. وتشير بعض الدراسات إلى أن الجمع

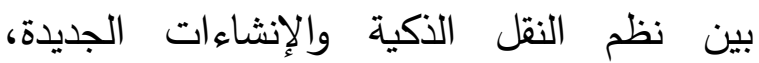
تسنطيع استيعاب النمو المروريّ المستقبليّ،

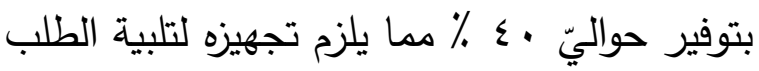

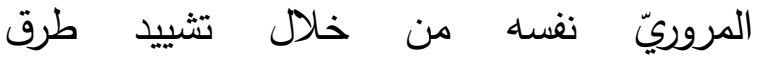
جديدة.) North Dakota 2011 : 8-9. .(Department of Transportation, وتوظف نظم النقل الذكية تقنيات الاتصالات

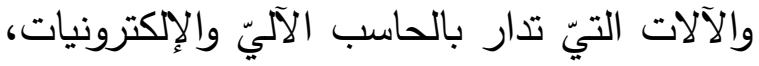
تتعلق بالازدحام فيّ الثوارع والانتظار الطويل عند التقاطعات وما يصاحبه من تلوث بيئيّ وحوادث مرورية ، إضافة إلى المشكلات المرورية فيّ بنية شبكة الطرق والتيّ لم تكن مصممة لاستيعاب هذا التزايد الكبير فيّ حركة النقل والمرور، وباتت مشكلة تتظيم حركة المرور والازدحام والسيطرة عليها معاناةً لجميع فئات المجتمع، وفيّ السابق كانت أبرز حلول مشكلة الازدحام بناء المزيد من الطرق، أو توسيعها لزيادة

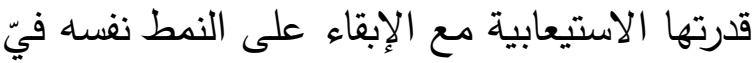

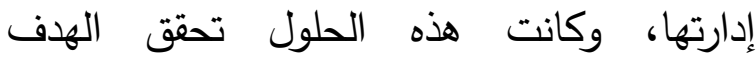
المطلوب على المدى القصير، ولكنها تتطلب موارد مالية وتثغيلية كبيرة مما يشكل عبئًا مالياً

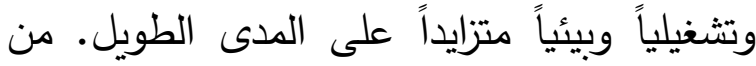

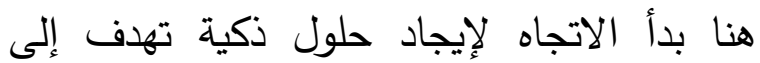
الاستفادة القصوى من السعة الكامنة غير لالئ لإناه المستخدمة للطريق بالاعتماد على التقنيات الحديثة وصولاً إلى إدارة مرورية أكثر كفاءة. ولقد ساعدت الثورة التكنولوجية والمعلوماتية والتقنية للمدينة الذكية في وجود أنظمة معلومات فعالة تلبيّ متطلبات مؤسسات النقل فيّ التعامل

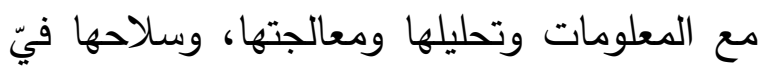
التعامل مع المشكلات الحضرية. وساعد الاستثمار فيّ حلول التقنية المتطورة التيّ تتميز بالفاعلية وقلة التكلفة فيّ تحسين مستويات الحركة النقلية، وإيجاد حلول للمشكلات العمرانية والمرورية

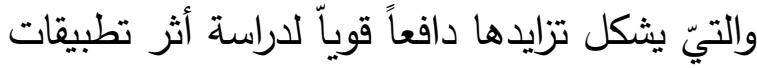


وذلك بتحديد وتسجيل مكان الحادث على شبكة الطرق الداخلية أو السريعة، وبثه إلى مركز المراقبة خلال •ع ثانية من حدوثه، وبثه كذلك الكي إلى لوحات التحكم المرورية، لأخذ الحيطة وتوجيه

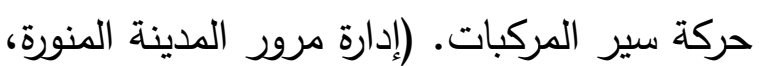

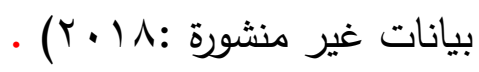

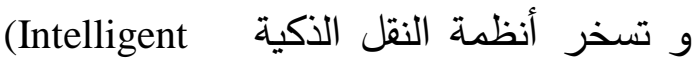
تكنولوجيا Transportation Systems, ITS) المعلومات والاتصالات ( ت م إ) وآخر تقنيات الاستقصاء (Detection) ومعالجة المعطيات (Communication) والاتصالات (Processing) والتحكم(Control) بهدف زيادة الكفاءة التثغيلية لنظام النقل وسعته والحركة العامة، وتخفيض استهلاك الطاقة والحفاظ على البيئة، وتحسين

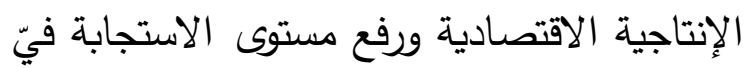

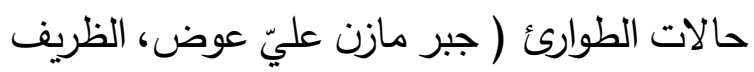

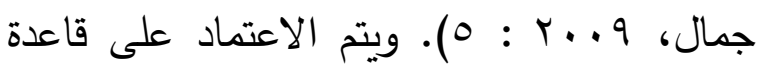
بيانات لأنظمة النقل الذكية ( ITS DATA) BASE والتيّ يتم الحصول عليها من متحسسات لانطئ الطرق ( ROAD SENSORE) والتقارير المرورية، وخرائط المدن، والخطط الانية، وكذلك ولك من سائقيّ المركبات، ورجال المرور، والباحثين في هذا المجال إضافة إلى أجهزة نظم تحديد

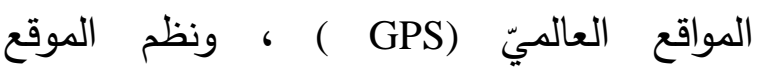
الأوتوماتيكي للمركبات(AVL )، وأجهزة مراقبة

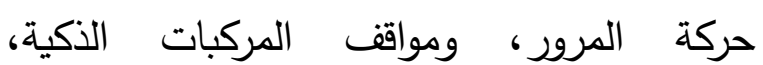

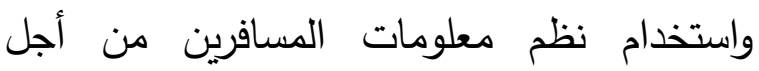
تثجيع الانتقال إلى وسائل النقل الجماعيّ والأقل اجل
ووسائل الاتصالات من الأرض وحتى الأقمار

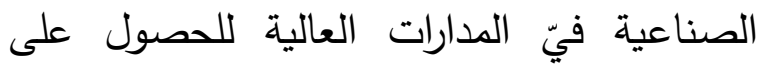
معلومات عن أداء مرافق النقل - من طرق وشوارع ونقل عام وقطارات - وعن الطلب على الى الع لعن النقل والاتصال المتبادل بين المركبات أنفسها،

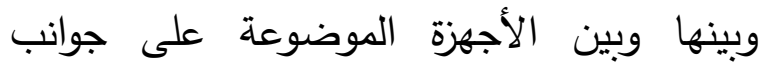
الطرق، وأحيانًاً عن الطقس والظروف الطنان الجوضية والبيئية، وأيضاً عن حوادث التصاديا عن الطفر التروفيكة الوقوع، وتوفير تلك المعلومات وإثاعتها للتداول. وتجمع هذه التطبيقات لنظم النقل الذكية بين القدرة الهائلة للمعلومات، وبين تقنيات التحكم فيّ سبيل إدارة أفضل للنقل (Bart van Arem,2006: 25). وقد تبنت المدينة المنورة عدة استراتيجيات لحل مشاكل النقل بها، لعل أهمها على وجه الإطلاق استراتيجية نظم النقل الذكية التيّ تقدم خدمات كثيرة ومتتوعة للنقل والمرور داخل المدينة منها: إدارة حركة النقل والمرور عند وعلى مداخل المدينة المنورة والطرق السريعة. وإدارة الحوادث المرورية وحالات الطوارئ على شبكة الطرق الداخلية بالمدينة، والطرق الإقليمية و الرئيسة التيّ تقع داخل نطاقها الجغرافيّ. والتحكم فيّ الإشارات المرورية فيّ كل أجزاء الثبكة النقلية. إضافة لتوجيه رسائل مرورية إلكترونية متتوعة عن حالة التهاه المرور، وتحديد الطرق المناسبة وغير المناسبة للحركة مع اقتراح طرق بديلة عبر لوحات منتشرة بشبكة الطرق. وبث معلومات عن حركة المرور

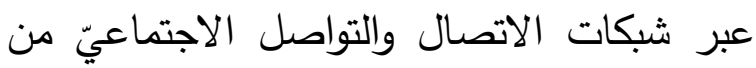
خلال الانترنيت، والجوال. وتتقليص الخسائر الناتجة عن الحوادث بسرعة إسعاف المصابين 
وتربط محاور الحركة الإقليمية للمدينة

المنورة بالمناطق الموجودة داخل المملكة وبالدول المجاورة مثل: الأردن وسوريا وتركيا ومصر ودول الخليج العربيّ شكل( r ) )، كما أن وجود المدينة

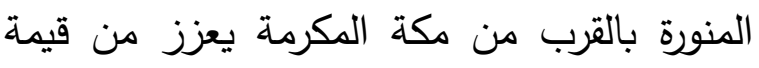
موقعها، إذ ترتبط هاتان الددينتان المقدستان منذ هابن بزوغ فجر الإسلام بشكل وثيق ببعضهما البعض.

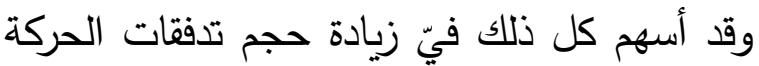
النقلية إلى منطقة الدراسة، وزيادة الضغط المروريّ على شبكة الطرق والثوارع بها، وظهور المشكلات المرورية بصورة جلية، مما استدعى المى البحث عن حلول لهذه المشكلات.

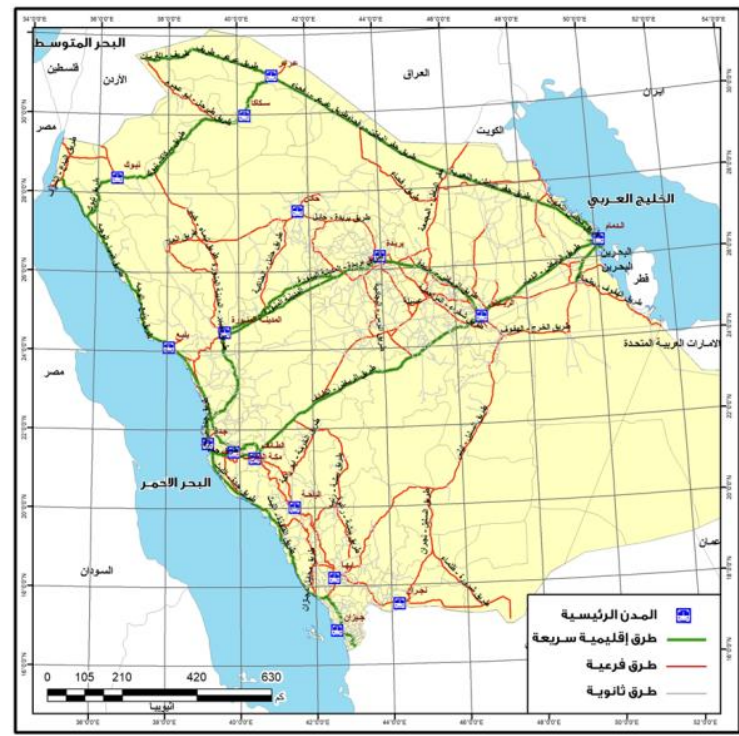

شكل ( r r ) موقع المدينة المنورة كعقدة نقلية رئيسة فيّ شبكة الطرق الإقليمية والدولية وتتوسط المدينة المنورة الإقليم الغربيّ من لإنيات

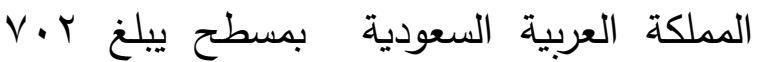
كمr r، مما ساعدها فيّ أن تكون عقدة نقلية رئيسة فيّ شبكة الطرق الإقليمية السريعة التيّ تربطها بمدن منطقتها ومدن الإقليم الغربيّ ومعظم مدن

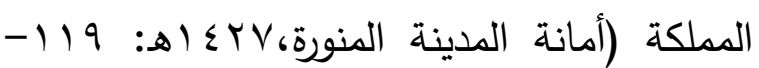

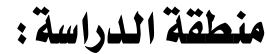

تمثل المدينة المنورة عاصمة إمارة المدينة والقاعدة الحضرية للإقليم، ممتدة بين دائرتيّ

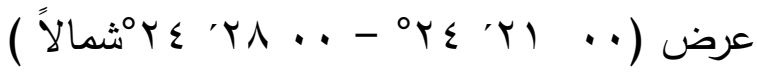

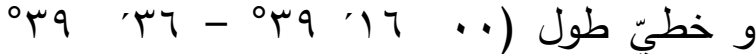
شرقاً)، وتثكل المدينة واحدة من ست مدن رئيسة داخل حدود الأمارة شكل ( 1 ) وترتبط بطرق سريعة تصلها بالرياض فيّ الاتجاه الثماليّ الشرقيّ بطول •90 كم ، و بمكة المكرمة بطول 91 ؛ كم ويتسع لعدة مسارات مرورية حديثة مزدوجة، وبمدينة بدر فيّ اتجاه الجنوب الغربيّ ويتفرع الطريق إلى فرعين الأول يصل إلى جدة فينة

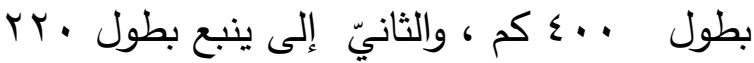
كم، كما ترتبط بتبوك بطريق يتجاوز . . اكم .

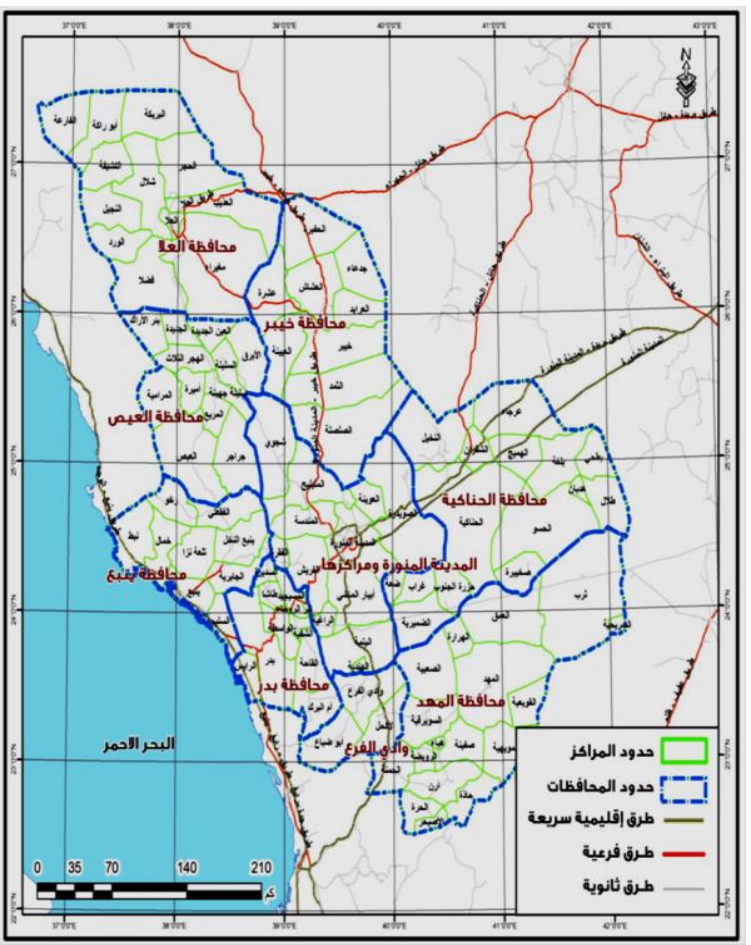

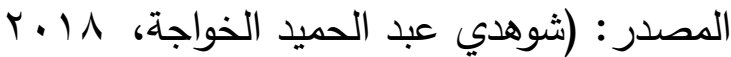
م: شكل (1) الموقع الفلكيّ والجغرافيّ للمدينة المنورة 
وتتأثر شبكة الطرق والثوارع فيّ المدينة المنورة بأشكال سطح الأرض وذلك لتأثيرها الواضح فيّ فئي تحديد محاور حركة النقل وإمكانية الوصول وسهولة التردد على الخدمة، وتأتيّ الجبال على رأس الأشكال التضاريسية المؤثرة فيّ توجيه العمران والطرق فيّ منطقة الدراسة، و تتميز المدينة المنورة بأنها منطقة حوضية رسوبية واسعة لا يزيد ارتفاعها عن بسج م فوق مستوى سطح

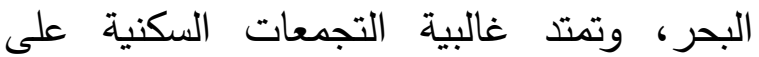

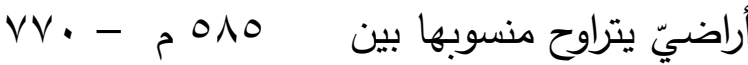
م فوق مستوى سطح البحر بما يعكس استواء السطح فيّ المدينة وقلة الانحدار .( Matsah,\&Hossain,1993:47-77) وتحيط بها الحرات من جهاتها الثرقية والجنوبية والغربية، ويحدها جبل أحد من الثمال،

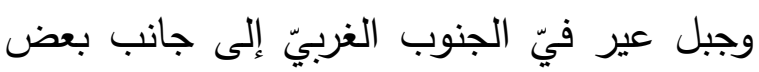
التلال قليلة الارتفاع كسلع وسليع وجبل الرماة، وهيّ تثكل حواجز أو محددات طبيعية لتوسيع النطاق العمرانيّ فيّ المدينة، ويقطع المدينة مجموعة من الأودية مثل: العقيق، رانوناء، مذيب، مهزور، قناة، وبطحان. ويقطع المنطقة السكنية واديّ العقيق ووادي قناه وواديّ بطحان والذين يلتقون فيّ منطقة العيون شمال الددينة ( حامد الخطيب، 0 . . 19 19 ).

وتثكل المدينة المنورة مع مكة المكرمة إقليماً من أكثر أقاليم المملكة سكاناً، بسبب مركزهما الدينيّ الذي جعلهما منطقة جذب للسكان داخلياً وخارجياً، و نتيجة لذلك أصبحت الدينة المنورة إحدى أكبر المدن السعودية المليونية التيّ يزيد
• Y ا )، كما تعد المنفذ أو المعبر الرئيس للمرور بشبكات النقل الثمالية والغربية للملكة العربية السعودية، اضافة إلى محاور حركة دولية تربطها ببعض الدول المجاورة، مثل الأردن وسوريا وتركيا مما ساهم فيّ تدعيم موقعها الذكيّ.. وتتقسم المدينة المنورة إلى V بلديات هيّ: قباء، وأحد، والبيداء، والعقيق، والعيون، والحرم، وتضم كل بلدية عدة مناطق بلغ إجماليّ عددها منطقة، وتضم كل منطقة عدد من الأحياء بلغ عددها فيّ المدينة 1 الميّ. ويأخذ النمو العمرانيّ للمدينة المنورة الثكل الدائريّ حول المركز الذيّ يتوسطه المسد النبويّ الثريف

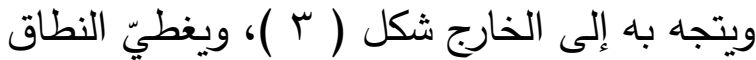

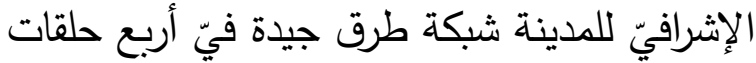
دائرية عملت على ربط الأحياء ببعضها البعض، فضلاً عن شبكة طرق إثعاعية تتجه إلى الخارج من النقطة المركزية والتيّ يمثلها الحرم النبويّ التيّ

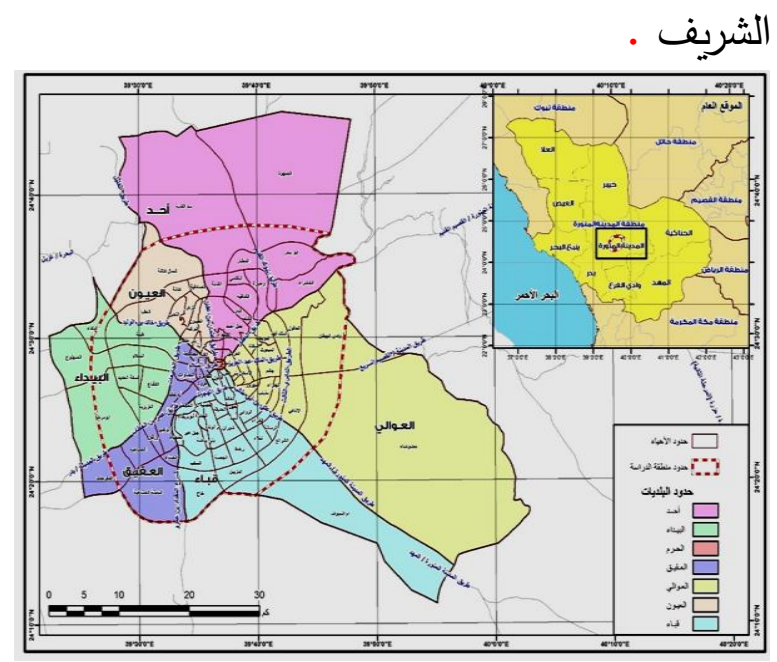

المصدر من إعداد الباحث بناء على خريطة

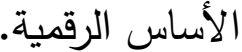
شكل (ץ) التقسيم الإداري للمدينة المنورة عام $\cdot a r \cdot i \mathrm{~V}$ 
الأمد، وتشجيع التطوير المستمر لتقنيات نظم النقل الذكية بمنطقة الدراسة كرد فعل لمتغيرات واحتياجات النقل، والتعرف على الخبرات الناجحة فيّ مجال أنظمة النقل الذكية المتبعة عالمياً، ومحاولة الاستفادة منها بمنطقة الدراسة.

مشكلة الدراسة: تكمن مشكلة الدراسة فيّ افتقار منظومة الإدارة العامة للمرور بالمدينة المنورة لمراكز تخصصية فيها خبرات متطورة بمجال إدارة وتنظيم وتخطيط النقل والمرور، وإلى سياسة عمرانية واضحة، فالتتمية العمرانية للمدينة تتطلب طرقاً

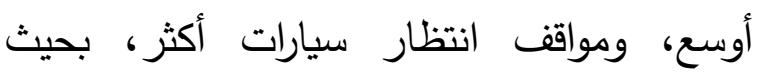
تغطيّ معظم أجزاء الددينة، لتخفيف الضغط على شبكة الطرق وما تعانيه من مشكلات خطيرة، تتمثل فيّ الاختناقات المرورية، وحوادث النقل،

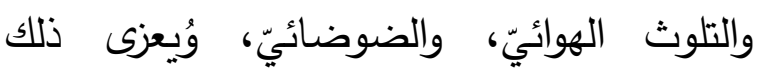
للاعتماد بصورة كبيرة على السيارة الخاصة كبديل لوسائل النقل الجماعيّ العامة، خاصة مع التزايد المتصاعد فيّ معدلات ملكية السيارات الخاصة للسعوديين وغير السعوديين المقيمين بالمدينة المنورة، فضلاً عن نقص آليات التخطيط الملائمة لتوفير منظومة نقل متكاملة التبيّ المتطلبات المتزايدة لحركة السكان، ضمن إطار استراتيجية شاملة لتطوير قطاع النقل تضمن التوصل إلى تخطيط حضريّ متكامل. ومن نافلة القول إن التباطؤ فيّ حل مشكلات النقل داخل المدينة المنورة يتسبب فيّ خسائر كبيرة لاقتصادها، و تزداد الخسائر بمرور الوقت إذا لم يتم علاج هذه المشكلات، ولذلك فقد تبنت المدينة
عدد سكانها عن مليون نسمة ، فالرياض ب, ب

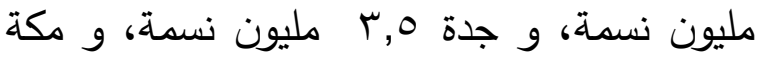

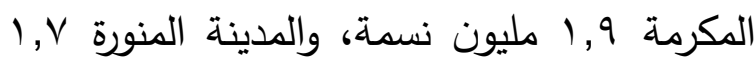
مليون نسمة، و الاحساء 1 .,1 مليون نسمة ومن المتوقع أن يصل عدد السكان بالدينة

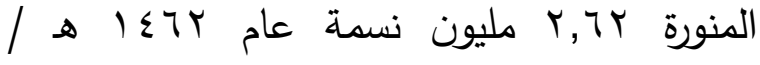

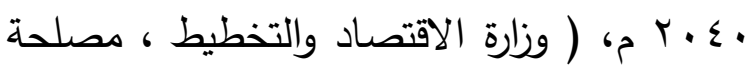

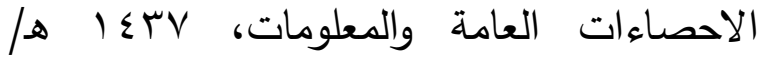

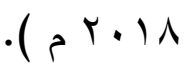

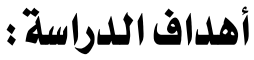
تهدف الدراسة إلى التعرف على نظم النقل الذكية وفوائدها وانظتها وأهم فروعها فيّ ظل التهان التطور السريع لتكنولوجيا المعلومات والاتصالات، وعلى منطلبات أنظمة النقل الذكية بقطاع المرور بالمدينة المنورة، وإلقاء الضوء على الإمكانيات

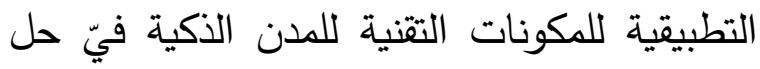
مشكلات النقل والمرور، ودورها فيّ رسم سياسات لهات التتمية الحضرية المستدامة فيّ المدينة من خلال رصد المشكلات المرورية الحالية والمستقبلية، وصولاً إلى إجراءات مقترحة تُهم فيّ حل هذه

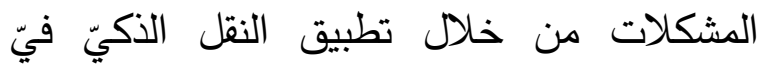
المدينة المنورة كحالة دراسية، وتعزيز كفاءة نظام النقل، وتحسين فاعلية شبكة الطرق والثوارع بزيادة طاقاتها الاستيعابية، وتحسين الحركة المرورية، و تأمين السلامة على شبكة الطرق الطائهانهان والحد من وقوع الحوادث المرورية، ورفع مستوى الإنقاذ لحالات الطوارئ، و إنشاء نظام نقل آمن وتحسين جودة الحياة، و الحفاظ على الطاقة وحماية البيئة فيّ إطار رؤية مستدامة وطويلة 


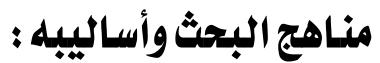

The اعتمدت الدراسة علي المنهج الإقليميّ Approach الثخصـية الجغرافيـة للمدينــة المنـورة، واسـتعان The Descriptive الباحث بالمنهج الوصفيّ النيّة Approach الأرقام والنسب فيّ إطار وصفيّ كميّ، بوصف أنظمة النقل الذكية ، مع إمكانية تطبيقها بقطاع الارفي

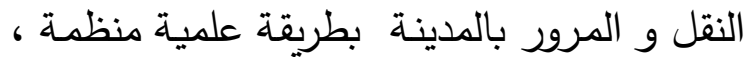
وتحليل وتفسير البيانات واستخراج النتائج ذات الدلالة بمشكلة البحث، ثم يأتيّ بعد ذلك خطوة تقديم المقترحات لحل مشكلة الدراسة.

The وتستعين الدراسة ببعض الأساليب الكمية Quantities Methods النسب المئوية والمعدلات بتوضيح العلاقات والارتباطات بين عناصر منظومة نظم النقل

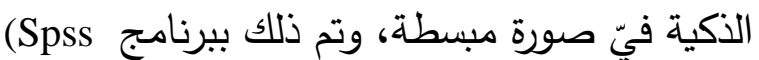
10, Excel XP) The Cartographic Techniques الكارتوجرافية ARC GIS ) حيث استخدم الباحث بعض برامج 10.3) ومنها (Map Info 7,0, Arc Map) وتعد بيئة (GIS) منصة بيانات مكانية مناسبة للكثير من محاور المدن الذكية مثل أنظمة النقل والطاقة Joseph, T. , ) (الاتصالات والسكان وغيرها . (2014: 41-45 كما تم استخدام أسلوب الدراسة الميدانية والذيّ يعتمد على جمع البيانات بواسطة استمارة الاستبيان Questionnaire،والمقابلات الحرة Direct Open Interviews والملاحظة المباشرة
استراتيجيات لمعالجة مشكلات النقل لعل أهمها

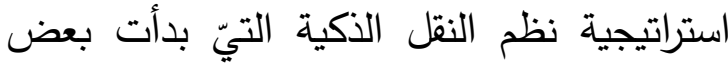

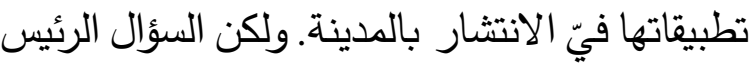
هنا : هل ساهدت تقنية نظم النقل الذكية فيّ حل

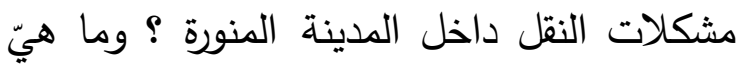
الآليات التيّ تم تطبيقها فيّ هذا الصدد لتفعيل هذه التقنية؟ وللإجابة عن هذه الإشكالية، جاءت هذه

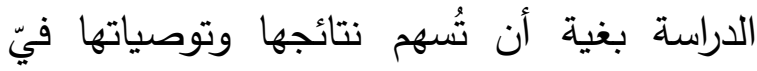
الارتقاء بنظم النقل الذكية ومحاولة تطبيقها فيّ المدينة.

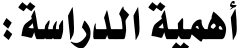

تتبع أهمية هذه الدراسة فيّ التعرف على أهم مقومات البنية الأساسية التيّ تخدم النقل فيّ لإه المدينة المنورة، و إفادتها بعض الادارات والهيئات المعنية بقضايا المرور بالمدينة المنورة، و القائمين على تخطيط إدارة وتنظيم النقل والمرور، بما تقدمه من بعض المقترحات، لنجاح أنظمة النقل الذكية فيّ قطاع المرور، و الحد من المشكلات المرورية بمنطقة الدراسة. ومساهمة أنظمة النقل الذكية فيّ مجالات التمية الاجتماعية والاقتصادية. كما تحقق إدارة أنظمة النقل الذكية المتكاملة التكامل بين وسائل النقل المتنوعة، وتحليل وسائل النقل الجماعيّ والنقل الخاص، وهيّ من الأمور الضرورية لتحسين مستوى ونيّ المعيثة، وجذب الاستثمارات الداخلية والخارجية، وازدهار الاقتصاد فيّ المدينة المنورة. ورفع معدلات الجودة والرضا عن أنظمة النقل الذكية بمنطقة الدراسة. 
حركة النقل بصفة عامة، وكيفية تطوير مستوى أنظمة وخدمات النقل ورفع كفاءتها في المدينة

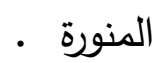

\section{الدراسات السابقة: - الدورة}

تعرضت هذه الدراسة لطرح عدد من الدراسات

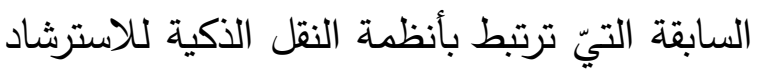
ببعض نتائجها وكانت على النحو التاليّي:

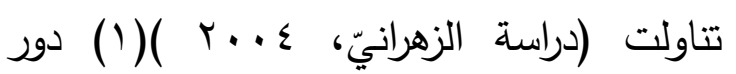
التقنيات الحديثة فيّ التقليل من الدخالفات التهات التانيل المرورية، حيث عالجت المخالفات الأكثر خطورة كالتيّ تقع عند التقاطعات، وتتمثل فيّ تجاوز الإشارة الحمراء، ومخالفات تجاوز السرعة التيّ تقع على الطرق التيّ تربط بين مدن المملكة، و ولئ نتج عن معالجة هذه المخالفات تقليل أعداد الحوادث المرورية و خفض الإصابات والوفيات،

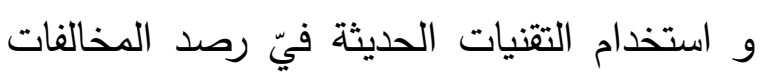

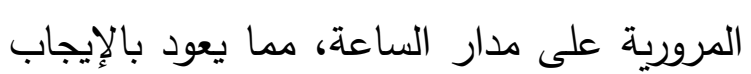

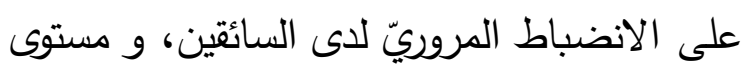

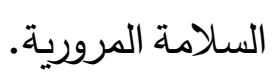

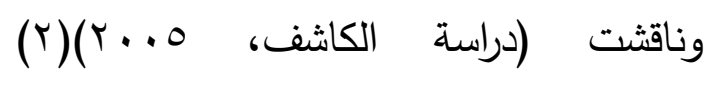

التقنيات الحديثة لتطوير سلامة المرور، ووجهت أنظار العاملين بمجال النقل والمرور إلى الوسائل

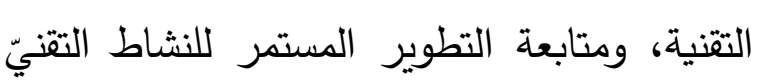
كرد فعل لمتغيرات و متطلبات النقل. وتأثيرها على أمان المرور، ومردوداتها ل الاقتصادية. ووضع الضوابط القياسية والإجراءات الملزمة لهيئات ومسؤوليّ إدارة الطرق والنقل ومستخدميّ وليّي الثبكة النقلية. وتوصلت الدراسة إلى عدة نتائج

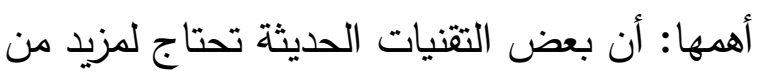

Observation وخصائص شبكة الطرق، والخدمات اللوجستية Logistic Services النقل، والتدفقات المرورية، و تحديد ساعات الذروة، والأحجام المرورية، وتصنيف المركبات ومراقبة تأثير حركاتها، ورصد المشكلات المرورية والتيّ تتثأ نتيجة مخالفة أو تجاوز

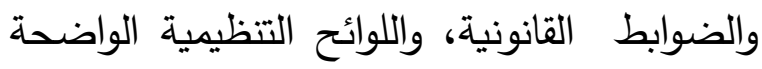

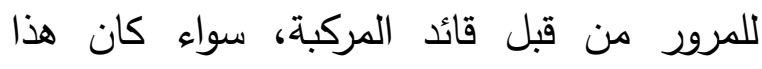

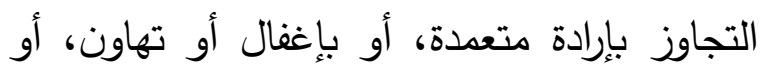

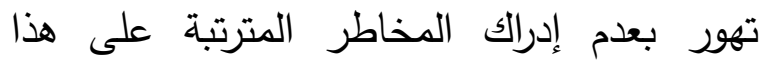
التصرف، أو نتيجة أخطاء فيّ تصميم وتخطيط هندسة شبكة الطرق والثوارع أو بالنسيج العمرانيّ تهيّ وتئي للمدينة . وقد تمت الدراسة الميدانية فيّ الفترة من شهر

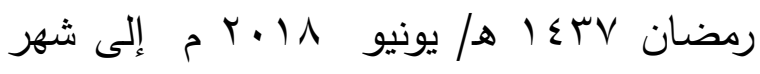

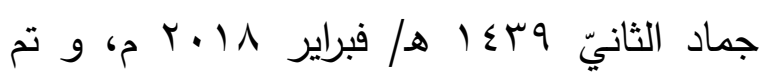

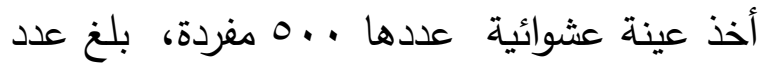

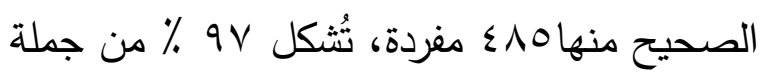
أعدادها، تم توزيعها على المقيمين والزائرين من من من منان داخل مناطق المملكة بنسبة ا,r؟ ٪ و و الزائرين

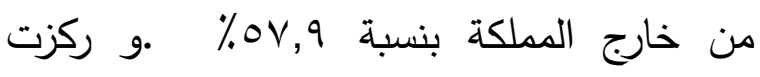

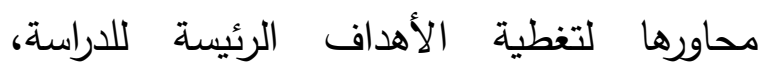
واستكثاف آراء وانطباعات المبحوثين ومستوى الاهي رضاهم عن جودة أنظمة النقل الذكية ومشكلات النقل بمنطقة الدراسة، وتقييمهم لخدمات النقل الداخليّ وخاصة النقل التردديّ ومواقف النقل الذكية أسفل الحرم النبويّ الثريف وفيّ المنطقة المركزية، والإرشادات المرورية، وسهولة وانسيابية 
الذكية بشكل كامل فيّ وسائل المرور المختلفة، وعدم فاعلية نظم ضبط المخالفات المرورية المتمثلة فيّ تجاوز السرعة، وعدم وجود بنية اتصالات لمواكبة احتياجات نظام المرور فيّ جميع أقاليم المملكة.

واهتمت (دراسة قستيّ، 9 ج. . r ) (0) بتثنيات السلامة فيّ السيارات والمركبات وأهميتها في تقليص خطورة الحوادث المرورية. وألقت الدراسة الضوء على التقنيات الحديثة المستخدمة فيّ السيارات والمركبات وأبرزت دورها فيّ الحد من خطورة الحوادث، والتعرف على أنظمة النقل الذكية من حيث أهدافها ومجالاتها وعناصرها وتطبيقاتها. والاستفادة من التقدم الكبير فيّ تقنيات الاتصال والمعلومات، ووضع معايير ومواصفات لأجهزة السلامة فيّ المركبات ليسمح لها الدخول والعمل على شبكة الطرق فيّ المملكة، وإجراء دراسة لوضع بروتوكول اتصالات خاص بأنظمة النقل الذكيّ ، وإنشاء مراكز ومعاهد لأبحاث النقل برون والمرور - (- مي

وسلطت دراسة ( مزرا ، • + • ) (T) الضوء على دراسة تحليلية لوجستية فيّ تطوير وتحسين خدمات النقل الخاص بالعراق، واستعرضت تطبيق نظم النقل الذكية فيّ العراق، والتيّ تبدأ بتعريف نظم النقل الذكية، ووظائفها، ومجالاتها التطبيقية الخمسة لغرض تأهيلها. و أوصت الدراسة بإنشاء مركز تخصصيّ بإدارة وتنظيم وتدريب سواق النقل الخاص على أحدث الأساليب والتقنيات المطبقة إقليمياً وعالمياً، و توفير الكادر البشريّ العلميّ من خبراء متخصصين فيّ خدمات النقل، ووضع
الدراسات الاقتصادية للتأكد من مناسبتها، وجدواها الاقتصادية، وقابلية تطبيقها، ثم أكدت الدراسة أن للتقنيات الحديثة تأثير إيجابيّ فيّ تجويد وتحسين

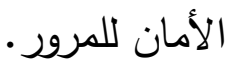

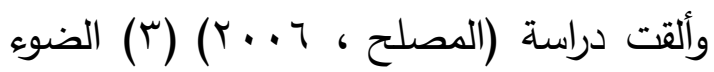
على تحليل ونظرة مستقبلية قصيرة الأمد لمخطط المواصلات فيّ مدينة جنين. وهدفت الدراسة لتحديد المشكلات والمعوقات المرورية فيّ شبكةِ الطرق والتقاطعات، ودراسة العوامل المؤثرة فيّ تطور الثبكة النقلية وعلاقتها بالتطور العمرانيّ للمدينة ومخططاتها الهيكلية، ووضع بعض المقترحات لتظيم وتخطيط الشبكة، ومعالجة مشكلات ومعوقات النقل القائمة فيّ المدينة. وتوصلت الدراسة إلى أن أعداد المركبات العموميّ كثيرة، مقارنة مع الطلب على هذا النوع من وسائل النقل، وأن التقاطعات المرورية بالثبكة تفتقر لعناصر التخطيط والتظيم فيّ التصميم، ولا يوجد استخدام لأنظمة النقل الذكية، والحاجة إلى زيادة ساحات انتظار المركبات الخاصة، وزيادة مواقف الحافلات والتاكسيّ العدوميّ للرحلات الداخلية

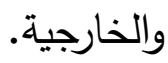

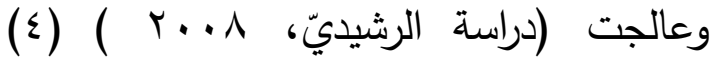
الضبط المروريّ ودوره فيّ الحد من المخالفات المرورية - نموذجاً المملكة العربية السعودية، و و هدفت الدراسة إلى: التعرف على تطور المخالفات المرورية والأساليب الرقابية لضبطه، و الحد من المخالفات المرورية باستخدام الضبط المروريّ الآليّ بوسائله وتقنياته الحديثة . وتوصلت الدراسة إلى عدد من النتائج أهمها: عدم تطبيق أنظمة النقل 
وتطوير وتفعيل نظام النقل الذكيّ طويل المدى مرن ومتكامل مع الرؤية للنقل.

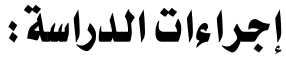

أُجريت الدراسة على أنظمة النقل الذكية ووظائفها ومجالاتها التطبيقية، ودورها في رفع مستوى السلامة المرورية وتحسين الحركة المرورية. مع مناقشة أهمية كل منها ومدى ملاءمتها لواقع المدينة المنورة وظروفها الخاصة، و التركيز على أهمية تطوير خريطة هيكلية لنظم النقل الذكية فيّ المدينة المنورة. وقد مرت إجراءات الدراسة بعدة مراحل عُنيت

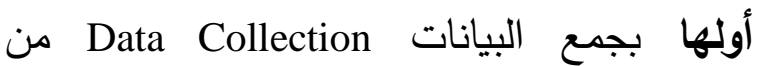
مصادرها الأساسية والثانوية، والاطلاع على الدراسات السابقة ، ومراجعة البيانات الإحصائية من الإدارات المختلفة كإدارة مرور منطقة المدينة المنورة، وأمانة المدينة، وهيئة تطوير المدينة، والمرصد الحضريّ، وركزت المرحلة الثانية على تصنيف بيانات أنظمة النقل الذكية، وتبويبها، والعوامل المؤثرة فيها، وتمثلت المرحلة الثالثة في التحليل المكانيّ لمواقع نظم النقل الذكية بأنواعها علي شبكة الطرق بالمدينة المنورة عام ^بـ اهـ اهتمت بالدراسة الميدانية لتحقيق أهداف الدراسة، وقد أُخْذت عينة تمثل مجتمع الدراسة وتوصلت إلى عده نتائج من تطبيق الاستبيان، وقد وزعت الاستمارات على ^اجنسية مختلفة، وكان أكثر

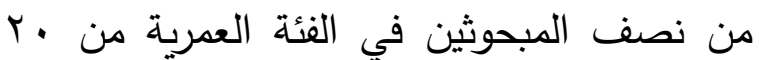
لأقل من ·ـ سنة، وما يزيد عن ثلثهم في الفئة

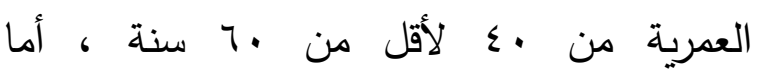

هيكلية إدارية وتتظيمية علمية وعملية لإعداد الخطط المستقبلية لقطاع النقل وأساليب تطوير عملة.

وتناولت دراسة (صادق - سفور، با. ץ)

المدن الذكية ودورها فيّ علاج مشكلات النقل (V) فيّ مدينة دمشق، واهتمت بنظام النقل الذكيّ، والعناصر المكونة له وتحديات تطبيقه، والدور الذيّ يؤديه فيّ حل المشكلات المرورية، ثم عرضت لمجموعة من التجارب المماثلة لتطبيق نظم النقل الذكية، وصولاً إلى وضع توصيات تُسهم في حل المشكلات المرورية في مدينة دمشق .

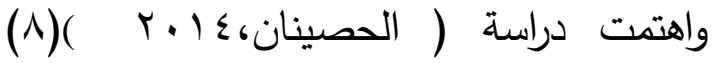
بأنظمة النقل الذكية مع امكانية تطبيقها بقطاع المرور بدولة الكويت، مشيرة إلى العناصر الأساسية لأنظمة النقل الذكية، وخدماتها فيّ مجال المرور، ثم عرضت خبرات الدول فيّ مجال أنظمة النقل الذكية، وقد توصلت الدراسة إلى عدد من النتائج أهمها: الحاجة إلى نظام نقل عاليّ الكفاءة للتقليل من المشكلات الاقتصادية والبيئية التي تسببها الأزمة المرورية ،وعدم وجود ربط بين قطاع النقل و الخطط التتموية للدولة .

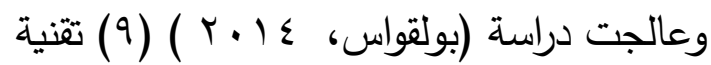
نظم النقل الذكية كاستراتيجية لتطوير قطاع النقل، وتتاولت تطبيقات نظام النقل الذكيّ كآلية لتطوير قطاع النقل العام والنتائج المترتبة على تبنيه، وخلصت الدراسة بأن تقنية نظم النقل الذكية ستساهم من دون شك فيّ التقليل من مشكلات النقل الحضريّ، وتوصلت الدراسة لضرورة وضع أطر قانونية لنظام النقل الذكيّ وتطبيقها بصرامة، 
الذكية من استغلال تقنيات الحوسبة الذكية وخدمات البنية التحتية الحيوية للمدينة فيّ تحسين الأوضاع الاقتصادية والاجتماعية والسياسية، التي

تقابل المجتمع( Washburn, D. , 2010: 26 (2). وتتعدد مفاهيم المدينة الذكية، ولكن المفهوم الأرجح هو "المدن الرقمية" و"المدن الإيكولوجية"، و ترتكز خدماتها على البنى التحتية لتكنولوجيا المعلومات والاتصالات، والتيّ تُسند إليها عمليات تحديد وتجميع وفرز وتصنيف وتثغيل وتحليل كافة البيانات التيّ تكون المدينة فيّ حاجة إليها، وإرسالها إلى متخذ القرار بالثكل الذيّ يتفق مع احتياجاته، وبالشمول والنوعية المطلوبة وفيّ التوقيت المناسب

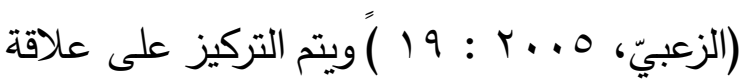
المعلومات بالتكنولوجيا والأفراد والمؤسسات والمجتمع ككل ، حيث تزود نظم المعلومات كنظام الأفراد والمؤسسات باحتياجاتهم من المعلومات

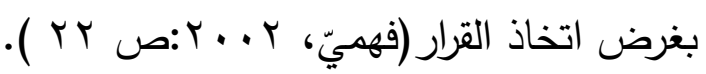
و تثير تكنولوجيا المعلومات أساساً إلى إلى التجهيزات المادية الملموسة (الحواسيب ولوازمها) وغير الملموسة (البرامج بختلف أنواعها)، ومختلف التقنيات التيّ تسمح بإنتاج المعلومات مثل أنظمة المرور الذكية التيّ تُدار آلياً، وقد مرت نظم المعلومات فيّ مجال النقل بتطورات أساسية منذ الستينيات من القرن العشرين فيّ أهدافها وغاياتها مسايرة بذلك التطورات في جميع أنحاء العالم نتيجة لزيادة التحضر والنمو السكانيّ وخاصة عدد السيارات الذيّ سمح بظهور ظاهرة الضواحيّ. وتساعد هذه التكنولوجيا فيّ ايجاد حلول مبتكرة لمشكلات الحضر خاصة الازدحام
المستويات التعليمية لأفراد العينة فكانت معظمها للمتعلمين من المرحلة الأساسية حتى ما بعد

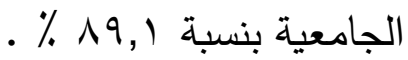
استخدم الباحث فيّ عرض موضوع الدراسة منهجا علمياً تناول النقاط التالية:

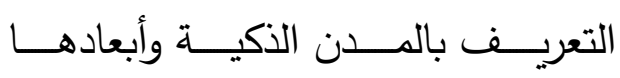
وتطبيقاتها فيّ المدينة المنورة.

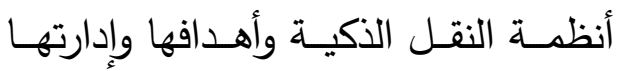
ومكوناتها فيّ المدينة المنورة. تحليل منظومة النقل وتقيمها فيّ المدينة المنورة.

مجـالات التطبيـق الرئيســة لـنظم النقـل الأكية ونتائجها فيّ المدينة المنورة. أليــة تنفيــذ اســتراتيجية النقـلـل الـــكي وتحديات تطبيقها فيّ المدينة المنورة. الخاتمـة وينتهي البحث بخاتمـة تضـنت نتائج الدراسة وأهم المقترحات.

أولاً : التعريف بـالملدن الذكية وأبعادهـا وتطبيقاتها في الملدينة المنورة ا - مفهوم المدينة الأكية smart city تُعرف المدينة الذكية بأنها منطقة حضرية متقدمة تتميز بمستوى معيشة مرتفعاً ومتطوراً، لتتحول أنظمتها إلى مستويات متقدمة مرتكزة على المعرفة للوصول إلى المعلومات والبيانات المطلوبة فيّ أيّ وقت، وزيادة القدرة على إيجاد الحلول للمشكلات الحضرية بالسرعة المرجوة ، و و قد ظهر مصطلح المدينة الذكية بعد سنة ... م، بهدف التوصل إلى تغييرات تعتمد على التقنيات الحديثة فيّ المدن. وتتبثق فكرة المدينة 


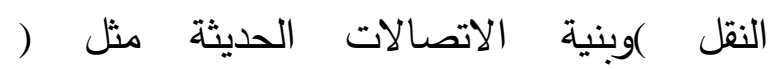
ت.م.ا)،وتحسين النمو الاقتصاديّ و وتحفيز مؤسسات الأعمال للاستثمار ، ورفع مستوى جودة الحياة ، وخدمات البنية التحتية الحيوية للمدينة لتكون أكثر ذكاءً وترابطاً وفاعلية "(24) .(Washburn, D. , 2010: وتركّز منظومة المدينة الذكية على كيفية استخدام التكنولوجيا الذكية فيّ حياة المدينة بصورة مستدامة وقدرتها على التطبيق بصورة دائمة. فالمدينة الذكية هيّ مدينة تتميز بمستوى عالٍ من

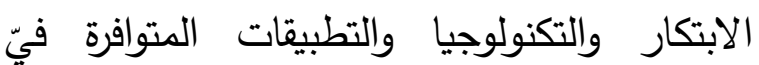

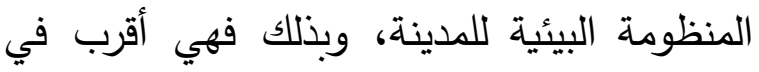
خصائصها من المدينة الرقمية، ومدينة المعرفة، والمدينة الخضراء، التيّ تربط التحولات التكنولوجية المعلوماتية بالتغيير الاقتصاديّ (Hollands, R.G والسياسيّ والاجتماعيّ والثقافيهي ، 2008:303-320)

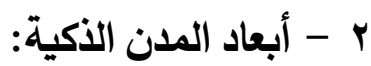
تتطور المدن الذكية بناءً على أبعاد عديدة، و

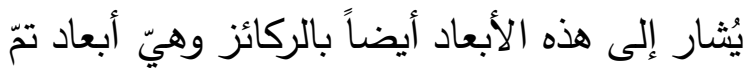

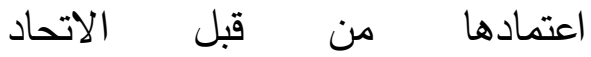
الاوروبيّي Giffinger,Retat,2007:56-57) وتمّ تصنيفها فيّ ستة مجالات رئيسية كلها أساسية فيّ وجود المدن الذكية، ودعائم لتطويرها .و يمكن تحديد ستة أبعاد مميزة للمدينة الذكية، ترتبط بدورها بنظريات التتمية والنمو العمرانيّ التقليدية كالنقل، والاقتصاد، والموارد الطبيعية، ونوعية

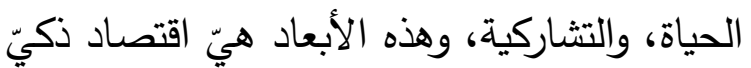

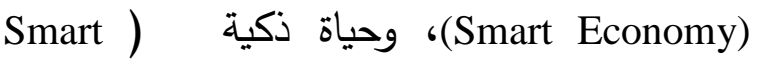

المروري، والتلوث البيئيّ، والضغط على المرافق العامة وتقليل وقت تتقل المواطن بالتخطيط مقدماً لرحلته والوصول إلى الوجهة النهائية بكفاءة،

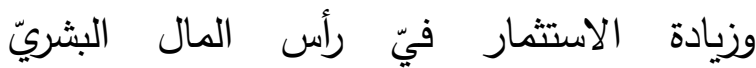

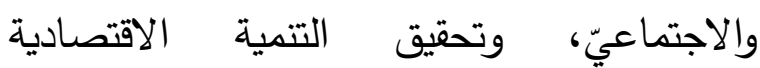
المستدامة والجودة العالية لحياة المواطنين، و Pardo, T., \& الإدارة الحكيمة للموارد الطبيعية .( Taewoo, N. , 2011 :. 282-293) و تعتمد المدينة الذكية على المشاركة الفعالة من المواطنين القادرين على اتخاذ القرار ، Internet of والأنظمة الذكية، أو أنترنت الأشياء Things، ليستطيع مزوديّ الخدمات استخدام البيانات فيّ تقديم الخدمات اليومية ومساعدة واضعيّ الخطط الاستراتيجية فيّ إدارة و اتخاذ القرارات، ومثال على ذلك أجهزة الاستثعار Real-time Sensors و وتكنولوجيات أخرى عديدة ـ وتسعى المدن الذكية لتوفير بيئة رقمية صديقة للبيئة ومحفزة للتعلم والإبداع تسهم فيّ توفير بيئة مستدامة تعزز الثعور بالسعادة والصحة و المشاركة (Link Sharing) أيّ اشراك المواطن فيّ تخطيط مشرعات كبيرة فيّ المدينة لتلبية احتياجاتها كي تكون ذكية ( Dameri, R.P.) ., 2013: 2544-2551

ويتطلب تطوير المدن الذكية رؤية تنموية حضرية تدمج مختلف تقنيات الحوسبة الذكية لإدارة أصول المدينة، بهدف تحقيق حياة سعيدة و آمنة وفعّالة للمواطنين. و الادارة الحكيمة للموارد

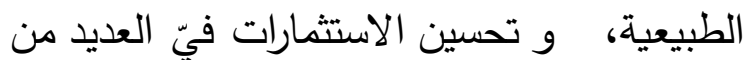

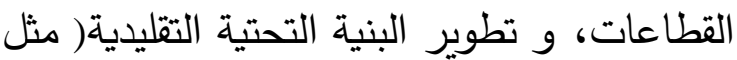


المبادرات المهمة للوزارة لاستكمال مشروع دراسة مكونات المدن الذكية، وتعميمها وتفعيل تطبيقها. وقد أظهرت دراسات المنظومة أن مدن المملكة تتفاوت فيّ مدى جاهزيتها للتحول إلى مدن ذكية، حيث بينت دراسة مكونات المدن الذكية أن مدينة مكة المكرمة تأتيّ فيّ المرتبة الأولى من حيث الجاهزية، تليها مدينة الرياض، ثم مدينة جدة،

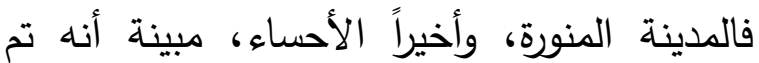
إعطاء وزن نسبيّ لـكونات الاستبانة التيّ

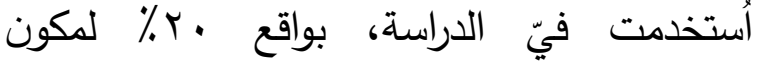

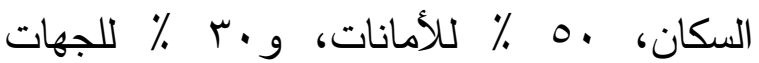
المركزية. و بدأت منظومة الثؤون البلدية والقروية فيّ صياغة سياسات وطنية واستراتيجيات محلية لتحويل المدن الخمس على مراحل عدة بحيث يتم تحويل مدينتين إلى مدن ذكية خلال

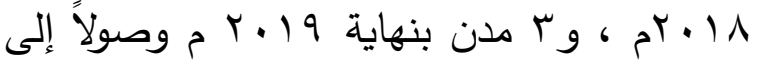
O مدن بنهاية •r.r.r • وكثفت المنظومة أنها تجريّ حاليا دراسة لتحديد مدى جاهزية المدن السعودية للتحول إلى مدن ذكية، وذلك بالاستتاد إلى أفضل الممارسات العالمية والعلمية بإعداد استطلاعات رأيّ ميدانية من خلال تعبئة استبانات تتضمن ستة أبعاد هيّ :الرؤية، ثقافة الابتكار والمشاركة، الإجراءات، التقنية، البيانات، التخطيط

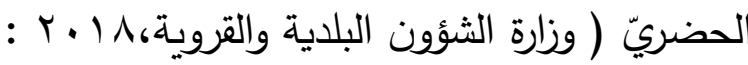
غير منشورة). كما أوضحت المنظومة أن الاستطلاع

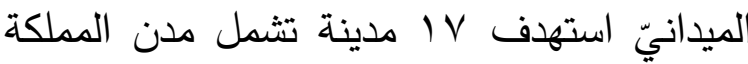

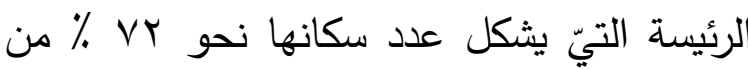
إجماليّ سكان المملكة، وهيّ: مكة المكرمة، لهئل
(Siving )، وبيئة ذكية ( Smart Environment)، (S)

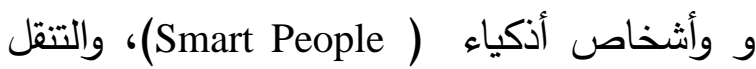

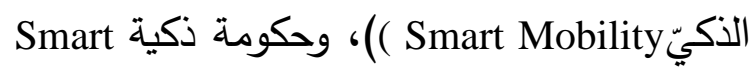
Governance الحاضر لزيادة تطبيق فوائد التقنيات الحديثة وتوسيع مجالاتها للتطوير الحقيقيّ لعناصر Stratigea ( المدينة بما يتماشى مع التحول التقنيّ لافيّي .( Anastasia, E.A, 2015 : 43 وتشها المدينة المنورة كغيرها من المناطق الحضرية فيّ المملكة العربية السعودية نمواً متسارعاً على تكنولوجيا المعلومات والاتصالات، والتحول الرقميّ فيّ أوساط الأفراد والثركات، والجامعات، والإدارات الحكومية. الأمر الذيّي الذيّي يشكل قوة دافعة للتحول الاجتماعيّ والاقتصاديّ فيّ المدينة لتحسين جودة الحياة للمواطنين، وتشجيع رجال الأعمال على الاستثمار، ودفع عجلة النمو الاقتصاديّ فيّ المستقبل. وقد وضعت المملكة العربية السعودية أكثر من مدينة فيّ خطط التحول إلى المدن الذكية، ففيّ إطار بلورة رؤية المملكة التطويرية ·. ·rمه تسعى المملكة للتحول إلى نموذج المدن الذكية، وأطلقت منظومة الثؤون البلدية والقروية مبادرة 》تطبيق مفاهيم الددن الذكيةه كإحدى مبادرات التحول البلديّ المنبثق من برنامج التحول الوطنيّ،·r·rم وتستهدف المنظومة تطبيق مفاهيم وعناصر المدن الأكية فيّ خمس مدن سعودية بلول.r.r.r بالثراكة مع القطاع الخاص، مشيرة إلى أن المبادرة تمثل إحدى 


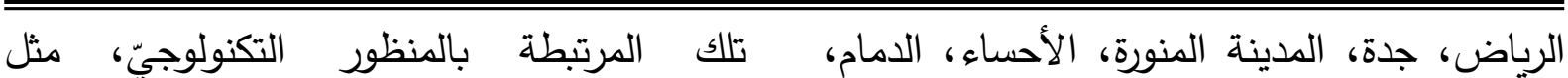
الاتصالات والحزم العريضة Broadband، بل تتخطاها الإلكترونية(E-Government)، والتجارة الإككترونية الخبر، القطيف، الطائف، بريدة، عنيزة، أبها، خميس مشيط، جازان، تبوك، نجران، سكاكا، (E-Commerce) ويُسهم تحول المدينة المنورة إلى مدينة ذكية فيّ لوتي والسياحة الآكترونية(E- Tourism)، ومناطق جذب الاستثمارات، وتوفير فرص العمل، ورفع الترفيه (Technology Parks)، والتعليم عن بعد التاني مستوى المعيشة ، و تمتلك المدينة المنورة الكثير

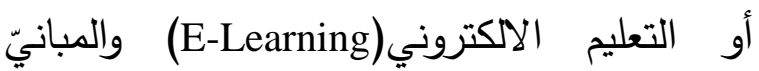
من المقومات التيّ تؤهلها بأن تصبح من المدن التصني الذكية، و ومنظومة الأمن والسلامة، والمراقبة، وحتى الثبكات المنطقية، و بخاصة للنقل وأنظمته الذكية، وذلك فيّ إطار نمو اقتصاديّ

مستدام، وتثكل الحركة الذكية ( SMART) MOBILITY إلى مدينة ذكية، وتعتمد على استخدام(ت م.ا ) فيّ دعم وتكامل أنظمة النقل و لوجستياته لزيادة الترابط بين أجزاء المدينة، وسهولة امكانية الوصول بكفاءة أعلى، وهو ما يسمى بالحركة الذكية .

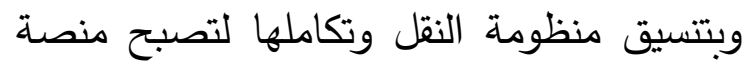
افتراضية موحّة، بما فيّ ذلك جميع وسائل النقل. ويساعد الاعتماد على منظومة النقل الذكيّ فيّ المدينة المنورة على توفير النقل السريع والآمن والنظيف، وزيادة الطاقة الاستيعابية للشبكة النقلية

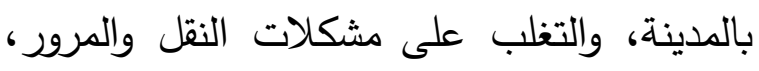

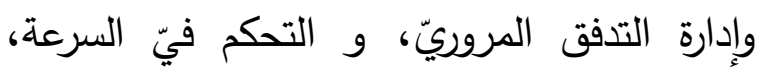

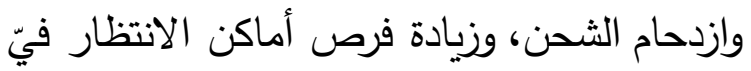

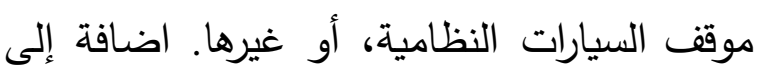

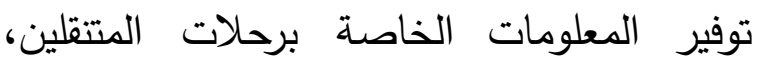
وتحسين الخدمات وإعطاء تغذية راجعة للمواطنين. لتوفير الوقت، وتحسين كفاءة التتقل، وتقليل

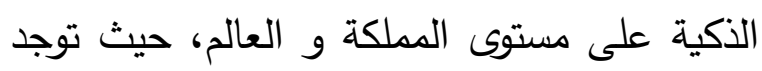

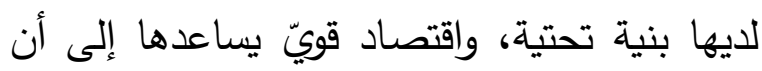
تتحول إلى واحدة من المدن الذكية لامتلاكها لإنها

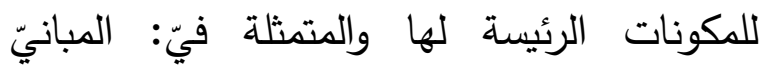

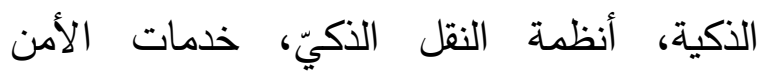

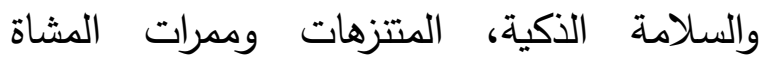
المزودة بوسائل التواصل (Wi-Fi)،الثبكات الذكية لتصريف مياه الأمطار والسيول، استخدام الإنارة

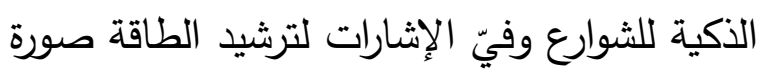
(1)، أنظمة مراقبة تدوير النفايات، سرعة الاتشاتئل

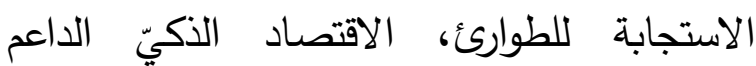
للشركات الصغيرة والكبيرة. r - تطبيقات المدن الأكية فيّ المدينة المنورة :

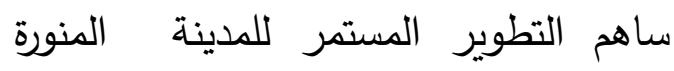

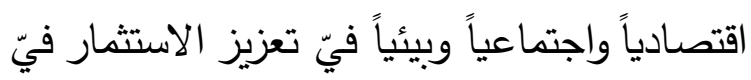
البنية التحتية اللازمة لتحولها إلى مدينة ذكية، وذلك لتحسين الاقتصاد، وزيادة الازدهار المحليّ لئي

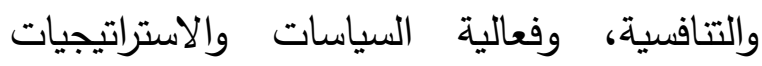
لتمكين التطوير الحضريّ والاجتماعيّ والثقافيّ وليّي والتقدم فيّ تطوير المدينة. وتشمل هذه البنى

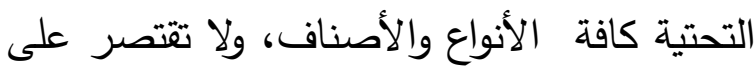


والطريق Intelligent Vehicle - Highway Systems, (IVHS ) الأمريكية، واسم تقتيات المعلومات للنقل على الطرق ( Road Transport Informatics, RTI) أو التقنيات المتقدمة للمعلومات والاتصالات فيّ النقل (Advanced Transport Telematics, ATT) فيّ أوربا، وأحيانًا بجمع الاسمين كليهما فيّ اليابان ) ( Shibata, Jun and .Telematics, ATT) Robert French, 2010 : 3) المصطلح الجديد يعتبر مصطلحا أكثر شمولية بالنظر لكونه لا يقتصر على الطريق والمركبة فقط كما كان عليه الوضع سابقا، وإنما يتسع هذا المصطلح ليشمل كل ما يتصل بهما من نظم اتصال وإدارة وغيرهما ( عليّ سعيد عبد الله الغامديّ، · • وأنظمة النقل الذكيّ عبارة عن منظومة تقنيات متقدمة، تعمل كأنظمة متكاملة تدمج تقنيات المعلومات والاتصالات الفورية الدقيقة المتعلقة بحركة النقل وأنظمه الاتصالات فيّ نظم إدارة النقل القائمة، لُيستفاد منها فيّ تسهيل عمليه النقل، و ترشيد استغلال البنية التحتية، وتوفير طاقة استيعابية أكبر ، وبكفاءة أعلى، دون اللجوء إلى إنشاء مرافق جديدة(وزارة النقل، أنظمة النقل

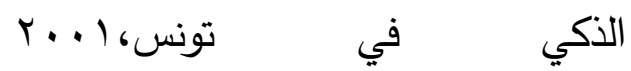
.(http://www.itstunisie.tn/index.php كما يتم من خلالها الاستخدام الأمثل للبنية الأساسية للنقل، لعلاج المشاكل المرورية المتعددة كالازدحام المروريّ والتأخير فيّ وقت الوصول التيّ تعمل على تقليل مستوى الخدمة والراحة
التكاليف، وخفض معدلات التلوث الهوائيّ من المركبات مثل انبعاث غاز ثانيّ أكسيد الكربون (CO2). كما تساعد أنظمة الحركة الذكية مديريّ النقل فيّ التخطيط الاستراتيجيّ القريب والمتوسط و البعيد المدى، وفيّ أنظمة المعلومات، وتتبع المركبات، و السلامة على متن أساطيل نقل الركاب أو البضائع، والسلامة العامة وألأمن . ثانياُ : أنظمة النقل الدكية وأهدافها وإدارتها ومكوناتها في الملدينة المنورة 1-مفهوم النقل الأكيّ (ماهية أنظمة النقل : (لأكية)

نعنيّ بمفهوم النقل الذكيّ التطبيقات المتقدمة والمتكاملــة والاتصــالات الحديثــة فـيّ مجــاليّ التواصـل الالكترونـيّ المرئسيّ والسـمعيّ لتنظـيم المـرور في المدينـة بـأجهزة الاستشـعار ، وأجهـزة الحاســب الآلـــيّ، وتقنيــات كثــف وتحسـس واتصــالات حديثــة، والكترونيــات، وبرمجيــات وتقنيـات واسـتراتيجيات للحصـول على معلومـات عن أداء مرافتق النقل و الطلب عليـة، والأحـوال الجويـة والبيئيـة، وتوفير تلك المعلومـات وإتاحتهـا للتــداول بـين المؤسســات والمســافرين، وتحليـل ومعالجـة البيانـات بـالبرامج الحاسـوبية فيّ مراكز إدارة المـرور للعدـل علـى معالجــة المشــاكل المروريـة، ولزيـادة كفــاءة أنظمـة النقـل وتعزيـز السـلامة المروريـة، ورفع كفاءة الإنتاجية والرفاهية

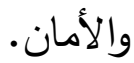
وقد برز مؤخرًا اسم"نظم النقل الذكية Intelligent) " "Transportation Systems, ITS) كلفظ موحد لما كان يُعرف سابقًا باسم" النظم الذكية للمركبة 


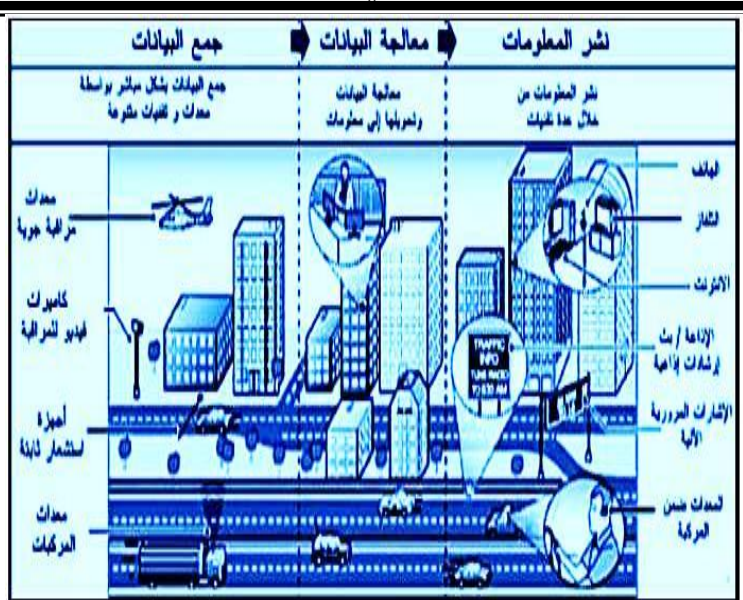

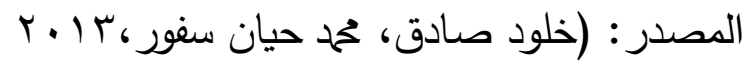
(E.Stephen, 2010 ) (O^T: شكل ( ع ) العناصر المكونة لنظام النقل الأكي وتستخدم نظم النقل الذكية تقنيات الحاسبات الآليّة (Computers) والإلكترونيات والاتصالات والأقمار الاصطناعية والحساسات( (Sensors) وأنظمة التحكم المروريّ، لتحديد وتجميع وفرز وتصنيف وتشغيل وتحليل كافة البيانات التيّ تحتاجها إدارة النقل والمرور، وبذلك يتم استخلاص المعلومات الفعالة منها، وإرسالها إلى متخذ القرارات بالشكل الذيّ يتقق مع احتياجاته وبالثمول والنوعية المطلوبة وفيّ التوقيت

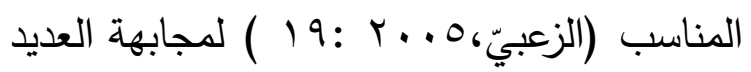
من التحديات التيّ تواجه النقل الحضريّ مثل تحسين مستويات السلامة والإنتاجية والحركة العامة، بالرغم من تفاقم الازدحام واستمرار الأخطار المحدقة بسلامة المتنقلين وزيادة الشح في ميزانيات الجهات المسؤولة عن النقل :ITS America Web Site) European ‘http://www.itsa.org) Telecommunications Standards Institute, (2009: 6)
والرفاهية، وللتقليل من عدد الحوادث ونسبة التلوث البيئيّ الناتج عن الزيادة المستمرة فيّ ملكية المركبات، ولخفض تكاليف النقل. وتقوم أنظمه النقل الذكّي بتطبيق التقنيات الحديثة للحصول على معلومات عن أداء مرافق النقل الحضريّ فيّ مجالات المراقبة، وجمع المعلومات والتحكم والاتصالات شكل ( ع )، بهدف الاستفادة القصوى من القدرة الاستيعابية للشبكة النقلية ووسائل النقل الأخرى. حيث تساعد فيّ انسيابية حركة النقل والمرور وتسهيل الوصول لمقاصد الرحلات، مما يترتب عليه التقليل من عدد الرحلات والمسافة المقطوعة الأمر الذيّ سيؤديّ إلى التقليل من نسبة الحوادث وجسامتها، وكذلك نسبة التلوث البيئيّ • كما أنها تساهم فيّ سرعة معالجه الحوادث المرورية وحالات الطوارئ من خلال المعلومات التيّ ستتوفر عبر هذه التقنيات، وعن الطلب على النقل، والاتصال المتبادل بين المركبات أنفسها، وبينها وبين الأجهزة الموضوعة على جوانب الطرق، وأيضاً عن حوادث التصادم الوشيكة الوقوع، وذلك لحل المشكلات المرتبطة وأجهزته

بالنقل

.(http://www.itstunisie.tn/index.php) 
r - أهداف أنظمه النقل الأكيّ:

تعتمد نظم النقل الذكية فيّ المدينة المنورة على تطبيق التكنولوجيا الحديثة فيّ النقل وسلامة نظامه. والاستخدام الفعال لتقنيات أنظمة النقل الذكيّ للتصدي بفاعلية أكبر لقضايا الازدحام والسلامة المرورية، من أجل تحقيق مجموعة من الأهداف تتمثل فيما ما يليّ:

المساعدة فيّ قيادة المركبات وتحديد المواقع،

خاصة استعمال نظام تحديد المواقع الجغرافية

. Geographic positioning system (GPS) • تعزيز وتسهيل انسياب تدفقات النقل وحركة المرور على مداخل ومخارج المدينة وشبكة الطرق والثوارع بها عن طريق زيادة السرعات وتقليل التوقفات، والتحكم فيّ الإشارات الضوئية المرورية، و زيادة الكفاءة التشغيلية لنظام النقل وزيادة سعته. زيادة الكفاءة التشغيلية لشبكة النقل حاضراً ومستقبلاً، و رفع مستوى إدارة الشبكة النقلية اعتماداً على زيادة وتحسين الفاعلية والطاقة الاستيعابية لشبكة (Effectiveness) الطرق والمرافق الحالية، وزيادة الإشغال للمركبات الخاصة، وتثجيع استخدام النقل العام، وبالتاليّ زيادة الكفاءة (Efficiency) وإنتاجية الأفراد والمؤسسات وقطاع الاقتصاد

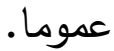
تعزيـز التنقل للأفراد وزيـادة سـرعة الرحلات،

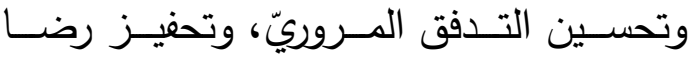
المستخدمين لجميع وسائل النقل عبر تحسين سبل الوصول إلى خدمات النقل، والمعلومات
وتوظف نظم النقل الذكية فيّ المدينة المنورة تقنيات الاتصالات والتحكم بغية الحصول على معلومات تتعلق بأداء مرافق النقل - من طرق وشوارع ونقل عام وقطارات - وعن الطلب على النقل والاتصال المتبادل بين المركبات أنفسها، وبينها وبين الأجهزة الموضوعة على جوانب الطرق، بهدف التغلب على الكثير من مشكلات النقل، مما يساهم في تحسين الحركة النقلية ـ والتقليل من حوادث التصادم الوشيكة الوقوع. وتجمع هذه التطبيقات لنظم النقل الذكية بين القدرة الهائلة للمعلومات، وبين تقنيات التحكم فيّ إدارة النقل Bart) .van Arem, 2006, : 25)

وتمثل نظم النقل الذكية تطوراً طبيعياً للبنية التحتية للنقل، وذلك من خلال تحديثها، لتواكب عصر المعلومات، ويُعزى ذلك لزيادة التحضر والنمو السكانيّ وزيادة عدد السيارات لمواجهة الطلب المتزايد على النقل كما هو الحال فيّ المدينة المنورة ، لذا فإن نظم النقل الذكية ستساعد على توفير طاقة استيعابية أكبر ، وبكفاءة أعلى ، دون الاعتماد الكليّ على إنشاء مرافق نقل جديدة .و تثير الدراسات إلى أن الجمع بين نظم النقل الذكية والإنشاءات الجديدة ، قادرة على استيعاب النمو المروريّ المستقبليّ ، بتوفير ـ ٪ مما يلزم تجهيزه لتلبية الطلب المروريّ نفسه من خلال الإنشاءات ( North Dakota Department of الجديدة Transportation , 2011: 
اسـتخدام الطاقـة النظيفـة، واسـتخدام وسـائل أكثر احتر اماً للبيئة. سـرعة وصــول سـيارات الإســعاف والـدفاع المـدنيّ لأمـاكن الحـوادث، وتقــديم الخـدمات الطبية فور وقوع الحوادث المروريـة، وسرعة الاســتجابة، ورفـع مسـتوى الإنقــاذ لحـالات

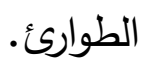

تقليـل عـدد الحـوادث المروريـة، والحـد مـنـ

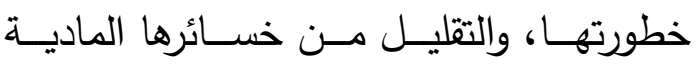
كالوفيات والاصـابات الناجمة عنها والتخفيف من جسامتها وتكلفتها وتقليل سرقة المركبات بمناطق المدينة المختلفة. تحسـين الإنتاجيــة الاقتصــادية، والتنســيق والتكامـلـ فـيّ عمليـات الثــبكات وإدارتهــا ،واسـتثماراتها، وتحسين التكيف مـع التغيـرات فيّ متطلبات أداء النظام ،وتقنياته والتوفير فيّ الاسـتثمارات لإنشـاء وتوسـعه شبكات الطـرق لـدعم التطـور الاقتصـاديّ وتعزيـز الإنتاجيـة الحالية والمستقبلية للأفراد والمؤسسات. يتضـح من ذلك أن نظم النقل الذكية تمثل التطور الطبيعيّ للبينـة التحتيـة للشبكة النقليـة بأكملها فيّ منطقة الدراسـة، وذلك من خلال تحديثها لتساير عصر التكنولوجيا و المعلومات، مما يُسهم فيّ توفير طاقة استيعابية أكبر وبكفاءة أعلى دون الاعتماد الكليّ على إنشاء مرافق نقل

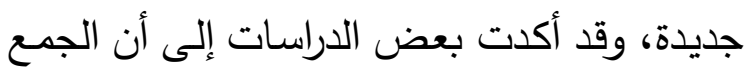
بين نظم النقل الذكية والتوسع فيّ إنشاءات جديدة بالشبكة يساعد على استيعاب النمو فيّ الحركة المروريّة المستقبلية بنسبة هب - • ع % مما يلزم
الخاصة بها لكافة فئات المستخدمين، و تقليل زمـن الرحلـة وتكلفتهـا، والتقليـل مـن حـالات التأخير ، وتحسـين مسـتويات الحركـة والراحـة

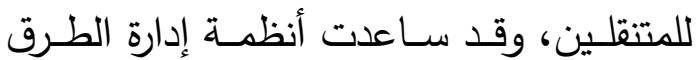
Arterial management ) وخاصـة الثربانية systems

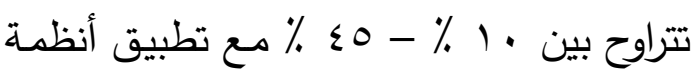
التحكم المتقدمة ونشر بيانات المسافر . تحسـين مسـتوى أمـن وســلامة مســتخدميّ ومشـــليّ وســائل النقــل، و إدارة الســلامة

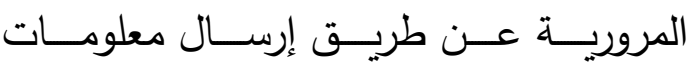
لمسـتـعمليّ الثـبكة النقليــة مثــل إرســـال معلومات حول الأحوال الجوية كالمطر ، وسوء الأحــوال الجويـة، وغيرهـا، وتحسـين مسـتوى السـلامة على شبكة الطـرق بمنطقـة الدراسـة بالحـد مـن وقـوع الحـوادث المروريــة (الهيئــة

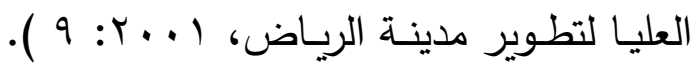
وســاعد تطبيـق أنظمــة إدارة الطــرق الحــرة على (Freeway management systems) تقليل الحوادث بنسب تتراوح بين 1 \% - ع ع \%، وزيـادة السـعة المروريـة، والتخفـيض مـن وقت الرحلة الكلية بنسبة تصل هـ \% (إدارة مرور المدينـة المنورة، 1 ـ • بم: بيانـات غير

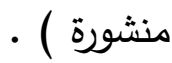
تقليل الآثار الناجمة عن النقل الحضريّ على بيئة المدينة المنورة، وخاصـة التلوث الهوائيّ والضوضـــائيّ، بالقضــــاء علـــى الازدحهـــام المـروريّ أو التقليـل منــهـ زمنيـاً ومكانيـاً، و و تخفــيض اســتهلاك الطاقــة والتحـــول إلــى 
ومن المهام الرئيسة لإدارة أنظمة النقل الأكية المتكاملة فيّ منطقة الدراسة ما يليّ: • وضع مجموعة متكاملة من الاستراتيجيات التنفيذية، والخطط الاستراتيجية لأنظمة النقل الأكية وتحديثها بشكل دائم، ومتابعة

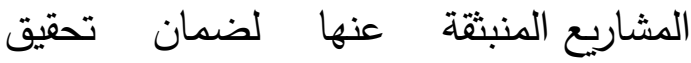
الأهداف المطلوب تحقيقها بكفاءة وجودة عالية، والاستخدام الأمثل للموارد المتاحة .

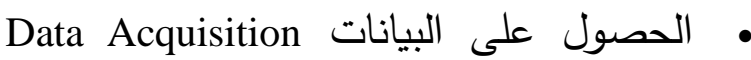
والاتصالات السريعة والشاملة والدقيقة للمراقبة والتخطيط الاستراتيجيّ بالوقت المحدد مما يعزز أنشطة نظم النقل الأكية. ومن اهم أدوات الحصول على البيانات:

أ - أجهزة الاستشعار ( Sensor) وتُستخدم أجهزة الاستشعار والكثف فيّ طرق وشوارع المدينة المنورة للعد والمراقبة والسيطرة، وتقدمت تقنيات الاستشعار والكثف مثل أجهزة الكثف المغناطسية ( magnetic detectors ) والاشعة تحت الحمراء، والموجات فوق الصوتية، والرادار، والكثف عن الموجات الدقيقة والتي تعتمد على الانعكاس والاشعاع، وكاشفات الدوائر

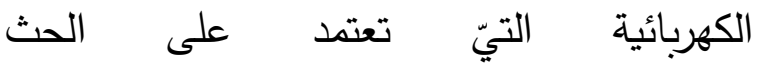
الكهرومغناطيسي، والفيديو، فضلاً عن استخدام الكثير من أجهزة الاستشعار التقليدية. وتقيس أجهزة الكثف والاستشعار التغيرات فيّ الحقول البصرية والمغناطيسية والصوتية والزلزالية الناجمة عن مرور المركبات وحساب حركة المرور المعتمدة على هذه القياسات. وتوضع هذه الأجهزة
تجهيزه لتلبية الطلب المروريّ نفسه من خلال الإنشاءات الجديدة فقط .( سعد بن عبد الرحمن

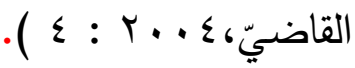

r - ادارة أنظمة النقل الأكية المتكاملة:

Traffic ） يُعد مركز إدارة المرور

(Management Center (TMC المسئول عن إدارة أنظمة النقل الذكية وضع تشريعاتها، وجمع المعلومات والتخطيط والإشراف على تصميم وتطبيق هذه الأنظمة، وإدارة وتشغيل مراكز التحكم الرئيسة للتأكد من تحقيق التكامل بين كافة أنظمة النقل الذكية ووسائل النقل المتعددة، لتحقيق سيولة وانسيابية حركة النقل، ورفع الكفاءة التشغيلية للشبكة النقلية للحد الأقصى، وتوفير متطلبات السلامة والأمان والكفاءة والاستدامة فيّ المدينة المنورة بما يتوافق وخطط النقل الشاملة، وتوصيل المعلومات المرتبطة بالنقل لوسائل الاعلام والسيارات العامة، ومكان يمكن الوكالات لتنسيق الاستجابة لحالات وظروف النقل. و مع رؤية المملكة العربية السعودية •r.rم، ومركز السيطرة والتحكم فيّ ادارة مرور منطقة المدينة المنورة مجهز بأحدث التجهيزات الفنية وفق أعلى المعايير العالمية صورة( r ) )، و يعد نظام إدارة الحركة المرورية المتكامل فيّ غرفة العمليات والسيطرة والتحكم أداة فاعلة فيّ رفع كفاءة إدارة الحركة المرورية. ويشارك معه عدة وكالات لإدارة البنى التحتية للنقل بواسطة شبكة من مراكز عمليات المرور . 
وبتحليل هذه البيانات يستطيع مهندو المرور تحديد معظم بيانات حركة المرور، وتقديم معلومات أساسيه كالخرائط الرقمية والمعلومات الأمنية و حركة المرور على الثبكة النقلية

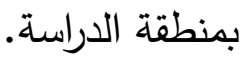

• وضع المعايير الفنية، واللوائح والسياسات المنظمة، ومقاييس الأداء المتعلقة بتطبيق وإدارة وتثغيل وصيانة أنظمة النقل الذكية فيّ المدينة المنورة. تحليل البيانات Data Analysis القادمة من البنور، أجهزة الاستثعار وباقي أجهزة جمع البيانات و تدقيقها و حذف البيانات المتعارضة والمتناسقة وحفظ البيانات المفيدة، وتوقع حالة حركة المرور وتزويد المعلومات الملائمة

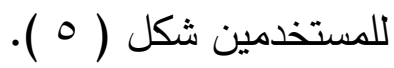
•القدرة على إدارة الازدحام المتكرر وغير العام

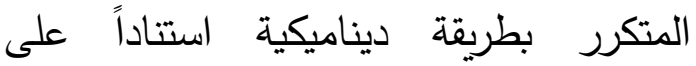
الظروف المتغيرة لحركة المرور، و إدارة الطلب على الرحلات، وتزويد معلومات النقل لكستخدمين الثبكة بواسطة العلامات المرورية

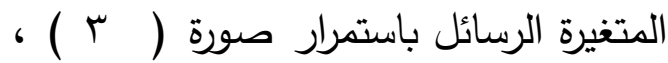
راديو الطرق السريعة، والانترنيت، وخدمات الرسائل القصيرة، ورسائل الهواتق المحمولة، وإعلانات الدذياع الدحلي، والتلفزيون وغيرها من وسائل الاعلام الحديث . تقنيات الدفع والتحصيل الآليّ الموحد لرسوم استخدام وسائل النقل لحافلات النقل العام باستخدام البطاقات الذكية ( CAP ) صورة (ع ) وبوابات التعريفة الإلكترونية للمواقف
فيّ الطريق وتوفر المعلومات عن حركة المرور على هذه النقطة من الطريق بالوقت المحدد.

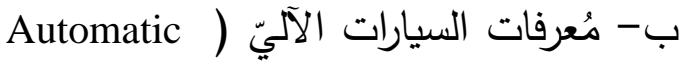
Vehicle Identifiers (AVI Automatic Vehicle Locators ) المركبة آليا (AVL ويستخدم هذا النظام مجموعة من أجهزة القراءة readers ، وعلامات داخل المركبات، ونظام حاسوب مركزيّ. تقع أجهزة قراءة وهوائيات antennas الطريق او على هياكل علوية او كجزء من حجرة جمع الرسوم الالكترونيّ، تبعث الهوائيات إثارات التردد اللاسلكيّ فيّ نطاق التقاط عبر ممر او اونات أكثر بالطرق السريعة. عندما تسير المركبة وتدخل نطاق التقاط الهوائي، تستجيب المركبة للإشارة اللاسلكية والهوية المعرف بها ويتم تحديد الوقت والتاريخ بواسطة القارئ. ثم ترسل هذه البيانات

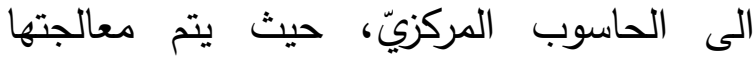
ID ) وتخزينها. و يتم تعقب ارقام التعريف بالسيارة (numbers ) على طول نظام الطرق السريعة،

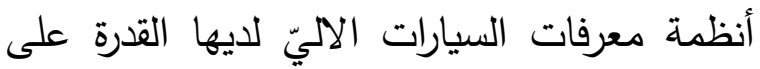

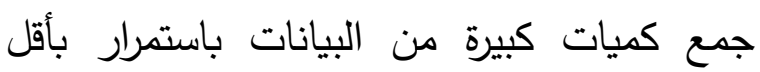
متطلبات من الموارد البشرية. ج - GPS هو نظام الملاحة عبر الأقمار الصناعية والتيّ توفر البيانات بسرعة ومرونة عالية و تكلفة قليلة نسبيا لتحديد مواقع وسرعة المركبات بالوقت المحدد، ويُستخدم GPS مراقبان اساسيان لتحديد المواقع والتتقل. ويوفر بيانات الموقع الأساسية من حيث تحديد احداثيات خطوط وليد

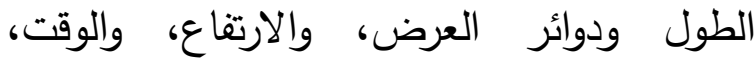




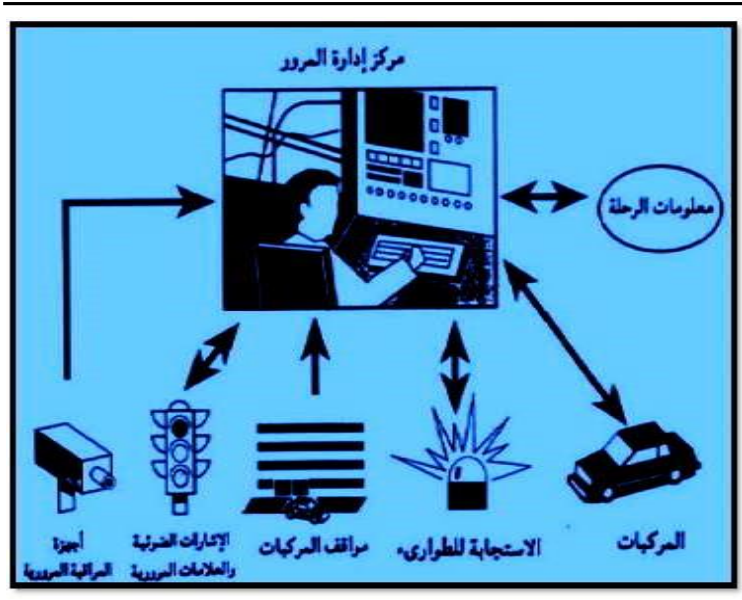

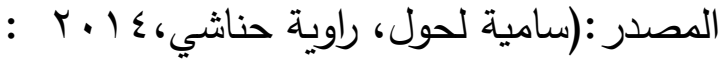
(o. (http://faculty.ksu.edu.sa/Ali_Alghamdi/book3/12.pdf)عن شكل ( ه ) النظم المتقدمة لإدارة المرور ولبنـاء نظـام متكامـل مـن الأنظمـة أعـلاه

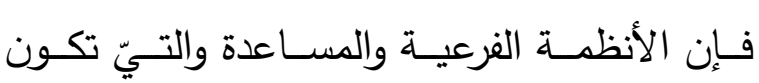
متكاملة مع هذه الانظمة هيّ كما يليّ :

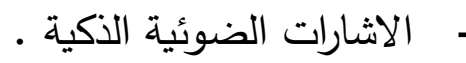
- أنظمـة جمـع المعلومـات المروريـة والتعداد المروريّ.

- أنظمـــة كــاميرات المراقبـــة التلفزيونيـــة .CCTV - أنظمــة قــراءة ارقــام الســيارات الآليــة .ANPR

Automatic Incident Detection .(AID)

Variable ～أنظمـة اللوحسات المتغيـرة (Message Signs (VMS الرسـائل للسـائقين لإعـادة توجيـه حركـة
الذكية المنتشرة في منطقة الدراسة، وغيرها

$$
\text { صورة (0 ). }
$$

ومن الأهمية بمكان أن نذكر فيّ هذا الصدد بأن أنظمة النقل الذكية المتكاملة فيّ المدينة

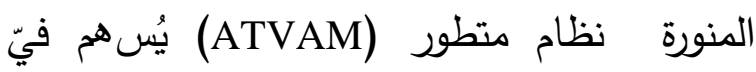

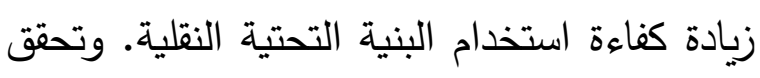
التكامل بين وسائل النقل المتنوعة، ما ترتب علية تحسين مستوى المعيشة وازدهار الاقتصاد، ويُعزى ذلك للعمل الجاد والتعاون المشترك بين الهيئات الحكومية ومؤسسات القطاع الخاص، لتنفيذ وتطوير تقنيات أنظمة النقل الذكية على أسس علمية مدروسة . وتملك إدارة المرور بمنطقة المدينة المنورة القيادات البشرية ذات القدرات العلمية والفنية المؤهلة لتشغيل انظمة المرور الذكية بكفاءة عالية، مما أسهم فيّ الاستفادة القصوى من الطاقة الاستيعابية للشبكة النقلية المتوفرة وذلك من خلال تطبيق الأنظمة التالية : - أنظمة نقل الطرق السريعة Freeway -

- Management Systems - أنظمة ادارة التحكم بالأنفاق Tunnel -

-Management Systems - أنظمة معلومات الطرق ومستخدميها Public Transit Information System - 
- وسائل تجميع المعطيات:

وهيّ الأجهزة والتطبيقات التقنية الحديثة التيّ

تقوم بجمع المعلومات والاستقصاء (Detection) الفوريّ الدقيق المتعلق بعمليات نظام النقل وخاصة فيما يتعلق ب ب :التدفق المروريّ، الإشغال، السرعة، التحكم، الاتصالات، لتسهيل حركة النقل، والتقليل من عدد الحوادث، والحد من خطورتها، والتغلب على المشكلات الناتجة عن ازدحام الحركة المرورية، والاستخدام الأمثل للبنية الأساسية للشبكة النقلية، وتتضمن كاميرات التعداد والتصوير للمركبات على الطرق، وكاميرات مراقبة المواقف ووسائل النقل العام، فضلاً عن أجهزة الاستشعار • وإنتاج التقارير والمعلومات عن أعمال الصيانة و الحوادث التي يجب أن تطلع عليها السلطات المختصة، والتقارير البيئية أو تقارير الطقس • (عادل مصطفى الكاشف ، ؟:0 . . . ). - تقنيات معالجة البيانات: وتتمثل فيّ الأجهزة الإكترونية وبرمجيات الحاسب الآليّ التيّ تحمل تدفق البيانات، وتعالج أداء نظام النقل، والأجهزة التيّ تعمل على معالجة البيانات والمعطيات (Processing)التيّ تُجمع لإدارة نظم النقل بمركز العمليات بمديرية المرور بمنطقة الدراسة، وبشكل يتجاوب مع المتغيرات التيّ تطرأ على هذه النظم ويلائم الواقع، وتقديم مختلف المعلومات للأفراد وشبكات الاتصالات، بهدف الاستفادة الكاملة من الطاقة الاستيعابية لشبكات الطرق ووسائل النقل العاملة عليها. حيث تساعد فيّ انسياب الحركة المرورية، وتساعد فيّ زيادة الوصول إلى مقاصد الرحلات والتقليل من
- أنظمـة كثـف المركبـات ذات الارتفــاع

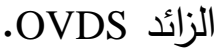

Lane Control أنظمة التحكم بالمسارات -

.Signs

- محطات وزن الثاحنات الآلية.

- ت تسـيق الإشــارات المروريــة لسـرعة نقـل

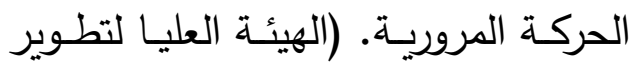

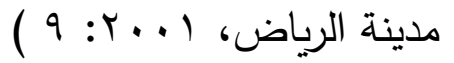

- أنظمة الرصد بالكاميرات CCTV نظام

كشف الحوادث بواسطة / VBID الفيديو.

- - أنظمـة ضبط مخالفات زيـادة السرعة

Speed Cameras

الأكــان، واسـتخدام الجـوال أثنــاء القيـادة

صورة ( 7 )، وقطع الاشارة وهي حمراء Red Light دقيق حيث انه يلتقط صورة واضحة للوحة المركبـة وهـيّ تتحرك بسـرعه على مـدار الساعة يستطيع التقاط المركبات المخالفة فيّ جميع المسارات فيّ نفس الوقت (إدارة مرور المدينة المنورة، بيانات غير منشورة

$$
(r \cdot) \Lambda:
$$

ع - أنظمة النقل الأكية وخدماتها فيّ المدينة

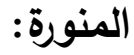

يتكون نظام النقل الذكيّ من منظومة تقنيات متقدمة تعمل بشكل متكامل، و تتكون من العناصر الأساسية التالية :

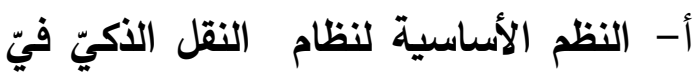
المدينة المنورة : 
- نظم تحديد المواقع العالميّ: ( Global Positioning systems( GPS تستخدم نظم النقل الذكية فيّ المدينة المنورة ، GPS Gكنولوجية نظام تحديد المواقع العالميّ وذلك بقياس المسافة ما بين مستعمل وبعض الأقمار الصناعية، وذلك بتحديد الموقع عن طريق الخرائط الرقمية. ويقوم النظام بالتحديث الآليّ لمواقع المركبات كل ستين ثانية، وإرسال البيانات المطلوبة إلى المستفيد على مدار الأربع والعشرين ساعة. كما يستخدم النظام شبكة General Packet Radio ) الاتصالات اللاسلكية Service( GPRS أسطول الشركة السعودية للنقل الجماعيّ(سابتكو)، والحافلات التابعة لشركات النقل الخاص العاملة فيّ نقل الحجاج والمعتمرين والزوار . - نظم الموقع الأوتوماتيكيّ للمركبات

\section{Automated Vehicle Location (AVL)}

تعتمد نظم AVL الأكثر شيوعاً على تكنولوجية GPS أو RFID. وتحدد الأولى موقع المركبة من خلال هوائيّ الوحدة GPS المثبتة فيّ المركبة التيّ تستقبل الإشارة الُمرسلة من الأقمار الصناعية، ثم يُرسل موقع المركبة إلى مركز Global (المراقبة من خلال الاتصالات اللاسلكية. System for Mobile, GSM, or GPRS حالة النظم التيّ تستخدم تكنولوجية RFID تقرأ الأجهزة المخصصة للاستجابة للذبذبات المثبتة فيّ المركبات من طرف مراكز المتابعة فيّ مواقف الف المركبات النهائية، من خلال الاتصالات اللاسلكية - (www.cirrelt.ca/DocumentsTravail/.pdf)
أعدادها، وتقليل المسافات الكيلو مترية التيّ تقطعها المركبات على شبكة طرق المدينة، وبشكل يحقق الأمان، والفاعلية فيّ استخدام مختلف وسائل النقل المستخدمة للشبكة النقلية

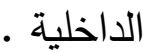
- تقنيات السيطرة والتحكم ونقل المعلومات: وهيّ التقنيات المعنية بتحويل نتائج معالجة المعطيات إلى أرض الواقع، ويشمل مختلف وسائل وتقنيات التحكم (Control) والسيطرة ونقل المعلومات، التيّ تشمل كاميرات مراقبة السرعة والتصوير للمركبات على شبكة الطرق والشوارع، Dynamic Message ) والإشارات المرورية Signs)، والإشارات الإرشادية والتحذيرية، وأجهزة

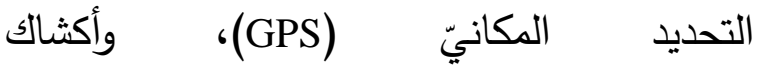
المعلومات(DMS)، وكاميرات مراقبة المواقف، والتنسيق مع وسائل النقل العام والهيئات القائمة على مختلف فاعليات النقل، وإنشاء غرف تحكم وبنوك معلومات المرور والنقل ووسائل النقل العام، إضافة إلى أجهزة الاستشعار والمراقبة، ووسائل نقل المعلومات إلى مستخدميّ نظام النقل فيّ أثناء الرحلة كالراديو والهاتف النقال، وشبكات الاتصالات المتكاملة وتثمل معلومات أساسية مثل الخرائط الرقمية، التيّ تساعد فيّ نقل البيانات. ( جبر مازن علي عوض، الظريف

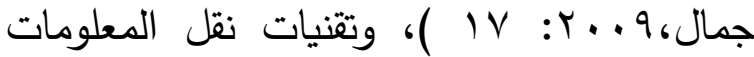
قبل القيام بالرحلة عبر التلفزيون والصحف والإنترنت وتطبيقات الهاتف المتنقل، والوسائل الإلكترونية المعتمدة لإيصال معلومات النقل العام فيّ محطاته ومواقفه. 


\section{- نظم معلومات المسافرين :}

ويهدف إلى تزويد المسافرين ومساعدتهم فيّ

التنقل خلال رحلاتهم، والتيّ قد تبدأ وتتتهيّ فيّ ولتروي

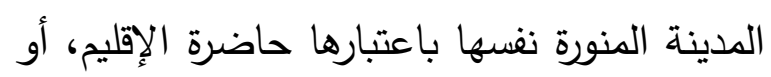

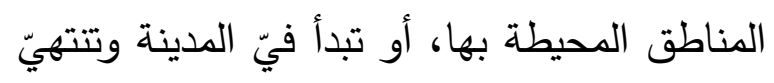
فيّ مدينة أخرى داخل المملكة. ولذلك يتم توفير أكثاك للمعلومات، ونظم معلومات، ولافتات فيّ مدئ

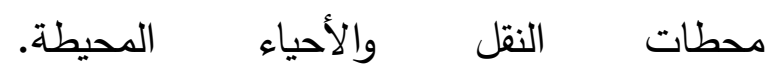
، (www.thisbigcity.net) والسائقين بما يلزمهم من معلومات عن الشبكة النقلية، وخدمات النقل العام. وتهدف هذه النظم إلى تقديم خدمات ومعلومات لمستخدميّ الثبكة تسهيلاً لعملية تتقلهم من مكان إلى آخر . وتمكن هذه النظم المسافر من الحصول على أدلة وخدمات ومعلومات وجداول الرحلات بمواعيدها الزمنية، و نشر هذه المعلومات فيّ الوقت المحدد وحدمات

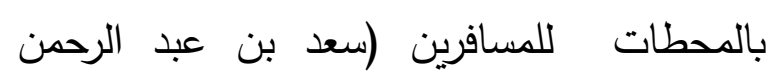

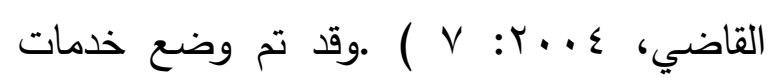
المعلومات على الشبكة العنكبوتية (الانترنت) بأحدث التقنيات، كما يتم نشر المعلومات من

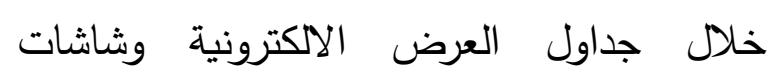
المعلومات والإعلانات الإذاعية. كما تستخدم نفس القنوات لتنبيه المسافرين فيّ حالة التأخير عن المواعيد المحددة. ب - أنواع خدمات النقل الأكيّ: تتعدد خدمات أنظمة النقل الذكية المطبقة في المدينة المنورة، وهيّ مستمدة من مؤسسة الهندسة الوطنية لأنظمة النقل الذكية بالولايات المتحدة الأمريكية، ويمكن حصرها فيّ ا Y خدمة فرعية
وتهدف هذه الأنظمة إلى تقليل الوقت

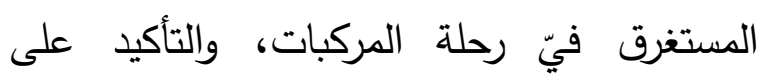
مصداقية الجدول الزمنيّ للرحلات وخاصة لحافلات النقل الجماعيّ العاملة على خطوط بشكل منتظم ، ومراقبة سلوك السائق والتزامه بتعليمات المؤسسة مثل: السرعة، ترك الحافلة فيّ وضعية التشغيل أثناء التوقف، إهمال نظام المرور أو إهمال الصيانة الدورية. ويسجل النظام كل ذلك ويُرسل تقارير مباشرة إلى مركز الإدارة والتحكم،

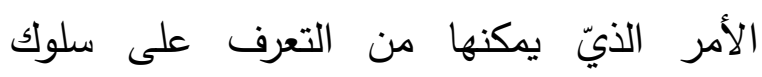
سائقيها واتخاذ الإجراءات اللازمة لحماية المركبة

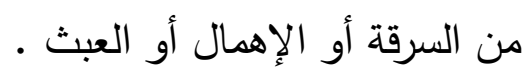
- نظم التعداد الأوتوماتيكيّ للركاب: (APC) Automatic passenger Counting APC تعتمد نظم التعداد الأوتوماتيكيّ للركاب على أجهزة كاشفات الحركة، وهيّ مثبتة تحت أبواب المركبات، و تسجل عدد الركاب الصاعدين أو النازلين من المركبة، وقد تم تطوير نموذج يدمج بيانات للتنبؤ بوقت وصول الحافلات فيّ المحطات، كما تم تطوير تقنيات تعالج بيانات AVLوAPC الحافلات فيّ المحطات، وبذلك يسمح استخدام نظم التعداد الأوتوماتيكيّ للركاب بتحسين وسائل النقل العام فيّ المدينة (حافلات ، وقطار ) والرقابة على لإنى إدارتها، بالإضافة إلى الحصول على معلومات تفصيلية عن الركاب واتجاهات الرحلات، وتقييم وتحسين تردد الركاب.-www.dilax.fr/comptage (de-personnes) 
مجمعة فيّ V أنواع من الخدمات الرئيسة عن الطارئة، ومتابعة منظومة السلامة فيّ المركبات حركة المرور والمسافرين، والتصرف فيّ الحالات (الجدول ( ) ). جدول (1) أنواع خدمات النقل الذكيّ المُطبقة في المدينة المنورة عامی I ـ ب م

\begin{tabular}{|c|c|c|}
\hline لخدمات الفرعية & الخدمة الرئيسة & \\
\hline 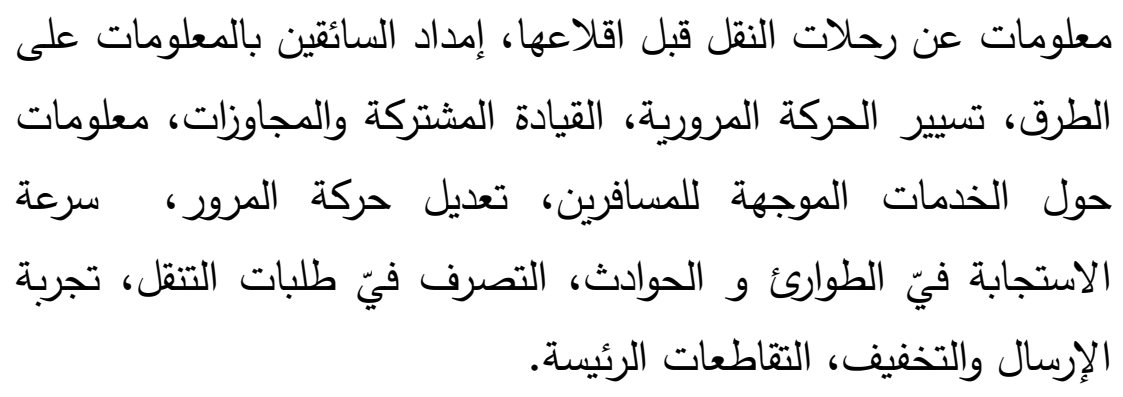 & التصرف فيّ حركة & 1 \\
\hline النقل الجمرّفيّ النقل الجماعيّ، الإعلان على شبكة الطرق والشوارع، & التصرف فيّ النقل & r \\
\hline الذكيّ أسفل الحرم النبويّ، وفيّ الإلكترونيّ فيّ حافلات النقل الجماعيّ، وفي مواقف النقل & الدفع الإلكترونيّ & $r$ \\
\hline 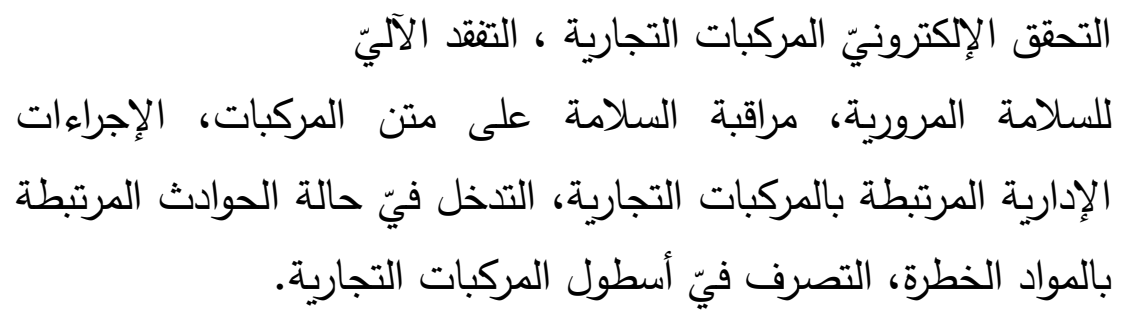 & التجل المركبات & $\varepsilon$ \\
\hline الطوارئ. & التصرف فيّ & $\bullet$ \\
\hline 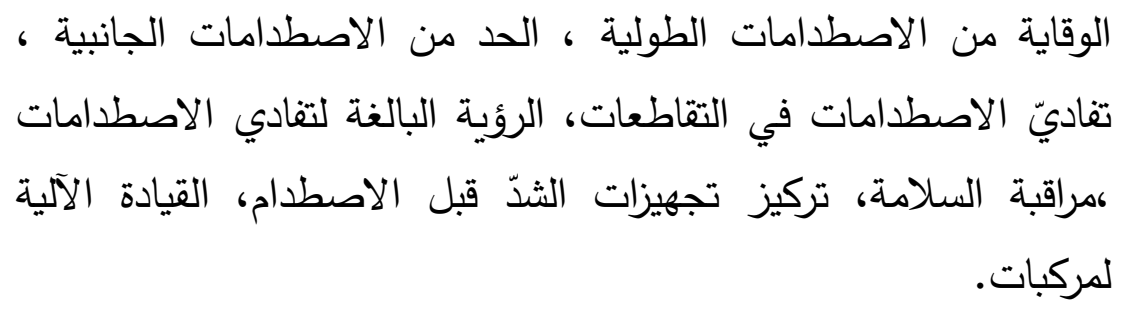 & المركبات & \\
\hline لمعلومات المجمعه واستر & إدارة المعلومات & \\
\hline
\end{tabular}

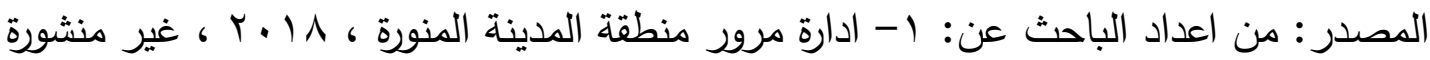




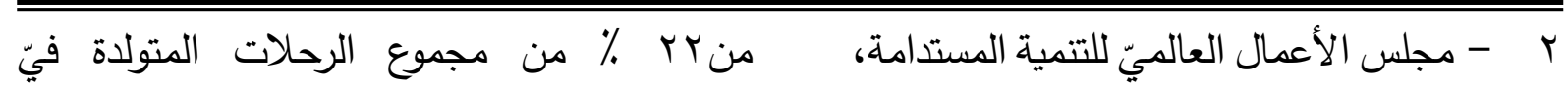
المدينة.

و مع استمرار النمو السكانيّ والاتساع

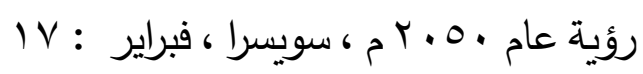
العمرانيّ فيّ المدينة المنورة، وما يتولد عنهما من ثالثًاً : تحليل منظومة النقل وثقيمها في الملدينة زيادة فيّ حجم الحركة المرورية خلال السنوات القادمة، فمن المتوقع أن تزداد المشاكل الحضرية

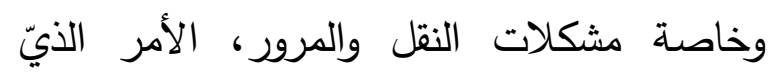
يستدعيّ النظر فيّ سبل تطوير وإدارة نظام النقل فيّ المدينة بشكل مستمر، والبحث عن بدائل فاعلة لزيادة الطاقة الاستيعابية لشبكة الشوارع، وزيادة الكفاءة التشغيلية لنظام النقل وزيادة سعته لهنه بمنطقة الدراسة، بما فيّ ذلك أنظمة النقل الذكية بهدف تلبية متطلبات الحركة النقلية الحالية والمتوقعة بالمدينة بيسر وأمان. وتعتمد محافظات المدينة المنورة إلى حد كبير عليها، نظراً لما توفره من فرص عمل لشريحة واسعة من السكان. وهذا بدوره أدى إلى اختناقات مرورية نتيجة لاستقطاب العديد من الرحلات اليومية بهدف العمل، أو التسوق أو الترفيه أو لتونيه التعلم أو العلاج، مما سيزيد من حجم حركة

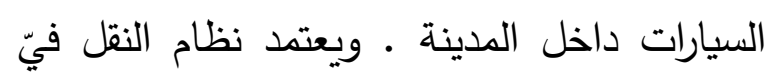
المدينة المنورة واقليمها بشكل رئيس على وسائل النقل ذات السعة الأركاب الصغيرة، ويبلغ اجمالي

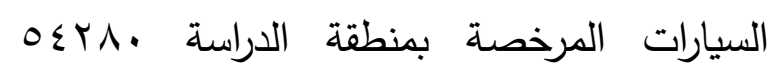
سيارة عام 11 1. م، وتستأثر السيارات الخاصة بحواليّ r, 9 ؛ ٪ من إجماليّ السيارات المرخصة

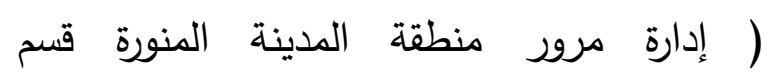

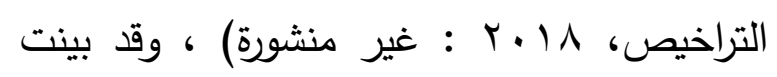
نتائج الدراسة الميدانية أن السيارات الخاصة

تشهد المدينة المنورة نمواً سكانياً سريعاً وتوسعاً عمرانياً كبيراً، حيث زاد عدد سكان المدينة عن 1,0 مليون نسمة عام 11 إب م، حتى أضحت المدينة المنورة واحدة من أسرع أربع مدن

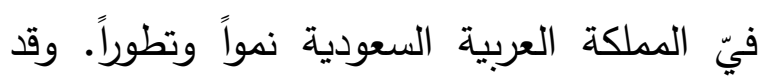
أدى النمو الذيّ شهدته منطقة الدراسة على مدى العقود القليلة الماضية، والمتوقع أن تشهده مستقبلاً، إلى المضيّ قدماً فيّ توفير نظام نقل مستدام لمواجهه التحديّ الرئيس الذيّ يواجه القائمين على أمر النقل، خاصة وأن المدينة تتمتع بشبكة طرق متميزة تعتمد بصورة أساسية على السيارة الخاصة فيّ تنقل السكان، ومع استمرار الأوضاع الحالية سيؤديّ ذلك حتماً إلى ظهور مشكلات سلبية خطيرة. وقد نتج عن النمو السكانيّ والتوسع العمرانيّ للمدينة المنورة، وما صاحبهما من تطور فيّ الأنشطة الاقتصادية المختلفة إلى ازدياد الحاجة

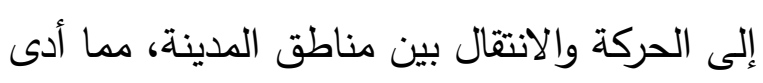
إلى ازدحام الحركة المرورية على شبكة الشوارع والطرق بالمدينة، وصعوبة الانتقال بين بعض إن أن مناطقها، خاصة فيّ أوقات الذروة كالتنقل بين المنطقة المركزية وباقي مناطق المدينة. لاسيما وأن ما يزيد عن V^,9 \% من الرحلات اليومية تتم بواسطة المركبات الخاصسة قليلة الأركاب، بينما تشكل رحلات حافلات النقل العام أقل 
السعودية للنقل الجماعيّ (سابتكو) ، ويُعزى ذلك لقلة خطوط سير حافلات النقل العام وعدم وجود

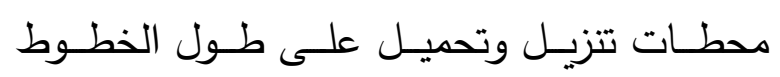

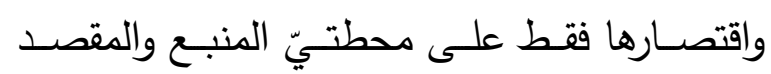

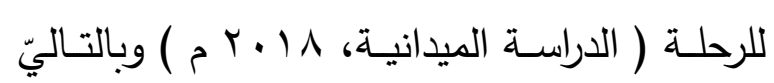

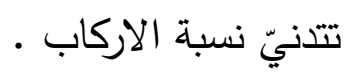

إن اسـتمرار تزايــد الاعتمــاد علــى الســيارة الخاصــة والحاجـة للتنقل يـؤديّ إلى زيـادة الفجـوة بـين كثافـة الحركـة المروريـة والطاقـة الاسـتيعابية للطرق. وتتطلب الحلول للمشاكل الحالية والمتوقعة تطبيق استراتيجية "ادفـع"و " اسـحب"، حيث يتت "ســـ" الركـاب مـن السـيارة الخاصــة و"دفـعـ" الركاب للنقل العـام التردديّ في مواقف منتشـرة

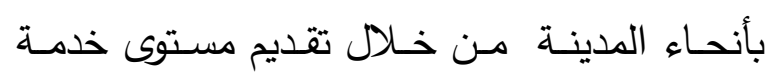

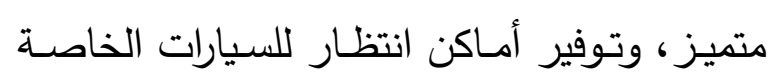
بجانب محطات النقل العام شكل ( 1 )، وتأمين

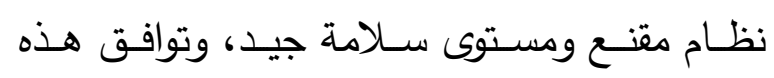
الإجـراءات مــع تطـوير الـنظم الحضـرية الذكيـة ومفاهيم النقل الذكية (مثل أنظمـة وخدمات النقل الذكية، وأنظمة الإدارة المرورية).
والتاكسيّ ذات سعة تتراوح بين ع إلى V راكب تنقل ب7 \% من إجماليّ الركاب من عينة الدراسة، وهو ما يعكس ارتفاع نسبة امتلاك السيارات

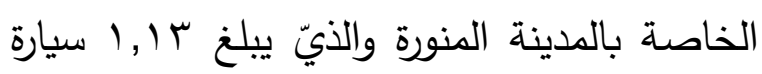
لكل أسرة فيّ المتوسط، وينقل الميكروباص حمولة ع ا راكب 1 1\% من المتتقلين، وانخفاض الوسائل العامة للانتقال حيث تتقل حافلات النقل الترددية r \% من الركاب صورة ( N ) )، وقد بلغ متوسط زمن رحلة العمل اليوميّ (ذهاباً/ إياباً) حواليّ

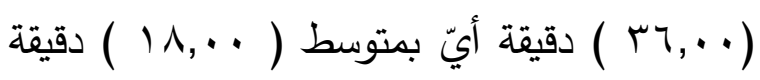
لرحلة العمل الواحدة. ومن ناحية أخرى بلغ متوسط نصيب الفرد من أطوال الطرق بالمدينة

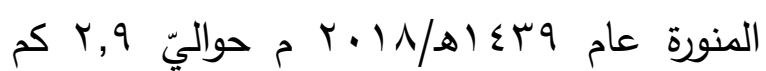
لكل ألف من السكان وهو مؤشر جيد إذا ما قورن

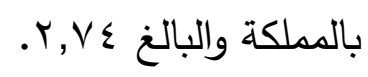
ويبــخ عـدد الـرحلات المتولـدة فيّ المدينـة المنورة فيّ الوقت الحاضر ب,r مليون رحلة فيّ اليوم، وأن المسـافة الطوليـة لهذه الرحلات تصـل الرفل

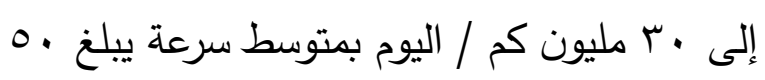
كم/سـاعة. ومن المتوقع ان يزداد أعداد الرحلات فيّ العشر سنوات القادمة إلى أكثر من ه مليون

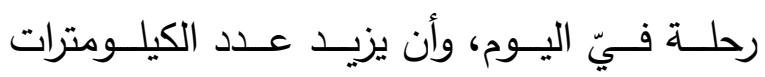

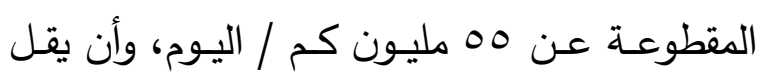
متوسط السرعة إلى حواليّ هب كم/سـاعة. ومـن

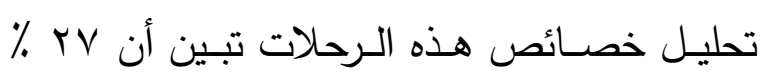
منهــا هـيّ رحـلات تعليميـة، وتسـتخدم السـيارة

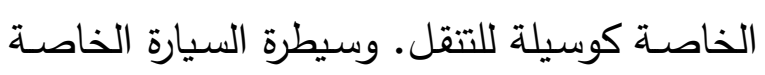
فيّ القيـام بـالرحلات داخـل المدينـة، إلـى جانـب تدنيّ مستوى الاركاب بالنسبة لحافلات الثركة 
ومع الزيادة المستمرة فيّ حركة النقل الحضريّ، وصعوبة توسيع الطرق والشوارع الداخلية، أو تشيد طرق جديدة تستوعب المزيد من الحركة، أصبح من الضرورة تحقيق الاستفادة القصوى من الطرق الحالية، ورفع كفاءتها باستخدام أنظمة النقل الذكية فيّ إدارة الحركة المرورية. ومن ثَّ فانن تحليل منظومة النقل وإعطاء صورة واضحة عن المشكلات المرورية يمكن من وضع الحلول لهذه المشكلات، مع مراعاة أن تكون الحلول متتاسبة مع الوضع المستقبليّ والرؤى التخطيطية المقترحة للشبكة النقلية بمنطقة الدراسة. و يتطلب ذلك المزيد من الفراغات المرورية، وأماكن لوقوف السيارات.

\section{شبكة الطرق والشوارع الداخلية بـالملينة المنورة:}

شهدت شبكة الطرق والشوارع الداخلية فيّ

المدينة المنورة تطوراً ملحوظاً منذ عام . وبار هـ/9V I م، م، تماشياً مع اهتمام الدولة بتشييد مجموعة من الطرق الاشعاعية التيّ تربط المنطقة

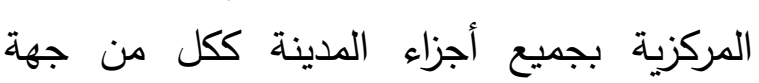
وبالطرق الإقليمية والدولية التيّ تخدم جل الزائرين والمقيمين والحركة التجارية بالمدينة من جهة

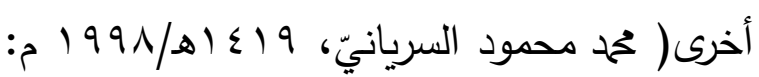
• و (Y) - (Yتمثل هذه الطرق فيما يليّ شكل

(

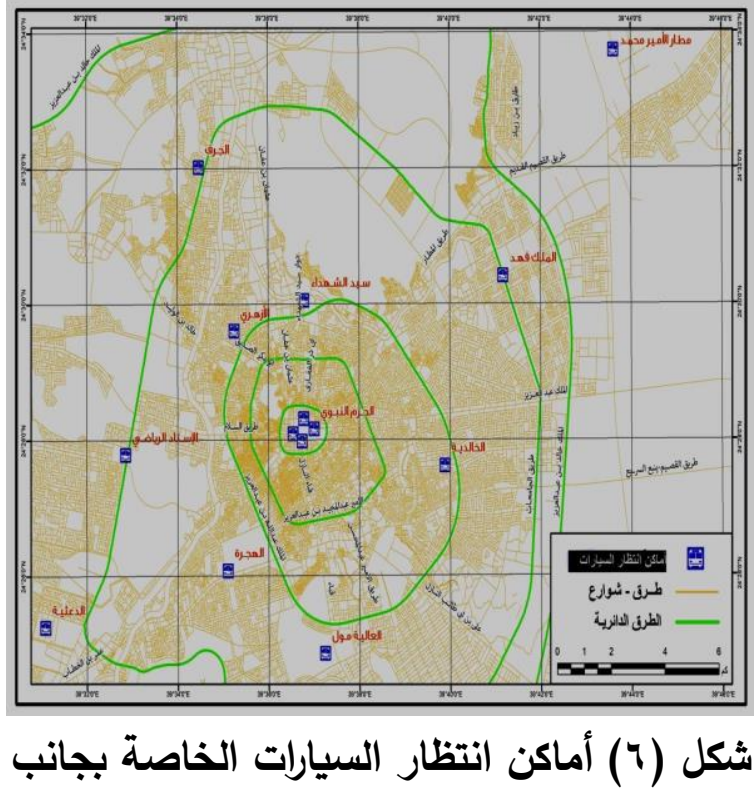

محطات النقل العام في المدينة المنورة

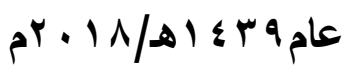

وبزيادة الطلب على الزيارة للمدينة المنورة

نتيجة لزيادة الطلب العالميّ للمسلمين فيّ جميع أنحاء العالم، وانطلاقاً من المتطلبات الأساسية لأهمية النقل البريّ لها فإن استخدامات النقل بها من الناحية الوظيفية تقدر بحواليّ ب \% من إجمالي مساحتها، ولقد تطورت شبكة الطرق بين أجزائها الداخلية لتبلغ أطوالها ما يزيد عن ل V. كم، كما ترتبط بالمدن والقرى الخارجية بمنطقة

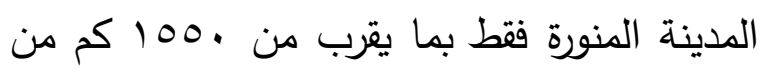
الطرق المرصوفة المخططة، هذا بالإضافة إلى شبكة الطرق الخارجية التيّ تربط المدينة المنورة بالمدن الأخرى، وترتبط كفاءة شبكة الطرق في منطقة الدراسة بمدى قدرتها الاستيعابية للحركة المرورية لوسائل النقل وحركة المشاة. وتتميز الحركة المرورية فيّ المدينة المنورة بالموسمية أو ما يطلق علية مواسم الذروة لاستقبال الزائرين حلال موسمين الحج والعمرة ، 
اضافة لما سبق تتنشر الطرق الشريانية باتساع يتراوح بين · + - 70 متر ، وبمتوسط سرعة يتراوح بين · ؟- . . كم / ساعة. ومن الأهمية بمكان الإشارة إلى الطرق الخدمية والرابطة المعبدة التي تخدم حركة النقل بالمدينة المنورة. فقد طرأ على شبكة الطرق والشوارع الرئيسة الكثير من التغيرات الوظيفية والكمية والنوعية فيّ نفس الوقت، حيث تثير المؤشرات الحضرية للطرق بالمدينة المنورة أنه لم يكن بها فيّ نهاية النصف الأول من القرن العشرين وبالتحديد عام ، 190 م سوى . ب كم من الطرق المرصوفة بنسبة ^, ^ \% من إجماليّ أطوال الطرق المرصوفة بالمملكة فيّ نفس العام جدول ( r r ) وزادت أطوال الطرق بالمدينة فيّ نهاية القرن العشرين إلى • rV كم بما يعادل T, · من إجماليّ أطوال الطرق بالمملكة والبالغة . . . 0ـ كم عام . . . . . م، ثم تضاعفت أطوال الطرق المرصوفة لتصل إلى ما يقرب من عشرة أضعافها فيّ المدينة حيث تم رصف وتحديث الطرق والشوارع بالمدينة المنورة لتبلغ

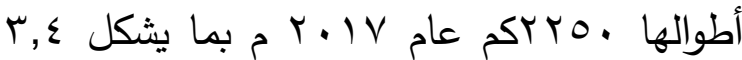
\% من إجماليّ أطوال المملكة والبالغة ... . 7. كم من الطرق المرصوفة.

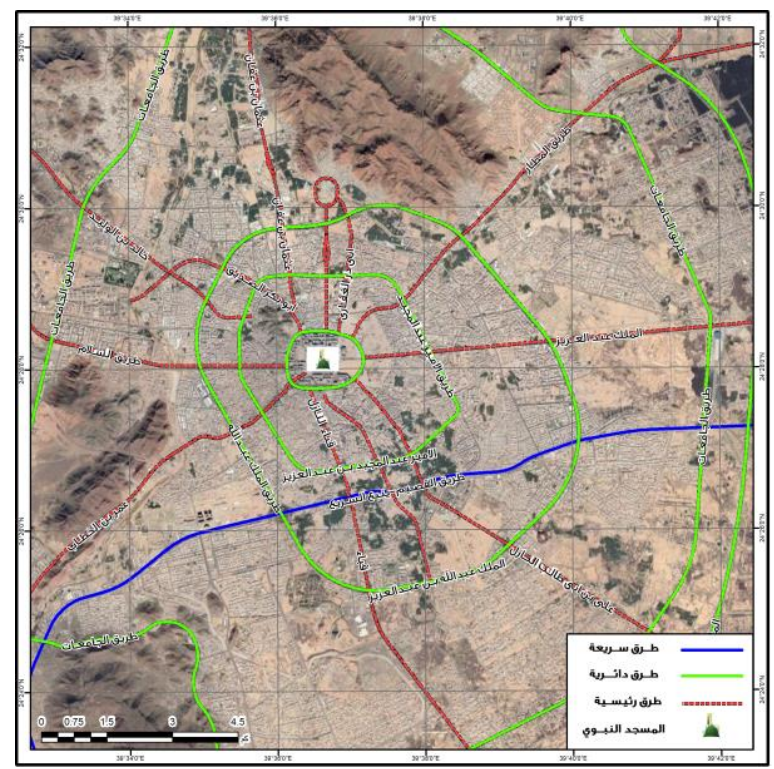

شكل (V) شبكة الشوارع بالمدينة المنورة 1- شارع الملك فهد (المطار سابقاً ) ويخدم شمال شرق المدينة مباشرة. r-شارع أبي ذر وشارع سيد الشهداء ويخدمان

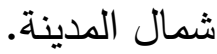
r-شارع أبي بكر الصديق ( سلطانة سابقاً ) ويخدمان شمال غرب المدينة . ع-شارع باب السلام، وشارع عمر بن الخطاب (العنبرية سابقاً) ويخدمان المنطقة الغربية. 0-شارع علي بن أبي طالب ( العوالي سابقاً )، وشارع قباء، وشارع الأمير عبدالمحسن (قربان سابقاً)، وتخدم هذه الشوارع الثلاثة المنطقة الجنوبية والجنوبية الشرقية من المدينة المنورة. 7-شارع الملك عبد العزيز ويخدم المنطقة الثرقية من المدينة المنورة. ويوجد نوع ثانيّ من الطرق الإشعاعية السريعة تخدم حركة النقل من وسط المدينة نحو أطرافها وخارجها بمتوسط اتساع . . متر ، وبسرعة قصوى · با كم / ساعة، 
جدول ( r ) تطور أطوال الطرق المرصوفة فيّ المدينة المنورة والمملكة العربية السعودية خلال

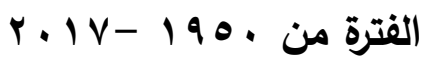

\begin{tabular}{|c|c|c|c|}
\hline \% من أطوال الطرق & أطوال الطرق بالمملكة & أطوال الطرق بالمدينة & السنة \\
\hline$\Lambda, \vee$ & rT. & r. & 190. \\
\hline$\cdot, 9 \leq$ & $9 \ldots$ & no & $19 \times 0$ \\
\hline 7, & $\leq 0 \ldots$ & rv. & r... \\
\hline$\mu, \varepsilon$ & $79 \ldots$ & rYo. & $r . I V$ \\
\hline
\end{tabular}

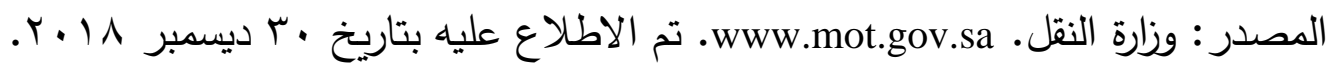

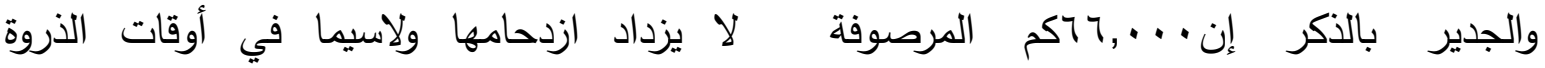
بالملكة تصنف كالتاليّ ..., كم من الطرق التقليدية للزيارة، وربط جميع شبكة الطرق الداخلية

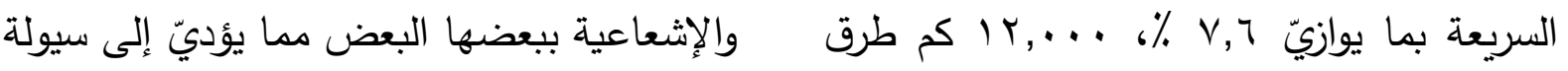

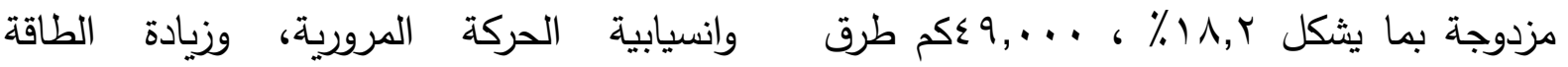

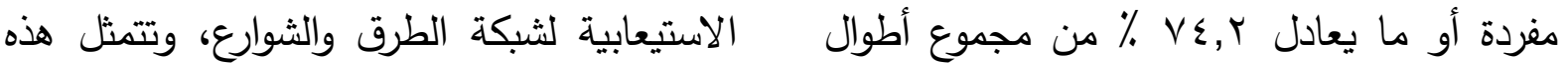

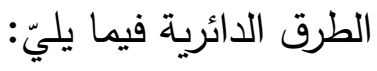
الطرق فيّ المملكة العربية السعودية. - الطريق الدائري الأول ( شارع الملك لكائ و تختلف الطرق فيّ سعتها بالمدينة فيصل ) والذيّ كان يعرف بشارع الستين

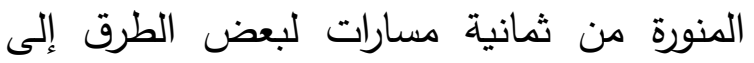

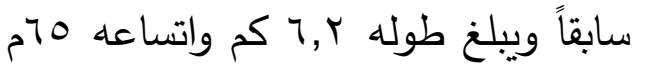
، ويحيط بالمنطقة المركزية وتتركز به وله وله

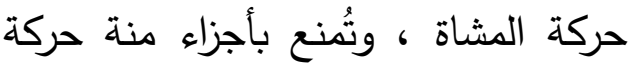
المركبات لزيادة طاقته الاستيعابية. طريق ذو مسارين فقط فيّ بعض المناطق، وتتم

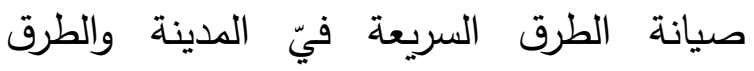
الرئيسية الأخرى بشكل دوريّ وأخذ بالاعتبار فيها

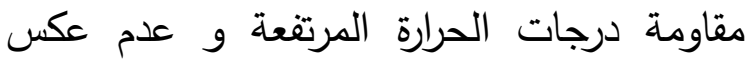

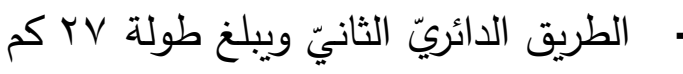
وباتساع 10 م، ويحيط بالمنطقة العمرانية التيّ تحد جبل أحد شمالاً وتمتد جنوباً حتى برج المياه ومن مسجد القبلتين غرباً إلى مخطط الخالدية شرقاً.

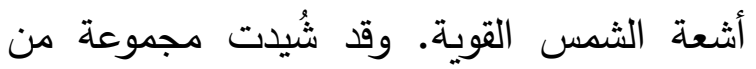

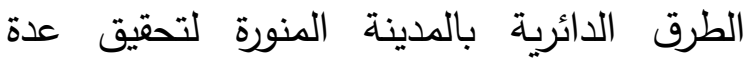
أهداف أهمها تفاديّ الحركة المرورية الإقليمية على الخطوط الدولية التيّ تربط المدينة المنورة بغيرها من المدن السعودية، أو ما يسمى بالحركة

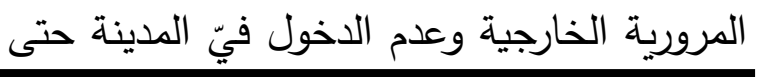


من وجود أربعة طرق دائرية تساهم في انسياب الحركة المرورية. يث يتراوح اتساعها بين .7 و . . . . مترك وباتجاهين يفصل بينهما جزيرة وسطى، وتبلغ السرعة القصوى على هذه الطرق الدائرية ، 11 كم / ساعة عدا الدائريّ الأولّ الذيّ حددت السرعة القصوى علية • . كم / ساعة، كما تشكل هذه الطرق الدائرية محاور نقلية لتعديل حركة المرور داخل المدينة، وبصفة خاصة حول المنطقة المركزية. إلا إنه توجد الكثير من الاختناقات المرورية وخاصة على التقاطعات مثل تقاطع العامر، وتقاطع عروة، وتقاطع الجامعة مع السلام، وتقاطع طابا الدائريّ الثانيّ مع شارع الملك عبدالعزيز، ودوار العنبرية، ودوار القبلتين، ويُعزى ذلك لأخطاء فيّ التصميم الهندسي للدوارات، وقد أشرت فيّ دراسة سابقة إلى مشكلات هذه الدورات وسبل علاجها (شوهدي عبدالحميد الخواجة

$$
(1 \cdot)(r \cdot 10
$$

تكدس الحركة المرورية على بعض الطرق الاشعاعية نتيجة الزيادة العددية للسيارات وتضخم كثافة سير المركبات فيّ ساعات الذروة وخاصة الصباحية، كما فيّ طريق السلام وبالتحديد تقاطع السلام مع الجامعة، حيث يصب عدد من الاحياء بما فيها حيّ العزيزية ذيّ الكثافة السكانية العالية وأحياء أخرى، بالإضافة
- الطريق الدائريّ الثالث والذيّ تم تطويره

فيّ ضوء المخططات الهيكلية القديمة والحديثة لمدينة المنورة، واستفاد هذا الطريق من وصله طريق الجامعات (طريق غير المسلمين) لتفاديّ المرور بالمنطقة المركزية، وليصل إلى طريق جدة ويصله بطريق تبوك والقصيم مما يسهر فيّ انسياب وسيولة حركة المرور بين جنوب المدينة وغربها وشمالها الثرقيّ. ولا شك أن هناك علاقة بين شبكة الطرق والحركة النقلية عليها، حيث ترتبط كفاءتها بمدى علاقاتها بقدرتها الاستيعابية لحركة النقل للمركبات وحركة المرور للمشاة، وخاصة مع تزايد الطلب الخارجيّ للزائرين عليها بصورة مضطردة ومستمرة، كما أن شبكة الطرق والشوارع فيّ المدينة المنورة قابلة للتطور والتوسع المستقبليّ وفقاً لمتطلبات حركة النقل والمرور وكثافتها على بعض الطرق أو في بعض الاتجاهات والمسارات المختلفة، وقد حدث ذلك بالفعل في توسيع طريق الجامعات في الاتجاهين، وطريق سلطانة، وطريق السلام، وغيرها من الطرق ( الدراسة الميدانية،

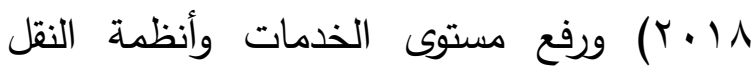
الذكية ووسائل السلامة المرورية على شبكة الطرق، لكن على الرغم من ذلك فقد تبين للباحث من الدراسة الميدانية بعض الحقائق عن الشبكة النقلية بمنطقة الدراسة تتمثل فيما يليّ:

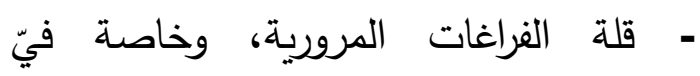
المنطقة المركزية ومحيطها، فعلى الرغم 
بالمدينة، مما يسبب الوقوف عند الاشارة مرة ومرتين وثلاثًا، بل وأكثر ويترتب على ذلك تداخل حركة السير وتوقفها. فالمساحة اللازمة من الطريق لشخص يستخدم حافلات النقل العام تتضاعف نحو عرين مرة فيّ حال استخدام المركبات الصغيرة. - مع ازدياد حركة النقل والمرور وزيادة المشكلات النقلية على شبكة الشوارع و و الطرق فيّ المدينة المنورة، فقد بات من

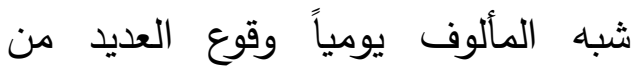
الحوادث، و عند وقوع أيّ حادث مروريّ تظهر الاختناقات المرورية ويصبح السائق رهين وصول رجال المرور أو الطوارئ، وما يتطلب ذلك من وقت لإعادة ضبط وتيسير حركة المرور. و يفترض أن يكون الوصول للحادث المروريّ فيّ اقصر وقت ممكن، ولكن قد توجد عددا من المعوقات التيّ تحول بين سرعة الوصول للحادث مثل التجمع حول الحادث، مما يضطر رجل المرور للسير عكس الاتجاه للوصول إلى موقع الحادث بسبب اغلاق الطرق من قبل المتجمهرين. والنظر لأهمية وجسامة الحادث، فالحادث الذيّ تتتج عنه وفيات يأتيّ فيّ الاهمية وسرعة الوصول إليه، وحادث الاصابات يأتيّ فيّ المرتبة الثانية، وحادث تصادم فقط فيّ المرتبة الثالثة، لأن مباشرة الحوادث الاولى أهم
إلى جامعة طيبة، كلها تجتمع فيّ هذا التقاطع حيث لا توجد شوارع أخرى غير هذا الثارع. - يادة الاختناقات المرورية بسبب إقامة بعض المشاريع من انفاق وجسور وكباري يستغرق تتفيذها اكثر من ثلاث سنوات للمشروع الواحد، و الحفريات التيّ تسببها مشاريع وزارتيّ المياه والكهرباء مما يتسبب في مشاكل مرورية صورة تعقد المشاكل المرورية خاصة فيّ منطقة الحرم والمنطقة المركزية، لأن شوارع

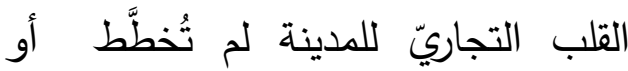
تُصمم لاستيعاب أعداد كبيرة من وسائل النقل، وإنما لحركة المشاة، فضلاً عن لهن صغر القطاع العرضيّ الفعال لنهر الطريق، ويُعزى ذلك للإشغالات الموجودة على جانبيّ الطريق، مما يقلل من الطاقة الاستيعابية لشبكة الشوارع بوسط المدينة، و ترتب علية عدم انتظام وسائل النقل العام وفاعليتها . - اختلال التوازن الحاليّ فيّ توزيع الطلب على وسائل النقل المتاحة مما يزيد من وقت الرحلات ويتسبب فيّ اختناقات مرورية، ويرجع ذلك لزيادة الاعتماد على وسائل النقل ذات السعات الصغيرة فيّ التقل، مما تسبب فيّ تقييد الحركة المرورية العامة، والاستخدام غير الفعال للطاقة الاستيعابية لشبكة الطرق والشوارع 
أ - النظم المتقدمة لإدارة المرور (ATMS) Advanced Traffic management Systems (التحكم المروريّ): تعتمد أنظمة النقل والتقنيات الذكية لإدارة الحركة المرورية فيّ المدينة المنورة على تقنيات حديثة مبتكرة، لجمع وتدقيق المعلومات من الطرق والمركبات باختلاف سعاتها إلى مركز السيطرة والتحكم و إدارة الحركة المرورية، فيّ غرفة العمليات المخصصة والمجهزة بأحدث التجهيزات الفنية وفق أعلى المعايير العالمية، لتجمع المعلومات التيّ تسمح بالتعرف على التدفق المروريّ الحقيقي والمتوقع، وأين ومتى يحدث الازدحام، علاوة على الاهتمام بطبيعة ونوعية وسائل النقل بأنواعه المختلفة، والقدرات التشغيلية والحركية للمركبات ودرجة الكثافة وعلاقتها بإدارة

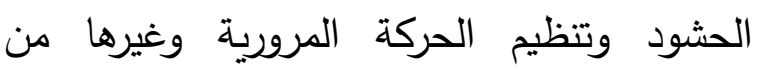
الاهتمامات مثل عمليات التلوث وانعكاساتها على الأداء والفاعلية والكفاءة المرورية، والتفاعل السريع والفوريّ مع الحوادث الطارئة، والاهتمام بدراسة الخدمات اللوجستية Logistics Services أو الخدمات المساندة للحركة النقلية مثل التشغيل والصيانة والتقليل من الأعطال ـ كما تساعد على تكامل النظم الحالية والمستحدثة لإدارة المرور ونظم التحكم المروريّ، من خلال ربطها بمركز تحكم عن بعد بواسطة شبكة اتصالات من أجل ضمان التدخل المباشر بشبكة النقل، لتستجيب للأحوال المتغيرة الديناميكية للمرور .فضلاً عن الإدارة المركزية للتقاطعات، التي تُسهم برفع كفاءة حركة النقل والمرور بشكل عام. ويمثل" الطريق الذكيّ
فيّ الاولوية القصوى فيّ سرعة الوصول وأحياناً تقع ما بين أربعة وستة حوادث فيّ لحظة واحدة، لذلك يكون الاهتمام بالحادث الأهم وبعد ذلك الحوادث الاقل أهمية، وهناك تتسيق مع غرفة العمليات

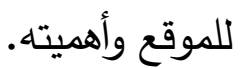
- عدم كفاية المواقف النظامية فيّ المدينة المنورة، خاصة فيّ مواسم: رمضان و العمرة والحج. - أدى زيادة ملكية السيارات، وارتفاع معدلات النمو فيّ حركة التدفقات إلى

$$
\text { التلوث الهوائيّ والتلوث السمعيّ }
$$

\section{رابعا : مجالات التطبيق الرئيسة لنظم النقل اللنكية ونتائجها في الملدينة المنورة}

نظراً لأهمية نظم النقل الذكية التيّ سبق الإشارة إليها سابقاً ودورها في حل المشكلات المرورية، فقد سعت مديرية النقل بمنطقة المدينة المنورة، لتطبيق أنظمة النقل الذكية بهدف الحد من الازدحام المروريّ الذي تعانيّ منه المدينة فيّ مواسم محددة بسبب أهميتها فيّ مجال السياحة الدينية، وقد تبنت وضع استراتيجية لتطبيق النقل الأكيّ، مستفيدة من التجارب العربية والعالمية فيّ عدة مجالات لتحقيق أهدف النظام الذكيّ البعيد المدى ، منها: تطبيقات نظم النقل الاكية فيّ المدينة المنورة : يوجد الكثير من تطبيقات أنظمة النقل الذكية فيّ المدينة المنورة، وذلك لتعدد مجالات استخداماتها www.trafficsafety-: وفيما يليّ دراسة لأهمها ( ksa.com/smar transfer system.doc $\mathrm{t}$ ) 
بالاعتماد على جهاز يسمى RFID Tags،وهو عبارة عن جهاز صغير يمكنه استقبال وإرسال البيانات والاستعلامات من خلال موجات الراديو. ويتم تركيب شريحة مميزة فيّ المركبة للتعرف على كل البيانات الخاصة بها، بواسطة أجهزة ذكية متواجدة على جوانب الطرق، تستطيع معرفة هوية المركبة وسرعتها واتجاهها والمخالفات التيّ هوري قد يرتكبها قائدها، ويتم رصد كل هذا أوتوماتيكيا دون الحاجة إلى ضابط مرور وتنتشر هذه الأنظمة فيّ TV موقع على شبكة الثوارع بالمدينة المنورة ( ادارة مرور منطقة المدينة المنورة، ادارة السلامة المرورية،هـ ( • ( ). ومن النتائج المترتبة على تحليل البيانات من استخدام هذه التقنية الذكية، التعرف على سرعة المركبات، وتحديد الطرق المزدحمة والأخرى التيّ بها سيولة مرورية، وفتح إشارة الطريق المزدحم فترة أطول من نظيرة الذيّ يوجد به فراغات مرورية، مما يسهم فيّ تخفيف التكدس المروريّ، وتقليل الوقود المستهلك و الحد من الحوادث، ورصد المخالفات، و استرجاع السيارات المسروقة، والقضاء تدريجيا على هذه المشكلات. - رصد وضبط وإدارة الحركة المروريـة

\section{آليا(ATVAM):}

وهو برنامج إدارة وتحكم المرور في المناطق

Urban Traffic Management \& الحضرية Control ، وتستند خدماته على نظام متطور لضبط وإدارة حركة المرور آلياً باستخدام نظم إلكترونيه تغطي المدينة المنورة، ويستخدم النظام أنظمة الرصد بالكاميرات (CCTV) عبر تقنية
أحد النظم المتقدمة لإدارة المرور الذيّ تتعامل معه المركبة الذكية، ويمثل ذلك أساس جميع التقنيات الأخرى لنظم النقل الذكية والتيّ تقدم خدمات للمستفيدين فيّ التطبيقات التالية :

\section{- - نظام المرور الأكيّ فيّ المدينة المنورة}

:Smart Traffic Information System يجمع النظام أكبر قدر من البيانات عن الحركة المرورية على الثبكة النقلية - الطرق والمركبات - والمتواجدة فيّ المناطق المحيطة بالتقاطعات والدوارات، و واستقبال تلك البيانات وتحليلها ومعالجتها بشكل دقيق، بهدف معرفة أنماط حركة المرور على الثبكة النقلية، لإنتاج معلومات أفضل تساعد على تتظيم الحركة وتوقع شكل المرور • ويعمل النظام بتطوير خوارزميات تسمح لغرفة العمليات بإدارة المرور بمنطقة المدينة بتوقع الحالة المرورية وتدفق السيارات فيّ أماكن معينة، ويقدم لهم الحلول المثلى، والمدة الزمنية اللازمة لتوقف المرور لإيجاد أسهل الحلول فيّ التعامل مع المشكلات المرورية، مما يسهم فيّ انسياب وسهولة الحركة المروية بشكل كبير، كما يمكن تحليل تغير أنماط القيادة من مكان لآخر وعلى أساس ذلك يتم تتظيم المرور • ويعد هذا النظام وسيلة هامة للقضاء على كل مشكلات المرور بالمدينة المنورة، بداية من مراقبة شبكة الطرق والثوارع، ورصد المخالفات المرورية، ثم إمكانية تجنب الازدحام وتفاديّ الحوادث ، ويعتمد النظام على تقنية تعرف باسم)Radio Frequency Identification (RFID) وهى تقنية تحدد هوية الأجسام بشكل تلقائيّ 
الطبية، وتجهيز المراكز المساندة والإسعافيه لنقل الركاب ومن ثَ تعزيز الأمن والسلامة المرورية، كما تساعد هذه التقنيات المتقدمة على استثعار وجود الحوادث الطارئة والتأكد من وقوعها، وعلاقة النقل بالسياسات Social Policies والتنمية الحضرية، وتأثير النقل على عمليات التفاعل والتواصل المعرفيّ والاجتماعيّ وبالتاليّ تقوم

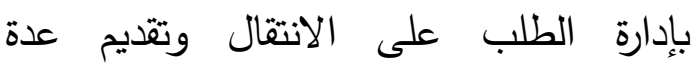
معلومات للأفراد منها تقدير زمن الرحلة، واختيار الطرق المناسبة، فضلاً عن تحديد الطرقات البديلة لتغيير الوجهة عند الضرورة، من أجل تحسين زمن الاستجابة لها، وإرسال فرق المساعدة المناسبة من الأفراد والمعدات لمعالجة هذه الأحداث الطارئة.

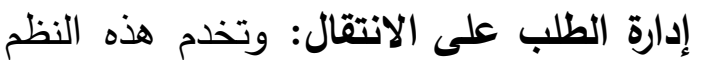

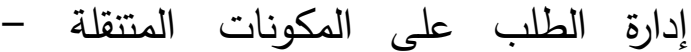
المركبات-و توفر معلومات آنية عن مواقع المركبات يساعد على الإدارة الفعالة لتقليل استخدام المركبات الخاصة، وتثجيع استخدام وسائل النقل العام، وتحسين كفاءة وجودة خدماته، ذلك عن طريق استراتيجية استخدام الحارات المرورية المخصصة للمركبات ذات

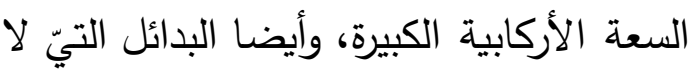

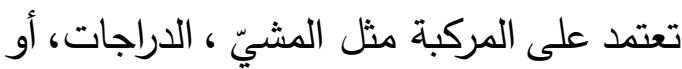
عدم الانتقال كلية، واستخدام أساليب إعطاء أفضلية الحركة، والتحكم بمواقف السيارات وتكلفته، و تخصيص مسار مروريّ لمركبات النقل العام صورة ( 11 ) واستخدام أساليب
شبكة الكاميرات الرقمية، المتصلة بمركز المعلومات الوطنيّ ل لوزارة الداخلية. وتنسيق الإشارات المرورية لسرعة نقل الحركة المرورية، وإعادة توجيه حركة المرور بواسطة لوحات بث الرسائل للسائقين (VMS). مما يُس هم فيّ زيادة مستويات الفاعلية والكفاءة لنظظومة النقل الذكيّ وخدمات النقل على شبكة الطرق والثوارع وبنيتها التحتية مثل الكباريّ والانفاق وطرق المشاة والاشارات المرورية، وتعظيم حركة النقل بالثوارع والطرق الرئيسة المزودة بإثارات مرورية، والتتسيق بينها وبين حركة النقل، و الطلب مع السعة ضمن نظام النقل .من خلال تعقب حركة المركبات وإرسال هذه البيانات إلى مركز التحكم بشكل فوريّ، مما يساعد على إدارتها، من خلال إيجاد طرق سريعة

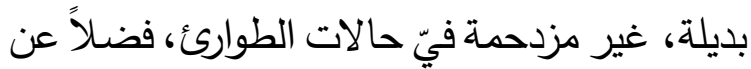
إمكانية التحكم الآليّ بنظم الإشارات المرورية المرشدة للمستفيدين، وهذه الخدمة ممثلة فيّ أنظمة التخدي التحكم المركزيّ بالإشارات المرورية داخل المدينة، وتطبق فيّ المدينة المنورة لازدحام شوارعها بصورة كبيرة خاصة فيّ مواسم الحج والعمرة صورة ( • (1) مما يساعد على الانسيابية فيّ حركة السير و

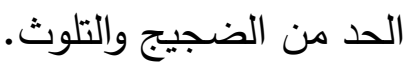
- إدارة الأحداث الطارئة : وتتمثل فيّ إجراءات التدخل السريع والعاليّ الكفاءة فيّ الحالات المرورية الطارئة، والظروف الجوية السيئة، وصيانة الثوارع أو مد شبكات الكهرباء والمياه والاتصالات والصرف الصحيّ، وفيّ المناسبات الخاصة .ويعزز تطبيق نظم النقل الذكية توفير خمات الطوارئ والخدمات 


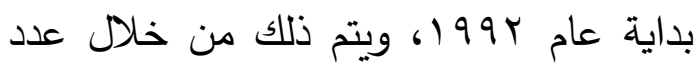
من الدحطات الدائمة ويقاس حجم الحركة

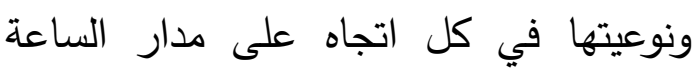

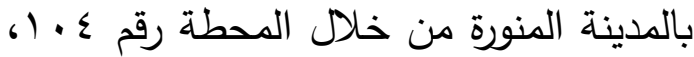
والتيّ تقع على طريق الددينة / الحناكية. ويقدم تقرير سنويّ ببيانات كل محطة. كما

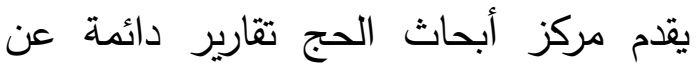
حجم حركة المرور على المداخل الرئيسة الأربعة للمدينة المنورة، ويتم تحليل ومعالجة هذه البيانات من قبل ادارة مرور المدينة.

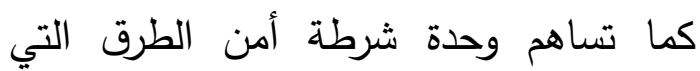
تشرف على حركة المرور على الطرق ولديها بيانات إحصائية دقيقة عن حوادث الطرق من حيث الموقع ودرجة الإصابة في دعم إدارة حركة المرور على الطرق من وإلى الدينة HANY SAMY ABU EL ELA , 2016:193) نظام التحكم المروريّ على مداخل الطرق

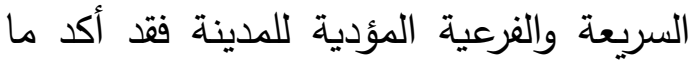
يقرب من نصف العينة بأنها ممتازة، ووضح لمدئه

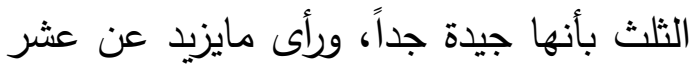

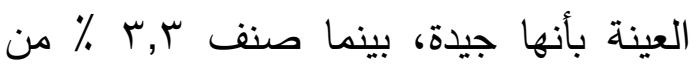

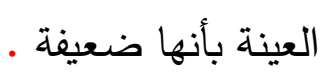
ج - زيادة الطاقة والكفاءة التشغيلية لشبكة النقل : ويتم ذلك بزيادة السرعات وتقليل التوقفات،

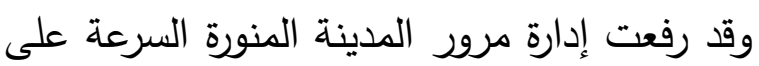

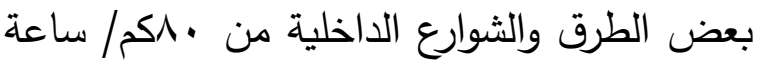

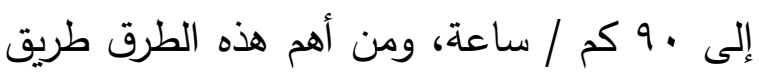

إعطاء أفضلية الحركة. وتسعى إدارة مرور المدينة المنورة لتحقيق إدارة فعالة لنظام النقل التحاه بتوفير معلومات دقيقة عن مكوناته بصورة مستمرة من خلال فرق الميدان المنتشرة بالبنية التحتية الثابتة (الطرق)، والمتنقلة (مركبات الطوارئ، وسيارات النقل). تقنيات وأنظمة أخرى تتمثل فيما يليّ: مراقبة الجودة العامة للهواء وإدارتها من خلال حساسات لجمع البيانات والمعلومات عن غازات العوادم واختبارها صورة ( I I ). وتقديمها بلاغات الطوارئ والأمن الثخصيّي،

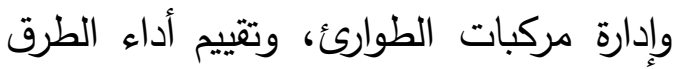
السريعة والثوارع والتتسيق بينها وبين عمليات النقل العام لموازنة الطلب مع السعة ضمن نظام

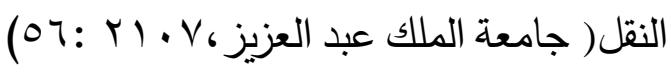
ب - نظام التحكم المروريّ عند مداخل الطرق لندي

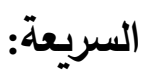

يُعد من أهم تطبيقات نظم النقل الذكية فيّ المدينة المنورة نظام التحكم المروريّ عند مداخل الطرق السريعة، و ذلك باستخدام إثارات ضوئية تعمل آلياً عند الدذخل من طريق الخدمة إلى الطريق الرئيس على الطرق تئل

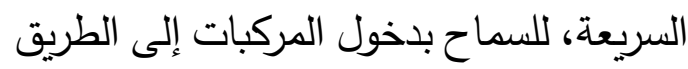

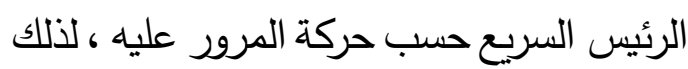

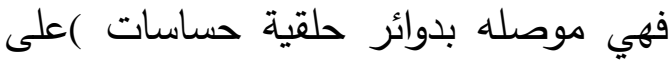
الطريق الرئيس( السريع )وكذلك بدوائر حلقية (حساسات )على المدخل نفسه لتعمل جميعها بنظام متكامل. ويتم قياس حجم الحركة المرورية على الطرق الإقليمية في الملكة منذ فئذ 


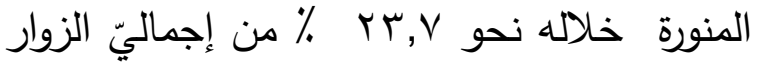

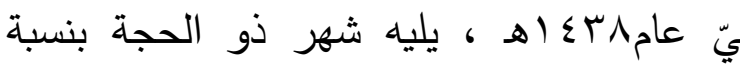

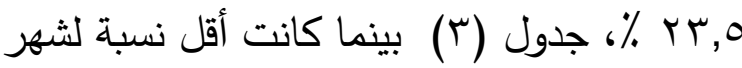

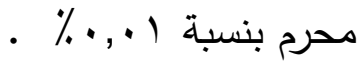
جدول(r ) التوزيع النسبي للزوار القادمين

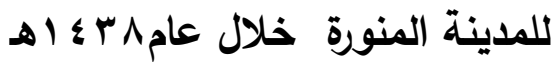

\begin{tabular}{|c|c|}
\hline نسبة الزوار & الثهر \\
\hline$\cdot, \cdot 1$ & محرم \\
\hline., 01 & صفز \\
\hline$r, q$ & ربيع أول \\
\hline$\varepsilon, 7$ & ربيع أول \\
\hline 7,1 & جماد أول \\
\hline$\neg, \wedge$ & جماد ثاني \\
\hline$\Lambda, r$ & رجب \\
\hline $1 \cdot, r$ & شعبان \\
\hline$r r, V$ & رمضان \\
\hline$r, \wedge \wedge$ & شوال \\
\hline $1 \cdot, 7$ & ذوا لفعدة \\
\hline$r r, \theta$ & ذو الحجة \\
\hline $1 \ldots$ & الإجمالي \\
\hline
\end{tabular}

ويُستخدم تطبيق التقنيات الإلكترونية المتقدمة لتنفيذ وتثغيل المركبات عالية الأركاب وذات الأركاب المشترك بما فيّ ذلك الحافلات صورة

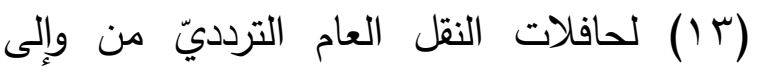
الحرم) وعربات القطارات صورة ( ؟ () محطة من سكك حيد المدينة المنورة.، وزيادة الطاقة

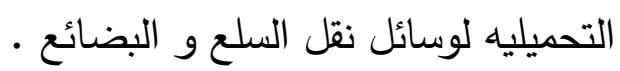

الجامعات، ورفعت السرعة على الطرق السريعة

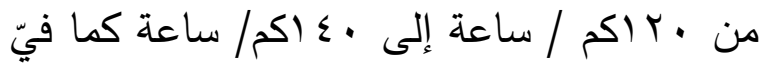

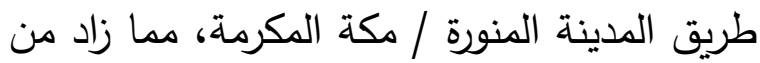
الكفاءة التثغيلية لشبكة الطرق بمنطقة الدراسة، وتقليل التأخير عند نقاط التحويل بين وسائل النقل، وتقليل تكاليف الازدحام، وزيادة الطاقة الاستيعابية لثبكة الطرق، وتخفيض تكاليف التشغيل للبنية التحتية لشبكة النقل.

دـ - النظم المتقدمـة لمعلومـات المتنقلين Advanced Traffic Management Systems(ATMS) الحركة والراحة للمتنقلين :

تسهم النظم المتقدمة لمعلومات المتنقلين فيّ الحصول على معلومات رحلات النقل العام، وتحليلها وتوصيلها وعرضها لمساعدة الركاب على لى الحركة من مكان انطلاق الرحلات (المنبح) إلى مقصدهم الذيّ يرغبون الوصول إليه .وتزويد المتتقلين بمعلومات لاختيار وسائل النقل، وأوقات الرحلات ، وقرارات اختيار المسارات، ووضع الدليل التجاريّ الإلكترونيّ "المتكامل مع نظام المعلومات قبل الرحلة والمعلومات أثناء الرحلة. وارشادات للمتتقلين عن كيفية الوصول لـقاصدهم، وتحسين مستويات الحركة للمتتقلين لكل مستويات الدخول

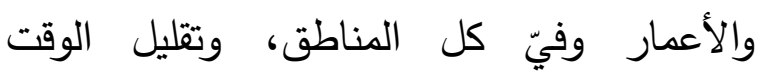
المستغرق فيّ الرحلة، ومن تكلفتها، و الجها ولاعل الهصاحب لها، و إدارة الطلب على النقل بتقليل استخدام النقل الخاص وتثنيع استخدام النقل العام وزيادة سعته الإركابية خاصة فيّ مواسم الذروة كموسم رمضان الذيّ تصل نسبة الزوار للمدينة 
والتأكد من وقوعها وتحديد مواقعها، واتخاذ إجراءات الاستجابة السريعة لها وإرسال فرق الطوارئ الملائمة لها من حيث الأفراد والمعدات، والتتسيق

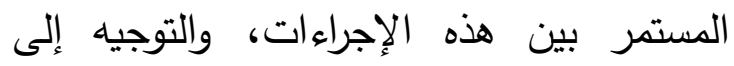

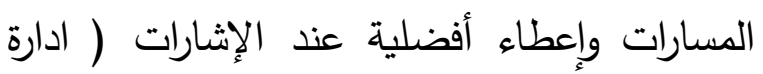
مرور منطقة المدينة المنورة، ادارة السلامة

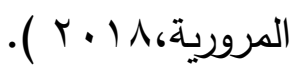
و - أنظمة اللوحات المتغيرة الرسائل : Variable Message Sign(VMS)

وهيّ نظم ذكية لتزويد قائديّ المركبات بالمعلومات الخاصة بحالة المرور على شبكة الطرق بتوجيه رسائل مختلفة عبر لوحات ارشادية

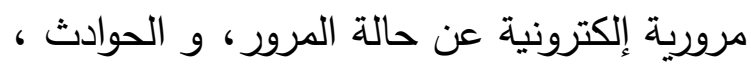

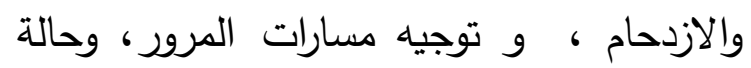

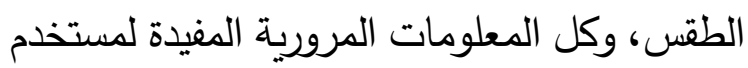

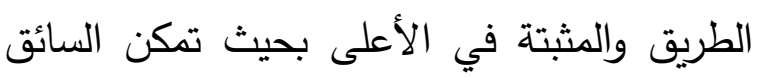
من اختيار اتخاذ القرار الصحيح فيّ تغيير مسار

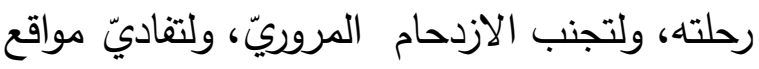
الحوادث .وتنتشر بشبكة الطرق والثوارع بمنطقة الثرانة الدراسة TVO لوحة متغيرة الرسائل. كما تتوفر

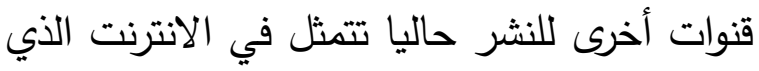
يسمح بتصور المناطق المزحمة قبل الدخول فيها. وهنالك نوعان من اللوحات المتغيرة الرسائل، إحداهما لوحات إرشادية ثابتة، والأخرى متنقلة، ويمكن

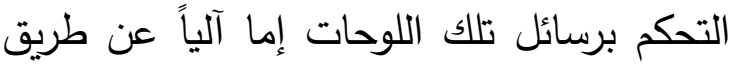
الحساسات المثبتة على الطرق، والتيّ يمكن من

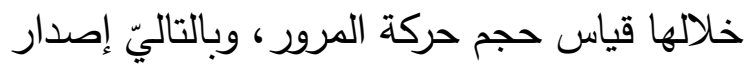
الرسائل الخاصة بذلك على تلك اللوحات .كما يمكن
كما تسهم هذه النظم فيّ تزويد السائقين بمعلومات عن مواقعهم وكيفية الوصول إلى لى لئ المقاصد المرغوب الوصول إليها وتحليلها وعرضها عليهم وتقديم المساعدات للسائيتين بأفضل طريقة ممكنة عن طريق إرشادات صوتية،

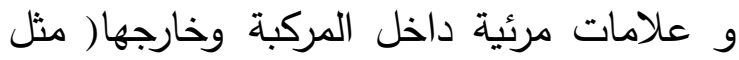
اللوحات ذات الرسائل المتغيرة على الطرق)، بهدف مساعدتهم على الحركة من مكان انطلاقهم وصولاً إلى مقصدهم بدرجة كبيرة من السلامة والراحة والكفاءة . هـ - إدارة مركبات الطوارئ :

تركز الجهات المختصة فيّ المدينة المنورة

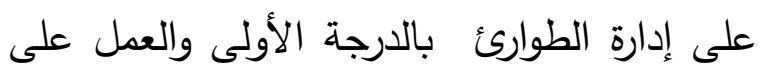

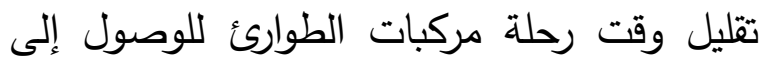
الموقع، عن طريق مراقبة المركبات وحالة الطرق والتقاطعات، وتحديد المكان، واتخاذ القرارات السريعة والتنسيق بينها، وتحديد المسارات وإعطاء الأفضلية لها، و تطبق هذه التقنية فيّ المدينة المنورة لتقليل الزمن الذيّ تستغرقه مركبات الطوارئ للوصول إلى مقصدها، وذلك من خلال إجراءات التدخل ذات الكفاءة العالية فيّ الحالات المرورية الطارئة، وأعمال صيانة البنى التحتية، وفيّ لئي المناسبات الخاصة كمرور المواكب الرسمية، والظروف الجوية السيئة التيّ ينتج عنها حوادث جسيمة. وتقديم معلومات عن الحالة الجوية، والإغلاق الآليّ للطرق المتضررة، فضلاً عن إدارة

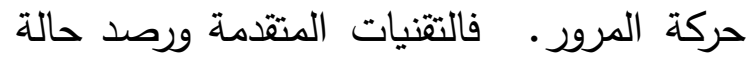
الطرق وحجم الحركة عليها وعلى التقاطعات، تركز على استثعار وجود الحوادث الطارئة 


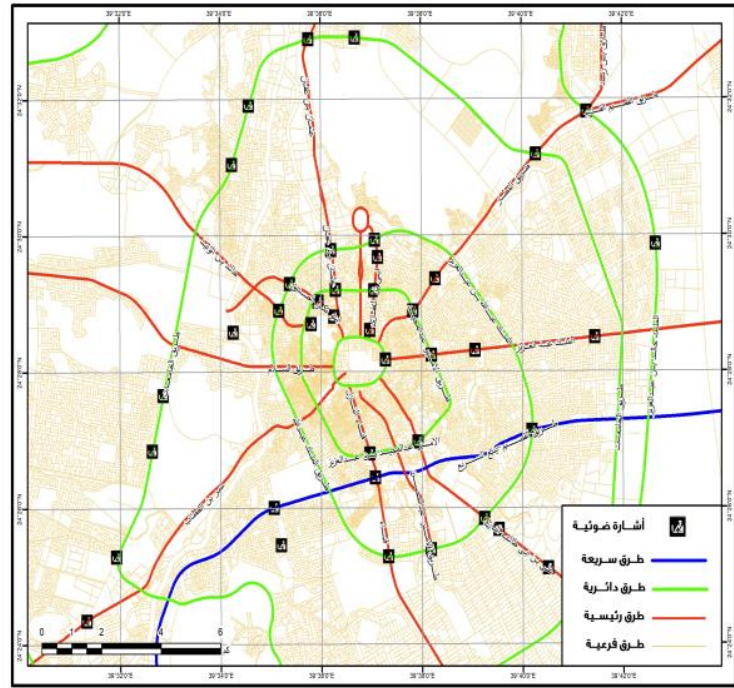

شكل ( ^ )التوزيع الجرافيّ للإثـارات المرورية على تقاطعات الثوارع بالمدينة المنورة عام

$$
\text { م } 11
$$

مركزيّ عبر شبكة اتصالات سلكية لتوفير الوقت وعدم التأخير عند تلك الإشارات، وتحسين الكفاءة، وتخفيض الانبعاثات، كما تم تركيب كاميرات فيديو صورة (10) لمراقبة حركة المرور

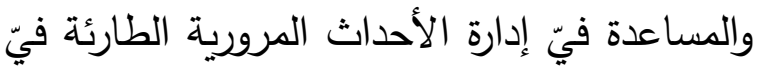
SV V موقع ، فضلاً عن إنشاء نظام لإدارة أعطال الإشارات الضوئية.

ومن تطبيقات نظم النقل الذكية هنا استخدام حساسات إليكترونية مثبتة عند التقاطعات، تقيس حجم حركة المرور على التقاطع، و تحدد أوقات

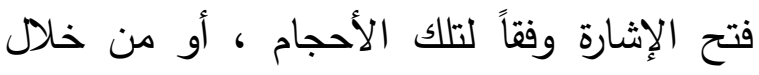

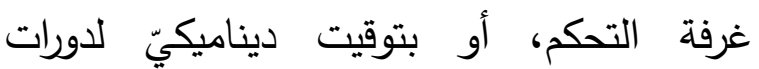
الإثارات الضوئية ومراحلها صورة (7 (1)، كذلك لكات يتم التحكم بالإثارات المرورية لإعطاء الأولويات

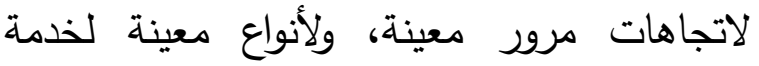
مركبات الشرطة و الطوارئ والإسعاف لسرعة نقل المصابين من موتع الحادث إلى المستثفى ـ كما
أن يتم تغيير تلك الرسائل من خلال غرفة التحكم المروريّ ، والتيّ يمكن أن تصلها المعلومات عن حالة حركة المرور من خلال الكاميرات المثبتة على لى لهن الطرق، أو من خلال الدوريات الأمنية على الطريق ، ومن أجهزه الاتصال ( ادارة مرور منطقة المدينة

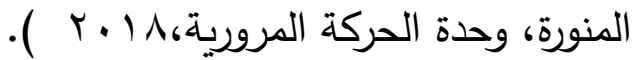
ز - أنظمـة التحكم الآلكي المـروريّ بالإثـارات الضوئية :

هو نظام ذكيّ جديد لإشارات المرور يقلل من الازدحام، حيث يتم التحكم فيّ أوقات تثغيل

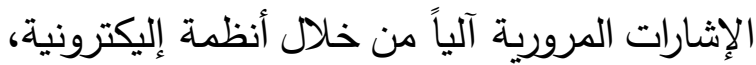
حيث تثهد ساعات الذروة في المدينة المنورة تكسسا مرورياً بشكل كبير، وازدحاما يجعل حركة النقل ثابتة فيّ مكانها على بعض الشوارع

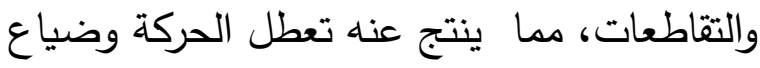

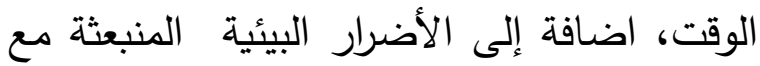
عوادم السيارات من المواد والغازات المضرة للبيئة بشكل كبير، وقد أدخلت أمانة المدينة المنورة

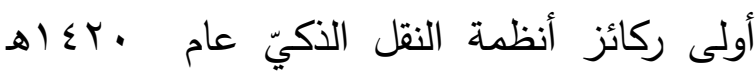
/999 /م ، وذلك بتطوير نظام جديد ذكى للتحكم الطما الآليّ وبرمجة إثارات المرور الضوئية و الذيّ

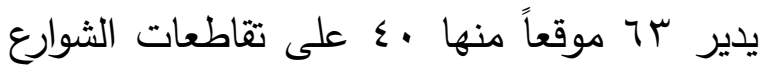
الداخلية شكل ( 1 ) ) ، وسr على تقاطعات

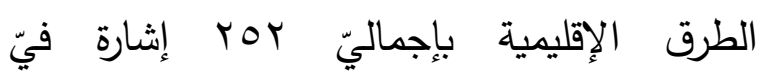
الاتجاهات المختلفة ( ادارة مرور منطقة المدينة

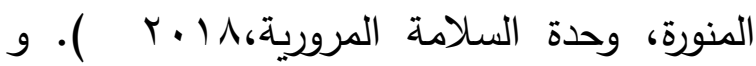
يجريّ التحكم بها بواسطة نظام تحكم محليّ متطور مرتبط بنظام تحكم شوشوا 
الانتظار الذكية المنتشرة بالمدينة المنورة، ويوجد نظاماً لمراقبة مواقف السيارات بواسطة كاميرات مع لوحات إرشادية الكترونية مربوطة كلها بمركز تحكم مركزيّ بواسطة شبكة الألياف البصرية، وعرض هذه المعلومات على أجهزة بهدف تقليل الوقت فيّ البحث عن موقف، وتعتمد هذه التقنية

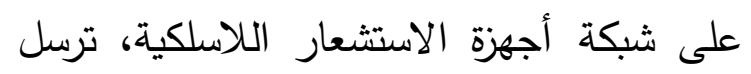
بياناتها إلى موقع مركزيّ لمعالجته والاستفادة

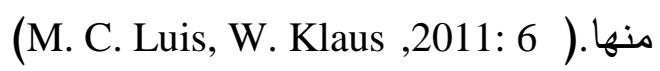
ولتيسير حركة وتتقل الأعداد الكبيرة من

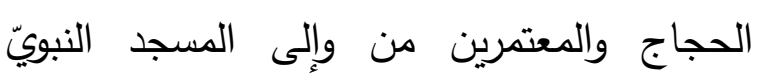
الثريف، أنشئ تحت ساحات المسجد مواقف

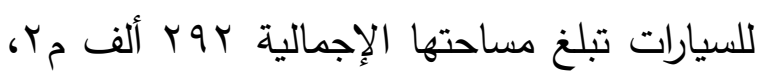
ومؤلفة من دورين لكل دور أربعة جهات، و تتسع

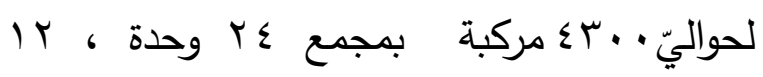

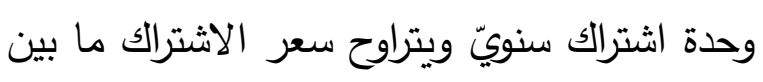

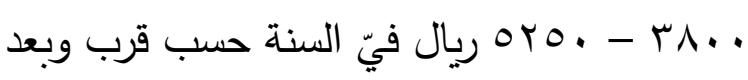

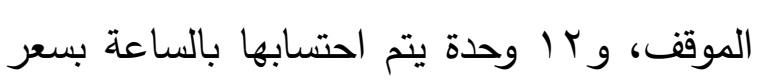
ـ., 1, ريال للساعة الواحدة، و المواقف مزودة بأنظمة النقل الذكية لتنظيم دخول وخروج السيارات

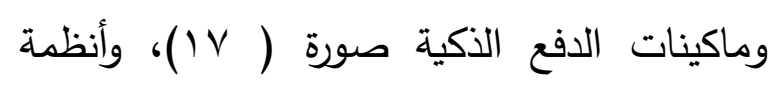

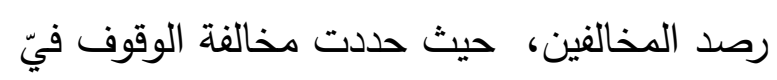

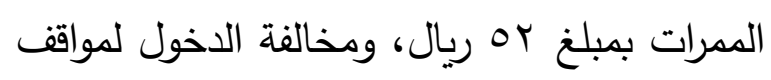

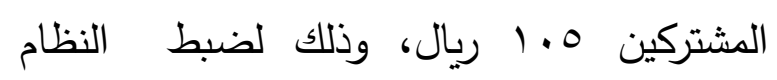
والحركة فيّ هذه المواقف، والمواقف مجهزة كما

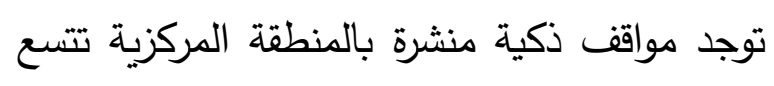

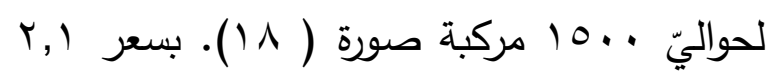

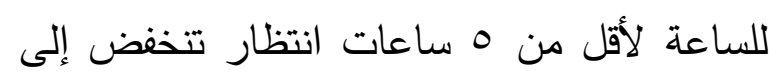
1, 1, ريال فوق الخمس ساعات، ويمكن من
تستخدم الإثارات المرورية فيّ الطرق الشريانية

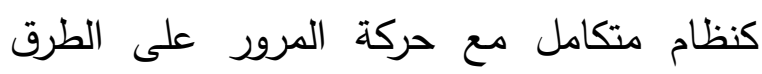
السريعة أثناء الطوارئ والأزمات على الطع الطرق على الطرق

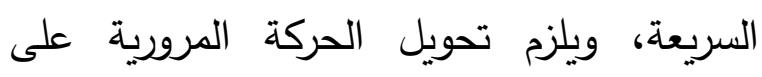
الطرق الشريانية من الطريق السريع. ومن نافلة القول أن انتشار الإنشارات

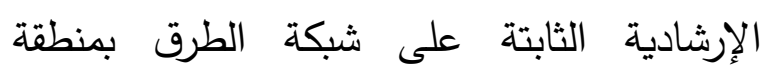

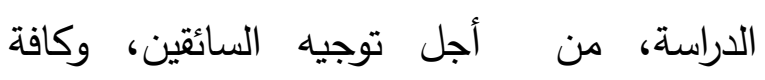

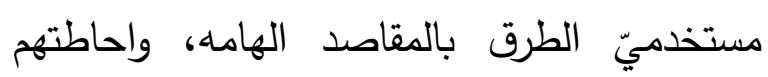

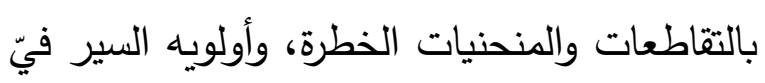
الدورات، وتحديد المسافات والاتجاهات، والأماكن

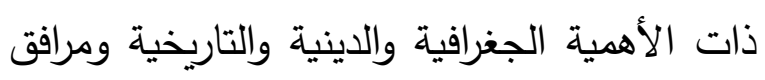

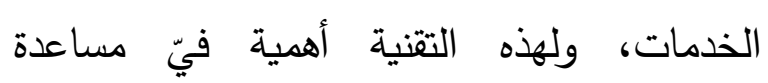

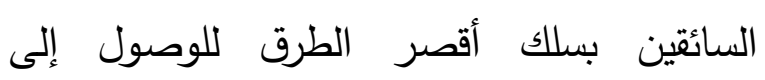

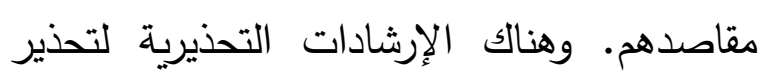

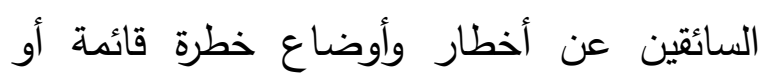
محتملة على الطريق أو الشارع ، حتى لا يفاجئ

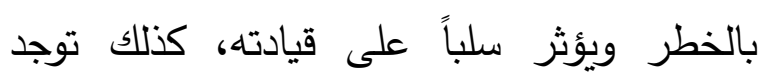
الإثارات التنظيمية لتعريف السائقين بأنظمة

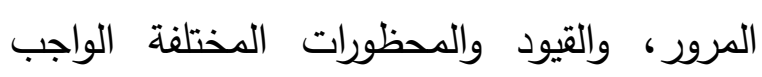
التقيد بها أثناء القيادة، وهيّ توضح أنظمة المرور

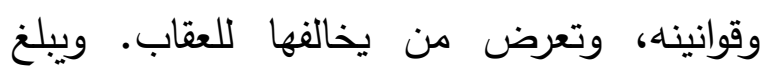

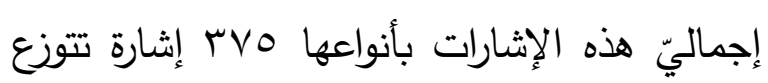
على شبكة الطرق بمنطقة الدراسة ( إدارة مرور الإناري

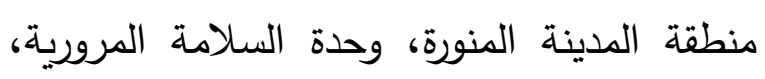
$(r \cdot) \Lambda$ ح - إدارة مواقف السيارات بكفاءة أكثر : وهيّ نظم تستخدم لإرشاد السائقين إلى أقرب

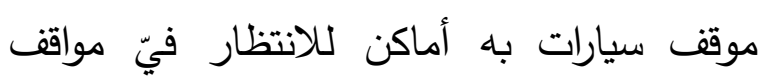


النقل، و تشجيع و تسهيل استخدام النقل

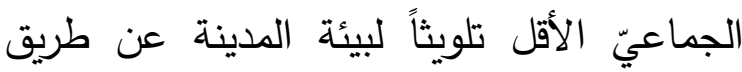
المعلومات المتعددة الوسائل والخدمات الاككترونيّة ومنظمات الإمداد الحضري الفعالة. و تستخدم تقنيات التقليل من الآثار الناجمة عن وسائل النقل الحضريّ على البيئة والطاقة ، لفالة وتصميم وتنفيذ البنية التحتية للحد من استهلاك المواد المضرة بالبيئة .من خلال تركيب حساسات

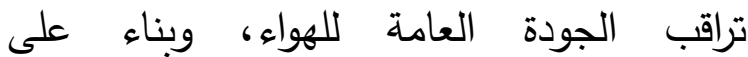
المعلومات التيّ تجمعها الحساسات يمكن تتفيذ استراتيجيات معينة لتقليل انبعاثات العوادم الضارة من المركبة، كذلك يتم فحصص دوريّ سنويّ للمركبات المرخصة بمنطقة الدراسة يتم فيّ أحد مراحله قياس الكربون فيّ محركات المركبة عن لعن لعال طريق ادخال حساسات فيّ عادم المركبة صورة (9). والتقليل من التلوث الضوضائيّ، ومضايقة المرور للأحياء السكنية، واحترام متطلبات الحفاظ على البيئة. وتثجيع التنقل اللطيف التتقل بالدراجات أو المشي على الأقدام، وقد خصصت هيئة تطوير المدينة مسارات خاصة للمشاة، وشجعت على استخدام الدراجات الهوائية ووفرت لركابها خوذات للحماية . ي- أنظمـة الملاحسة والإرشـاد فيّ المركبات

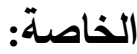

وُتستخدم هذه الأنظمة فيً المركبات لزيادة كفاءة الرحلة، وذلك بتزويد قائد المركبة بالمعلومات المرورية والامنية مباشرة من مركز التحكم و السيطرة المرورية بواسطة شاشة مثبته أمامه بالمركبة، بها خريطة رقميه لثبكة الثوارع و
خلال تطبيق "موقف" على الهواتف الذكية دفع أجرة مواقف السيارات بعد شحنه ببطاقة الائتمان والفيزا ( الرئاسة العامة لثؤون المسجد النبوي،

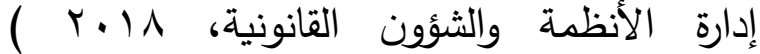

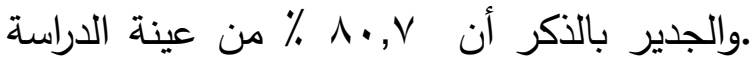
أكدوا أن المواقف الذكية بمنطقة الدراسة قريبة ومناسبة، حيث بين V,Tr ٪ بأن المواقف ممتازة

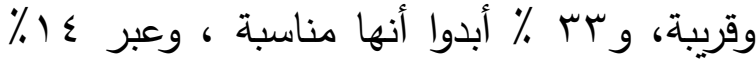

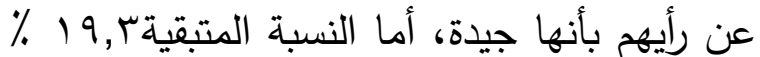
فقد أشاروا أنها بعيدة وغير مناسبة . ط - تقليل مستوى التلوث: عمدت المدينة المنورة على تطبيق نظم النقل الذكية لتحسين جودة الحياة فيّ المدينة وخدمات النقل المقدمة لسكانها وزائريها، وذلك من خلال إدارة الطلب على النقل و تقليل الحركة المرورية، والتحكم فيّ استهلاك الطاقة و خفض التض مستوى انبعاث الغازات الملوثة، من خلال التطبيقات الذكية المرتبطة بتثغيل المركبة وسلوك السائق، حيث تسمح بتخفيض استهلاك المركبات للوقود، ومن ثم تقليل انبعاث الغازات المضرة بالبيئة، والاحترام التلقائيّ لحدود السرعة واختيار الثوارع والطرق الخالية من الإشارات، وذلك بتحديد تلك المواقع بالأقمار الصناعية المرتبطة مع الخرائط الثرية في المعلومات الجغرافية ( www.developpement durable). gouv . fr بسرعة معتلة، وزيادة إمكانية الوصول accessibility للمساحات التيّ تعانيّ من نقص فيّ خدمات 
وهو نظام فترونك ليزر، أكثر تطورا، ويساهم في رصد المخالفات بدقة عالية، حيث يرصد لئد النظام السرعة الزائدة، وعدم ترك مسافة آمنة بين المركبات والمحدة بـ ب متر ، وتجاوز الثاحنات الخط الإلزامي لها، وعدم ربط حزام الأمان، واستخدام الهواتف أثناء القيادة وتوجد رادارات متحركة من نوع "فترونك" الألمانية مصممة لتصوير المخالفات بالفيديو وليس التصوير الفوتوغرافي فقط. أما عن تفصيل النظام فهو كالتاليّ :

- نظام تثغيل وإدارة الحركة المرورية آلياً :Traffic Management System (TMS) نظام الكترونيّ متطور، يهدف إلى تحسين

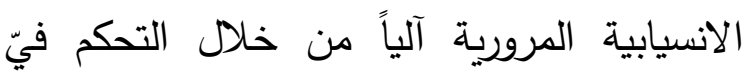
الإثارات الضوئية المرورية، معتمداً على رصد الإنيا حيّ لعدد المركبات فيّ كافة الاتجاهات لكل الإنارتهات تقاطع بما يسمى بالموجة الخضراء( Green .(Wave

- نظام تتبع مركبات جهاز المرور Vehicle Location (AVL) يهدف إلى تتبع وتحديد مواقع مركبات جهاز

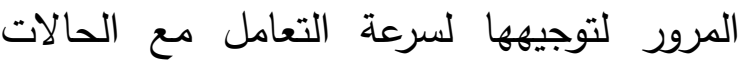
المرورية المختلفة وإدارة الفرق الميدانية. - نظام التعرف على لوحات المركبات (LPR) License Plate Recognition يتم تركيبه على مداخل ومخارج المدن، بهدف نطان التعرف على المركبات للأغراض الإحصائية والمركبات المطلوبة مرورياً، أو المسروقة من الإكرات

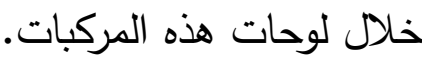

الطرق لخط سير الرحلة، وأفضل الطرق للوصول إلى مقصدها، وتحديد الوقت المستغرق للوصول

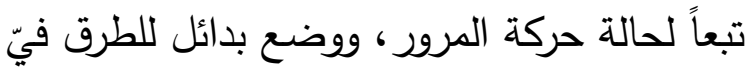
حالات الطوارئ للتقليل من وقت الرحلة، وشروط المتانة فيّ المركبة، ومواقع المركبات، والمسارات، ومعلومات عن المحلات والمواقف ومحطات الخدمة والوقود، ومعلومات عن الطقس ودرجات الحرارة •وتنتشر هذه الأنظمة فيّ المدينة المنورة

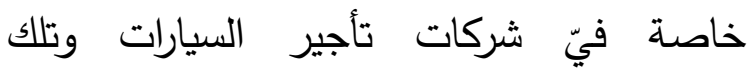
المشتركة بشركة أوبر، حيث تُزود المركبات بهذه

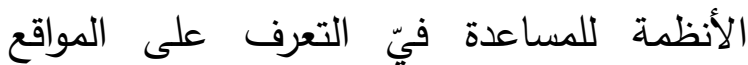

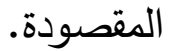
ك - أنظمة السلامة المرورية وإدارة الحوادث بالمدينة المنورة: - الطفا تبنت المدينة المنورة تطبيق استراتيجية نظم

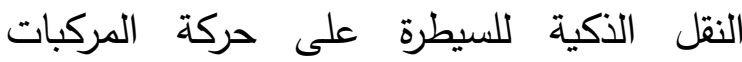
بالطرق والثوارع والتقاطعات، والتحكم فيّ سرعتها الزائدة التيّ كانت السبب الرئيس فيّ الحوادث المرورية، وتفاقم الآثار الناجمة عن هذه الحوادث، وقد قامت ادارة مرور منطقة المدينة

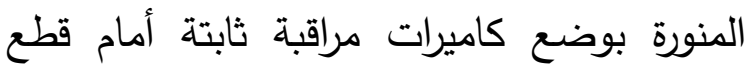
الإثشارات المرورية صورة ( •r) تعرف بنظام Red light ماهر أو كاميرات الضوء الأحمر cameras و هو نظام آليّ الضبط باستخدام نظم إلكترونيه تغطيّ منطقة المدينة المنورة تابع

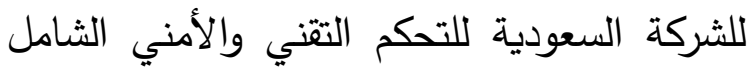
المحدودة والمشغلة لنظام مخالفات الرصد الآلي

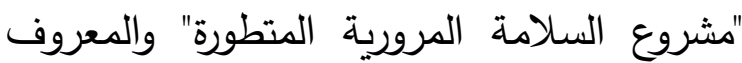

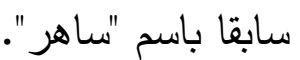


لجمع المال للدولة فقط، فيّ حين رأى البعض أن

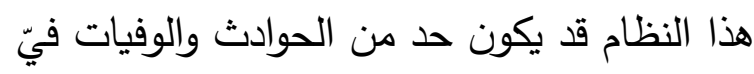
التقاطعات ولكنه زاد من عدد الحوادث من جراء الارتطام بخلفية المركبات عند الإثارات .

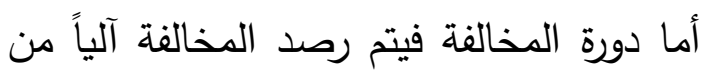
الكاميرات للمركبة المخالفة، و إرسال صورة لوحة

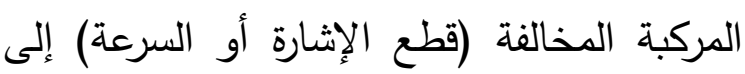
مركز معالجة المخالفات، ثم الحصول على العنى معلومات عن هوية المركبة من قاعدة البيانات

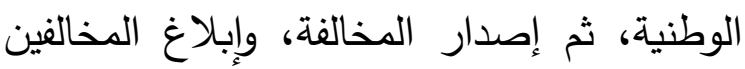
ليقوموا بسداد قيمة المخالفة بحدها الأدنى خلال

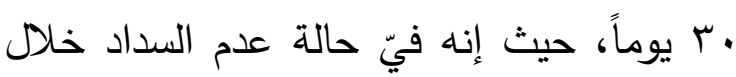
تلك الفترة يتوجب عليهم سداد قيمة المخالفة فيّ ئي حدها الأقصى حسب نظام المرور الجديد. وأخيراً يتم سداد الدخالفة عن طريق نظام سداد لادى لإن

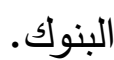
ك- الاستجابة لحالات الطوارئ تُّبق أنظمة النقل الذكية بقطاع إدارة الحوادث بالإبلاغ عن الحادث، وتحديد موقعه، و الوصول إليه فيّ أقل فترة زمنية، وتسير حركة المرور المتأثرة بالحادث .وقد طورت شركة نجم المسؤولة

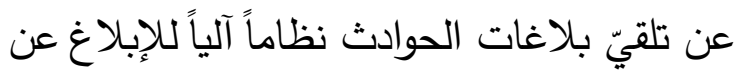

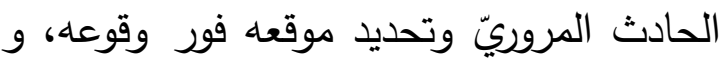

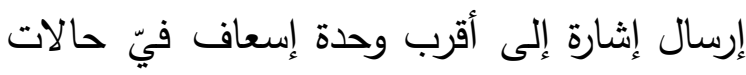
الاصابات أو الوفيات للموقع باستخدام أجهزه

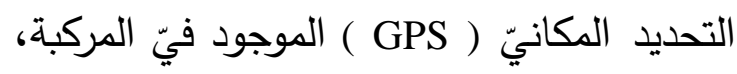

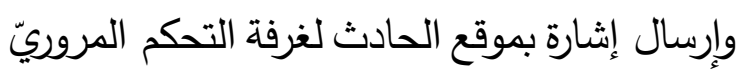
بادرة مرور المدينة، ليتم التنسيق بين دوريات المرور، والإسعاف، وفرق الصيانة لمعالجة
- نظام اللوحات الإرشادية الإكترونية على الطرق(Massaging Signs(VMS نظام شبكة لوحات إلكترونية إرشادية ذات بث حيّ يهدف إلى توجيه قائديّ المركبات إلى تجنب الاختناقات المرورية على الطرق. Close نظام كاميرات مراقبة الحركة المرورية العادية هو نظام إلكتروني يهدف إلى مراقبة حية للحركة المرورية على الطرق الرئيسة. - نظام الضبط الإلكترونيّ للمخالفات Law Enforcement System( LES كاميرات ورادارات ثابتة ومتحركة بهدف رصد وضبط المخالفات المرورية آلياً من دون أي تدخل بشري وإصدار المخالفات وإشعار المخالفين آليا.

ويهدف هذا النظام إلى تحسين مستوى السلامة المرورية، وتوظيف أحدث التقنيات التين التيناف المتقدمة في مجال النقل الذكيّ (ITS) لإيجاد بيئة مرورية آمنة، ورفع كفاءة شبكة الطرق المتوفرة حاليا، وتدعيم الأمن العام باستخدام أحدث أنظمة النها المراقبة، والعمل على تنفيذ أنظمة المرور بدقة واستمرارية. ويستخدم النظام تقنية شبكة الكاميرات الرقمية المتصلة بمركز المعلومات الوطنيّ لوزارة الداخلية

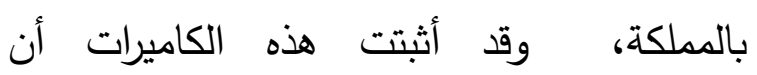
باستطاعتها المساعدة في الحد من حوادث الطرق

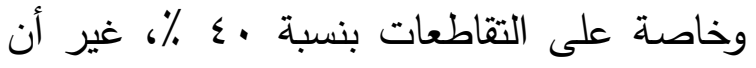

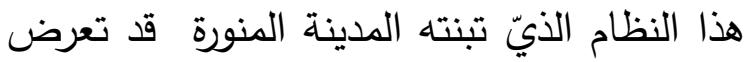
للانتقاد، ذلك أن البعض قد اعتبره بمثابة نظام 


\section{م - الفحص الآليّ للسلامة:}

يشمل القدرة على الوصول إلكترونياً لمستندات

السلامة الخاصة بالناقلين والمركبات والسائتين. و

فحص الأنظمة الضرورية للمركبة، ومدى ملاءمة

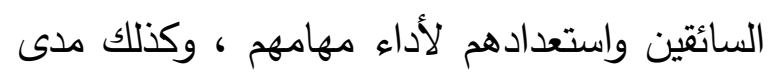

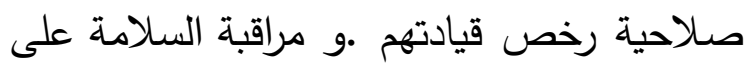
متن المركبة لكل من السائق والمركبة والثحنة، مرافها

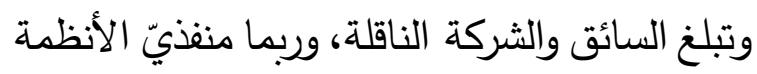
عن أيّ وضع غير آمن. وتبنت ادارة مرور منطقة

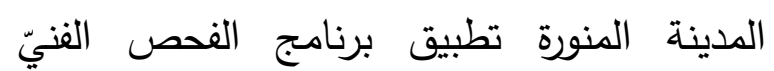

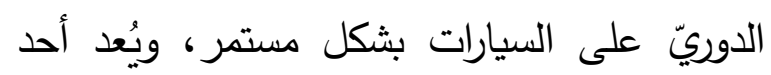
أهم برامج السلامة المرورية، حيث تحرص الإدارة العامة للمرور من خلاله على تتفيذ أعلى قدر

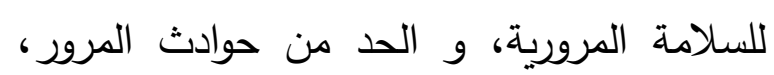
بالإضافة إلى ضرورة فحص السيارة في حالة التعرض لأي حادث مروريّ ، أو اقامة أيّ تعديل

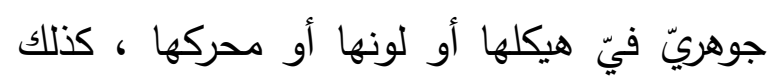
يتوجب فحص السيارة فيّ حالة كون السيارة مستعملة، و يرغب المالك للسيارة بنقل لوحاتها

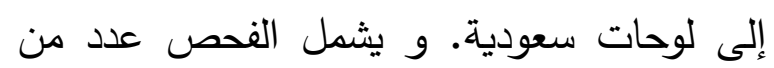
الأجزاء الخارجية بالسيارة من بينها لون السيارة وهيكلها واللوحات و الأنوار والإثارات، و غيرها.

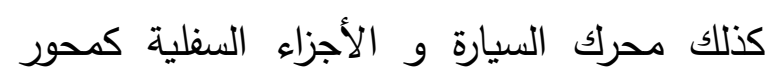

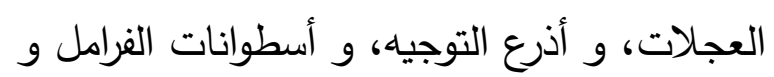

$$
\text { غيرها صورة ( (r) ). }
$$

و عن مدى جودة تطبيقات نظم النقل الذكية

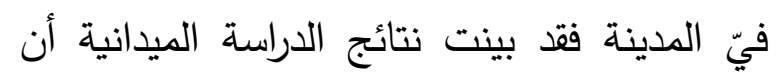

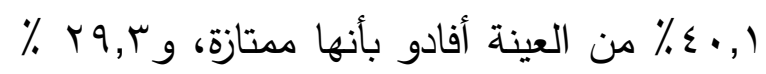

الحادث والآثار الجانبية لحركة المرور المترتبة علية. وتساعد الاتصالات ذات التقنية الحديثة وحدات الطوارئ فيّ تقديم المساعدات العاجلة

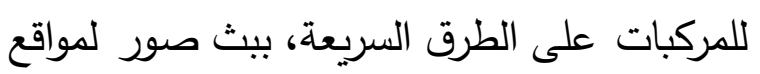
الحوادث، عن طريق التقاطها بواسطة سيارات الطوارئ المجهزة لاستقبال هذه الصور ، و تحليل

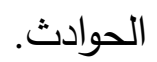

ل- أنظمة مراقبة الأساطيل:

تُستخدم أنظمة النقل الذكية فيّ مراقبة أساطيل نقل الركاب والبضائع فيّ المدينة المنورة، حيث تُطبق فيّ(شركة سابتكو) لمتابعة أساطيل

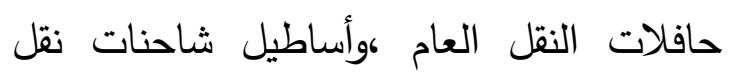
البضائع .وكان لذلك الأثر الكبير فيّ التقليل من النات عدد المركبات المستخدمة على شبكة الطرق، وبالتاليّ زيادة طاقتها الاستيعابية داخل المدينة، وتثغيل حافلات النقل بشكل منتظم لتشجيع مستخدميها وتقليل الاعتماد على المركبات الخاصة. وتعتدد الأساطيل على أنظمة الملاحة والمراقبة لمتابعة حركة الحافلات بأجهزة التحديد

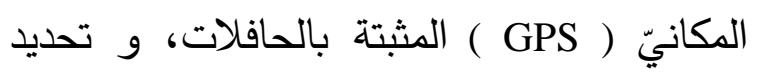
مواقعها أثناء سيرها، ومتابعة الحافلات بمركز المراقبة من خلال شاشة الكمبيوتر ، وبذلك يمكن

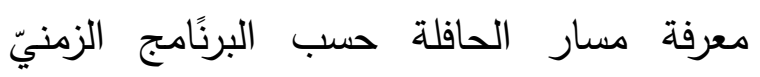
المخطط لها. وتخضع جميع المركبات لنظام المراقبة الإكترونية لمتابعة التزامها بالمسارات المحددة وتوضيح الوقت المتبقيّ للوصول للمحطة الإلئية

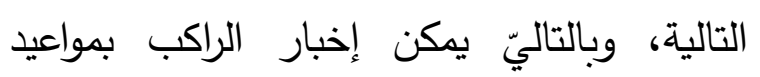

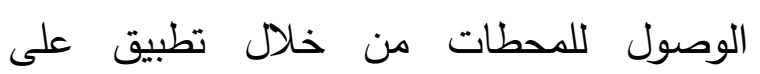
التليفون المحمول الثخصيّ • لون 
العام فيّ المدينة المنورة بجميع مكوناته من شبكة المترو وشبكة الحافلات السريعة وما يرتبط بهما من مواقف وحافلات فرعية مغذية ومحطات ومراكز خدمة وصيانة وأنظمة نقل ذكية. وقد عملت (سابتكو) بإدخال وسائل نقل حديثة لأسطول مركباتها، وهيّ شركة مساهمة سعودية تم تأسيسها فيّ عام 9V9 1، برأس مال مليار ريال سعوديّ، وغرضها الرئيس هو نقل الركاب بالحافلات على شبكة الطرق العامة داخل المدن فيّ كل من مكة المكرمة وجدة والمدينة المنورة، والرياض وفيما بينها. وبشبكة خطوط منتظمة تربط بين بر مدينة و قرية على مستوى المملكة، وترتبط المدينة المنورة بخطوط نقل جماعيّ منتظمة تصلها بمدن : مكة - جدة مهد الذهب - ينبع - العلا - تبوك الساحلي تبوك الصحراوي - الرياض - الدمام - حايل ويبلغ عدد المركبات العاملة بالشركة ــ مركبة. كما تعدت خدمات الشركة النطاق المحليّ إلى النطاق الدوليّ لتصل برحلاتها إلى ثمان دول خليجية وعربية هيّ: الإمارات والبحرين وقطر والكويت ومصر والأردن واليمن، والسودان. وتقوم الشركة بتسيير رحلات مجدولة يومياً تصل إلى ولى . . . رحلة فيّ الأيام العادية ، و . . . 1 رحلة فيّ المواسم تتتوع بين رحلات بين مدن المملكة ورحلات دولية، كما بلغ عدد وكلاء الثركة المحليين والدوليين ـ10 وكيلاً. والجدير بالذكر فيّ هذا الصدد إن نسبة المعتمرين الذين يستخدمون الحافلات فيّ انتقالهم من مكة المكرمة

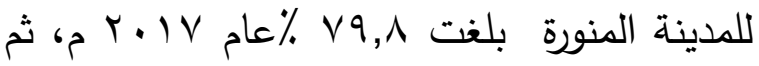

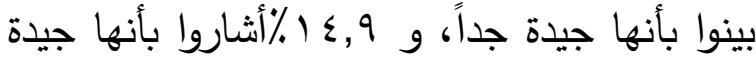
بينما كان رأي النسبة المتبقية بأنها صعبة . ن - النظم المتقدمة للنقل العام: تعتمد النظم المتقدمة للنقل العام على تطبيق التقنيات الإكترونية الحديثة فيّ تشغيل المركبات ذات السعة الإركابية الكبيرة، وذات الأركاب المشترك مثل الحافلات، وعربات القطارات، و تتمثل الخدمات التيّ تقدمها هذه التطبيقات فيّ المدينة

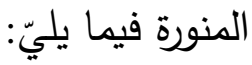
- إدارة النقل العام : وتتمثل فيّ وظائف التشغيل والتخطيط والإدارة بطريقة آلية، وتتمثل هذه الخدمة فيّ الشركة السعودية للنقل الجماعيّ (SAPTCO)، و مساهمتها فيّ النقل العام داخل المدينة و النقل التردديّ من وإلى الحرم، والنقل الخارجيّ بين المدينة المنورة وباقيّ مدن المملكة. - تطوير نطام النقل العام فيّ المدينة المنورة: سايرت المدينة المنورة التوجه العام بالمملكة فيّ خطتها الاستراتيجية لتطوير خدمات النقل العام بالمدن، ومشاريعه الرئيسة سعياً للارتقاء به به بـ لاستقطاب شرائح جديدة وصولاً إلى الأهداف المرورية والبيئية والاقتصادية والاجتماعية المنشودة. وذلك من خلال استقطاب الخبرات العالمية والاستفادة من التقنيات المتطورة للتعامل مع التحديات المرتبطة بالاعتماد على السيارة الخاصة كوسيلة أساسية فيّ ركة النقل الحضريّ، وتتضمن منظومة النقل العام فيّ المدينة المنورة ثلاثة مكونات رئيسة تضم " الحافلات - قطار الحرمين والمترو - الطرق" وقد وافق مجلس الوزراء السعودي على مشروع النقل 
وأخيراً السيارات الخاصة ساهمت بنقل با \% من

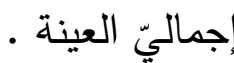

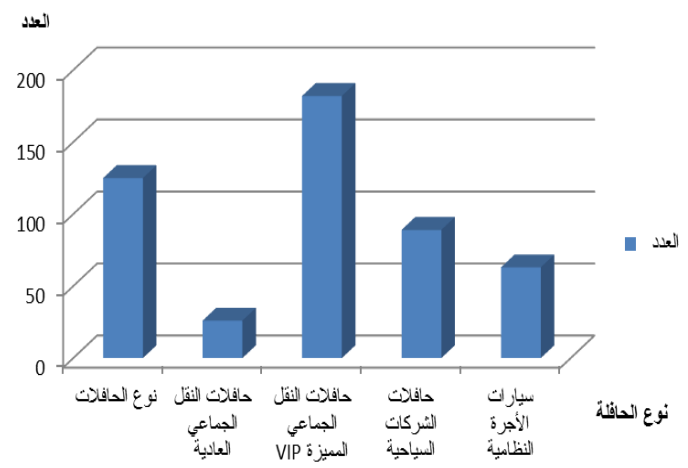

شكل ( 9 ) نوعية الحافلات التيّ استخدمها

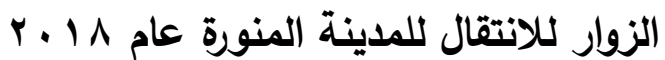
وأطلقت "سابتكو" خدمة النقل الداخليّ عبر شبكة خطوط تغطيّ المدن الرئيسية فيّ المملكة وذلك من الساعة ال ه صباحاً إلى . • 11: مساءاً، بينما حددت الشركة المشغلة بالتنسيق مع هيئة تطوير المدينة المنورة أوقات العمل لحافلات المدينة المنورة خلا شهر رمضان ابتداءً من الساعة ... . عصراً وتتواصل حتى بعد صلاة التراويح بساعة، فيما ترتفع الطاقة التشغيلية خلا العشر الأواخر لتستمر حتى بعد صلاة التهجد بنصف ساعة. وجميع الحافلات مصممة حسب أعلى معايير الأمن والسلامة العالمية ومجهزة بأحدث التقنيات الذكية، فبها تجهيزات تمكن ذويّ الاحتياجات الخاصة من استخدام تلك الحافلات بكل يسر وسهولة . كما يمكن شراء البطاقات الذكية عن طريق أجهزة الخدمة الذاتية وعن طريق تطبيق سابتكو. وقد وقعت (سابتكو) اتفاقية Ratp Dev الشراكة الاستراتيجية مع شركة

جاءت السيارات الأجرة بنسبة ؟, 1 1 ٪، بينما

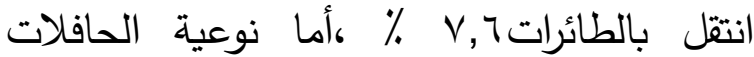
المستخدمة في الانتقال فيبنتها نتائج الدراسة

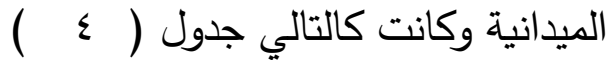
جدول (ع) نوعية الحافلات التيّ استخدمها الزوار للانتقال للمدينة المنورة عام ^1 ـ ؟

\begin{tabular}{|c|c|c|}
\hline$\%$ & العدد & نوع الحافلات \\
\hline Yo, & Iro & الجماعلات النقل العادية \\
\hline $0, \varepsilon$ & r & الجماعي المميزة \\
\hline$\mu v, 0$ & $1 \wedge r$ & حافلات الشركات \\
\hline $1 \wedge, r$ & 19 & سيارات الأجرة \\
\hline ir & Tr & السيارات الخاصة \\
\hline $1 \cdots$ & $\varepsilon \wedge 0$ & الاجماليّ \\
\hline
\end{tabular}

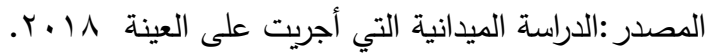
يتضح من تتبع وتحليل الجدول ( ع ) أن النقل بواسطة الحافلات يحتل المرتبة الأولى حيث اش,V استخدمها سب فرد من العينة بما يوازيّ \%، وتتصدر الحافلات السياحة وسائل نقل الزوار بنسبة rV,O \% و تأتيّ حافلات النقل الجماعيّ فيّ المرتبة الثانية بنقل 101 فرد من أفراد العينة بما يشكل r, اس \% شكل ( 9 )، منهم ع,0 \% ت ت نقلهم بحافلات النقل المميز VIP وجاءت سيارات الأجرة النظامية فيّ المرتبة الثالثة بنسبة ؟,ی 1 ٪، 
السعة الإركابية عماد شبكة النقل العام بالمدينة.

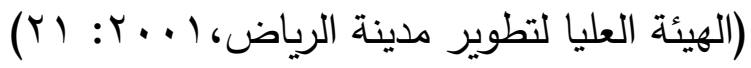
وتخدم حافلات النقل العام نحو.7 الف مستفيد يومياً فيّ المدينة المنورة من المواطنين والمقيمين، على مدار الساعة من أحياء المدينة المنورة إلى الحرم النبويّ خلال شهر رضضان المبارك. إضافة إلى خدمات نقل المعتمرين والزوار القادمين من داخل وخارج المملكة، وخدمة الجولات السياحية ورحلات المدارس والجامعات والجمعيات وخدمة نقل الموظفين والطلاب. .https://www.alyaum.com/articles/6016486) وحقق المشروع الذيّ تُشرف عليه إمارة منطقة المدينة المنورة، وتثارك فيّ تنفيذه أمانة المدينة المنورة، وهيئة تطوير المدينة، ومديرية الطرق و النقل بمنطقة المدينة، وشرطة المنطقة والمرور ، والثركة الناقلة، نجاحًا خلال السنوات الماضية فيّ خدمة النقل التردديّ من وإلى الحرم النبويّ الشريف، مما دفع القائمين إلى زيادة أسطول الحافلات المقدمة للخدمة لتصل إلى ، 10 حافلة، وزيادة خطوط سير الخدمة لتشمل مناطق المدينة المختلفة عبر محطات موزعة جغرافيًا أهمها محطات: شظاه ، الأزهريّ، الدعيثة والجامعة الإسلامية، مخطط الملك فهد، العالية، سيد الثهداء، ومحطة الخالدية، والهجرة، وغيرها شكل( • (). وذلك بهدف تخفيف الحركة المرورية للمركبات الصغيرة فيّ المنطقة المركزية ومحيطها والثوارع المرتبطة بالحرم النبوي، من خلال تسخير خدمات النقل التردديّ إلى المسجد النبويّ والتيّ تنطلق من المحطات الرئيسة داخل الأحياء
الفرنسية وهيّ واحدة من أكبر شركات تشغيل وصيانة النقل العام فيّ العالم ( الثركة السعودية

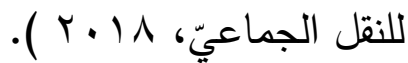
وساعد مشروع النقل الداخليّ التردديّ بالمدينة المنورة فيّ تسهيل حركة النقل على امتداد الشوارع الرئيسة وفيّ المنطقة المركزية، حيث أسهم فيّ تقليص الازدحام المروريّ على شبكة الشوارع، خاصة خلال أوقات الذروة وبنسب تصل إلى هب\%، وبخاصة فيّ فترة شهر رمضان الذيّ يشهد توافد آلاف الزوار من الخارج ومن مختلف مناطق المملكة. وتقليل استخدام النقل الخاص وتثجيع استخدام النقل العام، ويشمل تخصيص حارة مرورية لمركبات النقل العام، والتحكم بمواقف السيارات، و افتتاح فروع خدمة العملاء فيّ كافة الصالات الدولية والداخلية بمطار الأمير محمد بن عبدالعزيز بالمدينة المنورة · وقد حدث تقدماً ملحوظاً فيّ تحسين تشغيل الحافلات فيّ المدينة المنورة وذلك لما تعانيه من الازدحام. ويعتمد هذا الثكل من النقل العام على إعطاء الأولوية لحافلاته على طرق وشوارع الحركة المرورية، وتخصيص طريق ثابت لاستخدام حافلات النقل العام فقط . - الع

وقد استفادت المدينة المنورة من تجربة مدينة قرطبة في البرازيل والتيّ اعتبرت طريق الحافلة جزءاً من خطة تكامل النقل مع استخدام الأرض والذيّ تبنته المدينة فيّ عام .99 19 م . حيث خصصت مسارات للنقل العام فيّ المناطق المرتفعة الكثافة السكنية و السكانية، والأنشطة التجارية حيث تثكل حافلات النقل العام عالية 


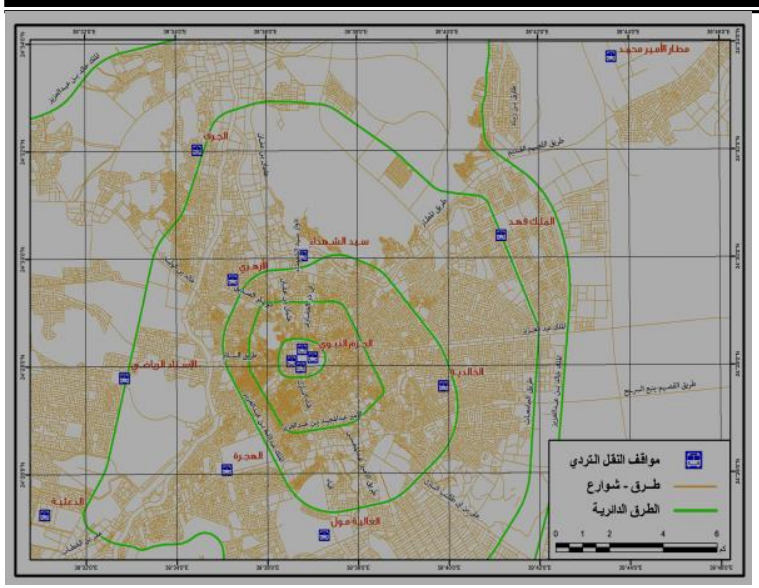

شكل (·) مواقف النقل العام التردديّ في

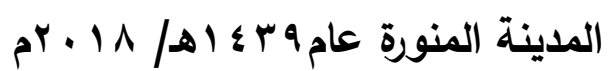

وفترة الذروة، وأثر أنظمة النقل الذكية المستخمة

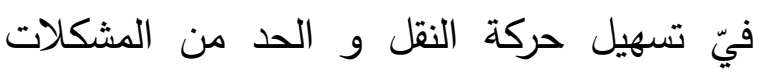

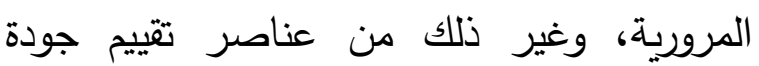

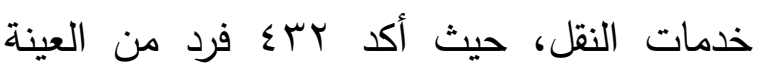

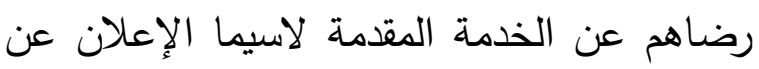

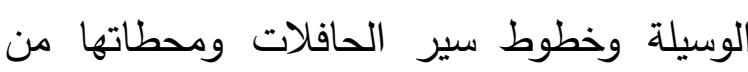

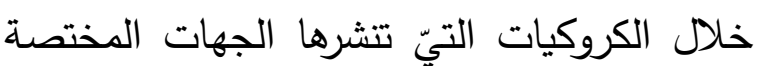

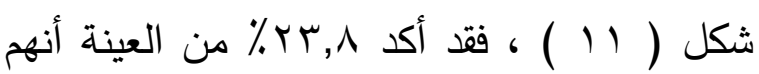
تعرفوا على الوسائل من خلال الإعلانات والمواقع الدانع

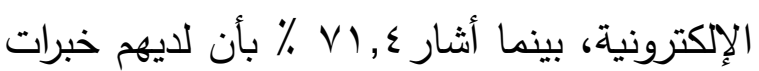

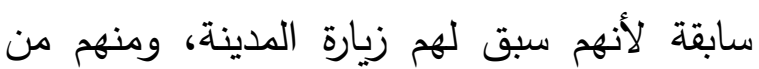

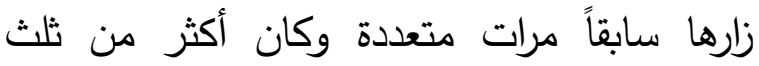

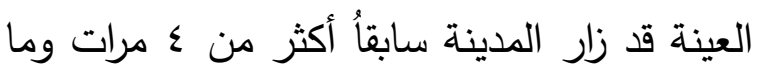

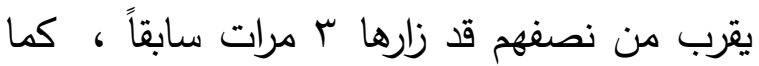

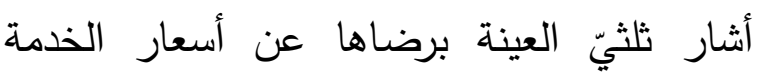

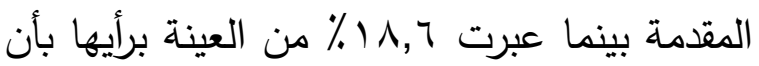
مستوى الأسعار غير ملاثم ومرتفعة خاصة فئي

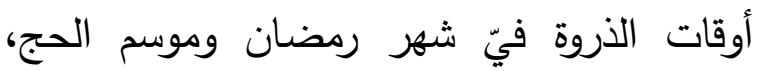

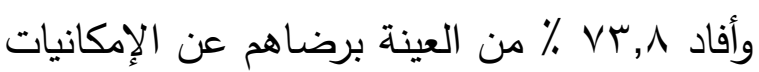

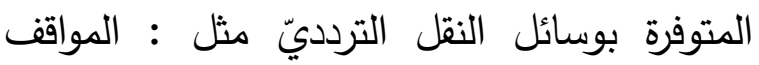

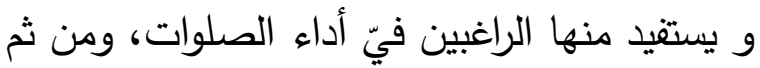

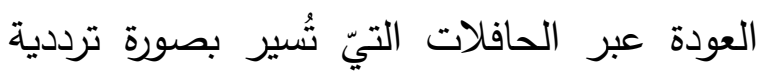
وفق المحددات الزمنية المعتدة للخذمة. بتعريفة

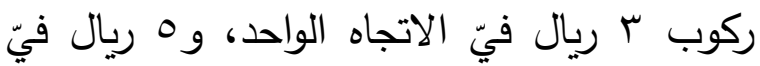
الاتجاهين ذهاب وعودة.

وشيدت هيئة تطوير الدينة المنورة التطبيق الإلكترونيّ لحافلات النقل الحضريّ، بهلف زيادة تواصل المستقيدين من خدمات النقل العام عبر المنصة الإكترونية المتكاملة، و التيّ تتيح إمكانية الوصول للنظومة النقل عبر نافذة

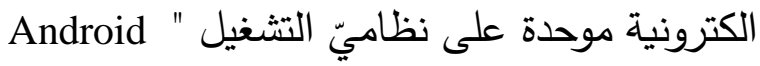

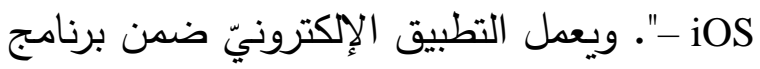
أنظمة النقل الذكية فيّ إدارة الأسطول الآليّ النيّ

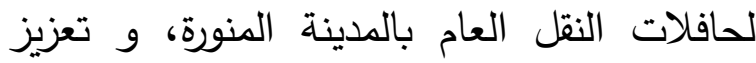
التكامل مع نظام حجز التذاكر، وأنظمة التتبع والتثغيل، ومتابعة حركة الحافلات والتعرف على التى

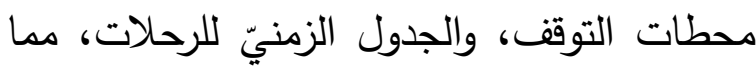
يُسهم فيّ رفع مستوى المتابعة لكافة الجوانب التباتي التثثيلية والفنية للحافلات ومتابعة أداء السائقين وتتبع مستوى الخدمة والكفاءة التثشغيلية.

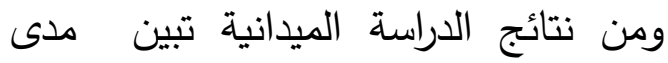
الرضا عن خدمات النقل العام في الددينة المنورة

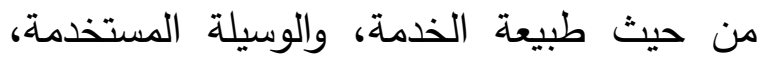
والوقت المستغرق في الرحلة، ونوعية المعاملة، 
ساعتين ونصف الساعة، وبلغت تكلفة قطار الحرمين بمرحلتيه الأولى والثانية ومليار ريال. (https:/ /haramainrailway.com) وانطلقت أول رحلة للقطار بين المدينة المنورة ومكة المكرمة فيّ سبتمبر 1 1 • r م و بواقع أربع رحلات اسبوعياً، فيّ أيام (الخميس والجمعة والسبت والأحد)، بواقع 1 رحلات بين مكة المكرمة والمدينة ذهابا وإيابا، أما فيّ سبتمبر 9 1 ب r ستنطلق الرحلات اليومية بين المدينتين

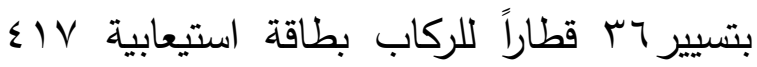
مسافر/ رحلة ، و و ا ألف راكب /يومياً وكل قطار يحتويّ على سا عربة ركاب مكونة من أربع عربات درجة أولى، وثمانيّ عربات درجة سياحية، وعربة مطعم، إضافة إلى قاطرتين للقيادة فيّ مقدمة ومؤخرة القطار • ومن نافله القول أن إن القطارات مجهزة بالأنظمة الذكية وخدمات الإرشادات والاتصالات. و سينقل قطار الحرمين السريع ، الإرديون مسافر سنوياً بين مكة المكرمة

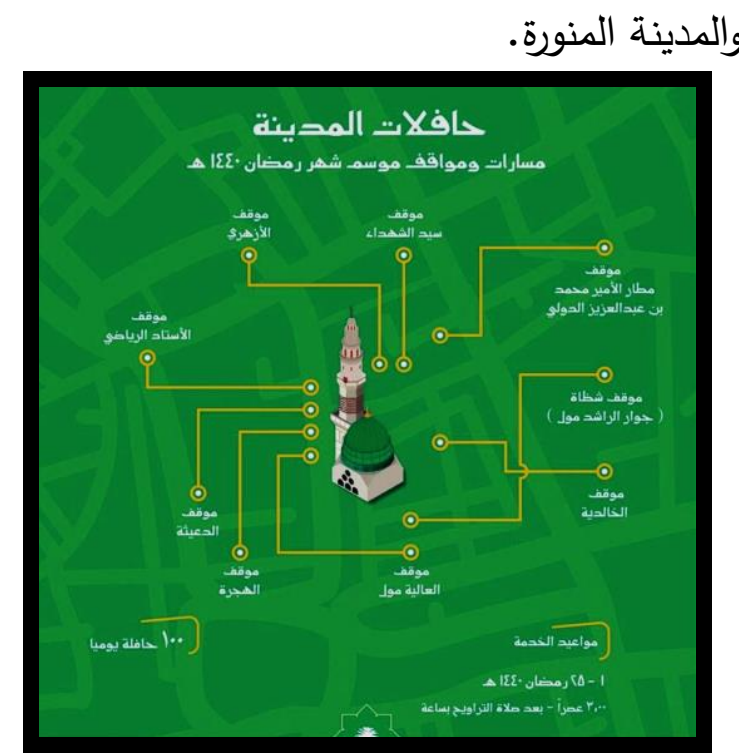

شكل (11 ) نموذج الكروكيات المعلنة لخطوط سير ومحطات النقل الترددي بالمدينة المنورة
الخاصة بذويّ الاحتياجات الخاصة فيّ كافة المسارات، وخدمة الانترنت wi fi المجانيّ، ومكان لشحن الموبايل، وسماعات بجوار كل USB كرسي بالإضافة للدفع الإكتروني للتذاكر وعدم السماح قطعيا بوقوف أي راكب. بهدف التحسين المستمر لجودة الخدمة مع الالتزام بمعايير الأمن

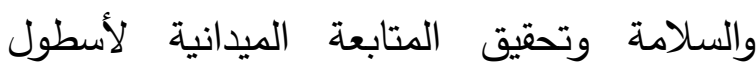

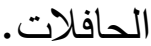

ويتميز التطبيق الإلكترونيّ الجديد بسهولة الاستخدام وتطوير أنظمة الرقابة على مستوى أداء وسائل النقل العام، ويُشكل خطوة جديدة فيّ التشجيع على الاستفادة من خدمات النقل العام، ويُسهم فيّ تمكين المستخدمين من التنقل على جميع مسارات الخدمة عبر منصة موحدة .( هيئة تطوير المدينة المنورة، تدشين تطبيق حافلات المدينة) ( https://www.okaz.com.sa/article/1)

\section{مشروع قطار الحرميز في الملدينة المنورة:}

تم تطوير نظام حضري عام متطور لخدمة المدينة وهو مشروع قطار الحرمين، ويأتيّ مشروع قطار الحرمين ضمن منظومة النقل العام فيّ المدينة المنورة لخدمتها ومكة المكرمة وجدة، ويُعد ضمن أكبر مشاريع النقل العام فيّ الثرق الأوسط، و الأول من نوعه فيّ المملكة العربية السعودية، وأول قطار كهربائيّ سريع فيّ المنطقة بأكملها، بمسار مزدوج يبلغ طولة 0ـ كم بين المدينة المنورة و مكة المكرمة بسرعة تشغيلية

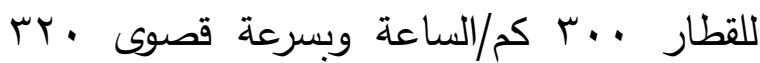
كم/الساعة، ومختصراً المسافة بين المدينتين إلى 


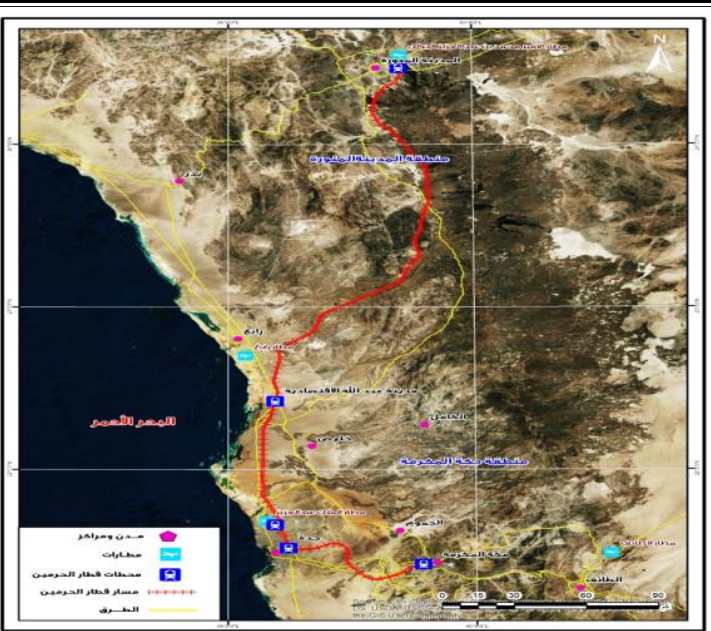

المصدر : إبراهيم عبد الفتاح طلبه ص (YVq)،

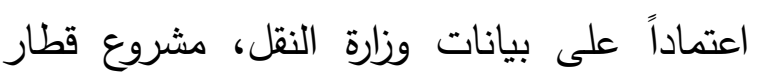

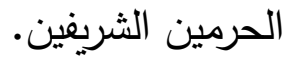

شكل (Y ( ) مسار قطار الحرمين الشريفين

بالمملكة العربية السعودية ومحطاته الرئيسة وُحددت أسعار رحلات قطار الحرمين السريع بين

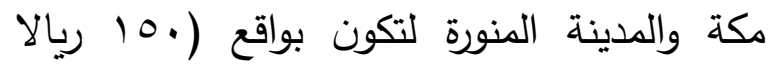

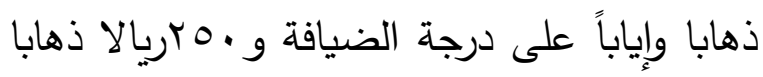

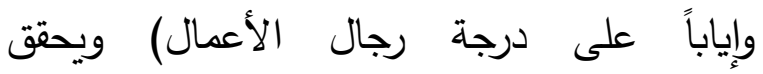

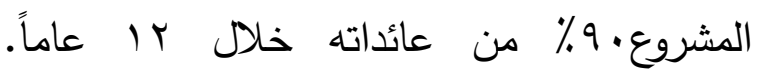
واستخدمت الهيئة المشغلة لقطار الحرمين السريع أنظمة النقل الذكية وذلك من خلال خدمات إلكترونية لحجز التذاكر، وذلك عن طريق إطلاق تطبيق مخصص لقطار الحرمين يرتبط بخرائط

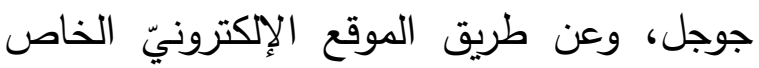
بقطار الحرمين السريع،والذى يمكن الحجز من خلاله (https://www.arrajol.com/content/143581 ويساعد مشروع قطار الحرمين فيّ التخفيف من الاختناقات المرورية على شبكة الطرق

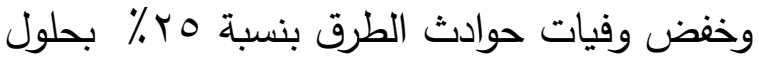

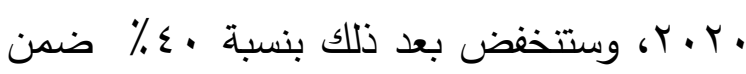

ومن المتوقع أن يصل عدد المسافرين على

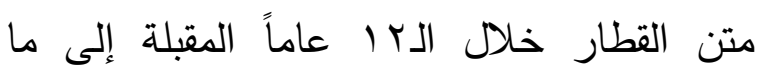
يقارب الـ عــ مليون راكب بين محطات المشروع فيّ المدينة المنورة ومكة وجدة. عبر خمس محطات هي : (المدينة المنورة - مكة المكرمة ولة "حي الرصيفة" - جدة "حي السليمانية" - رابغ " محطة مدينة الملك عبد الله الاقتصادية"- محطة

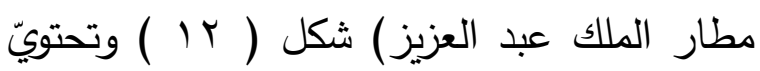
كل محطة على صالتيّ قدوم ومغادرة، إلى جانب توفر مسجد ومركز للدفاع المدنيّ ومهنط للطائرات المروحية، وأرصفة لوقوف القطارات والركاب، ومواقف للسيارات قصيرة وطويلة الأمد، وصالات لكبار الثخصيات، ومحلات تجارية ومطاعم ومقاهيّ. كما توجد حافلات نقل عام إلى لى محطة قطار الحرمين بالمدينة المنورة تنطلق من المنطقة المركزية، حيث تتطلق حافلة كل 10 دقيقة من السادسة صباحاُ حتى السابعة مساءً أيام

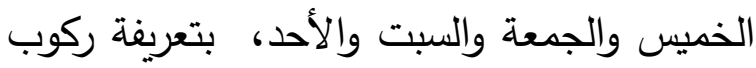

$$
\text { 0 ريال فيّ الاتجاه الواحد . }
$$


الحافلات التيّ تتكامل مع شبكة المترو وتغذيتها من خلال خطين للحافلات السريعة ذات المسار المخصص BRT بطول هب كيلومتر ، إضافة إلى أربعة خطوط حافلات سربعة بطول نحو .9 كم، وسبعة خطوط مغذية تخدم المناطق الداخلية لربطها مع شبكة المترو بطول نحو . . 1 كم ، وبذلك يبلغ إجماليّ طول شبكة الحافلات ما يزيد

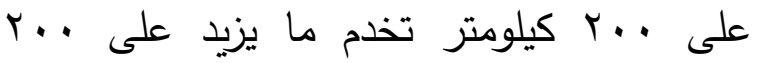
محطة، وتضم مخازن ووش لخدمة الشبكة. وتحرص الهيئة على أن تكون الحافلات على أعلى مستوى من ناحية راحة الركاب حيث سيتم تشغيل حافلات ذات أرضية منخفضة لسهولة صعود ونزول الركاب، مع اتباع أحدث أنظمة النقل الذكية ذات المواصفات العالمية المتعلقة بحماية البيئة من الانبعاثات الكربونية.(إدارة النقل والطرق فيّ المدينة المنورة، هيئة تطوير المدينة المنورة،1 ( • ب) كما يشمل مشروع النقل العام فيّ المدينة المنورة مكوناً ثالثاً خاص بتطوير شبكة الطرق الرئيسة وتقاطعاتها، بهدف رفع كفاءتها، وتحقيق انسيابية الحركة المرورية، إضافة إلى إنشاء

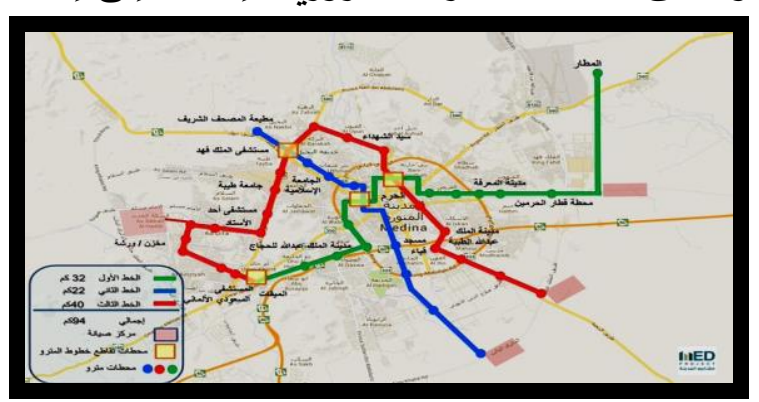

المصدر :(إدارة النقل والطرق فيّ المدينة المنورة، هيئة تطوير المدينة المنورة، 1 ( • ) ). شكل (M I ) خطوط شبكة المترو المقترحة ومحطاتها في المدينة المنورة
أهداف رؤية المملكة .ب · rو تتفيذ مشروع النقل العام بالمترو فيّ المدينة المنورة، والذيّ سيتم على ثلاث مراحل، ويُشيد الخط الأول للمترو وما يصاحبه من حافلات مغذية وأنظمة نقل ذكية خلال ثلاث سنوات من بدء التنفيذ، على أن يتبع ذلك إنجاز باقيّ مراحل المشروع خلال خمس سنوات لتكون المدة الإجمالية للمشروع ثمانيّ

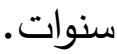
و ينطلق الخط الأول من مطار الأمير محه بن عبدالعزيز الدوليّ إلى مدينة المعرفة ومنها إلى المسجد النبويّ الثريف، ثم إلى مدينة الملك عبدالله لاستقبال وتوديع الحجاج والمعتمرين والزوار، وينتهيّ عند مسجد الميقات فيّ آبار علي. مع إنشاء شبكة متكاملة حول المنطقة المركزية تتضمن شبكة مترو وقطارأ معلقأ وشبكة للحافلات ترتبط بمواقف وحافلات فرعية ومراكز خدمة وصيانة وأنظمة ذكية إلى جانب استكمال الطرق الرئيسة التابعة لوزارة النقل. (هيئة تطوير المدينة المنورة، ،1 1 • ب م). وتشمل شبكة المترو ثلاثة خطوط بإجماليّ أطوال \&q كم، ونحو .V محطة شكل (IT )، منها محطات ذات طبيعية متميزة Iconic بالمواقع المهمة مثل: المسجد النبويّ الثريف، والمطار والميقات ومحطة قطار الحرمين السريع ومشروع شركة دار الهجرة، إضافة إلى مراكز التحكم والصيانة، وتحرص الهيئة على أن تكون قطارات شبكة المترو من أحدث القطارات على المستوى العالميّ من ناحية الأداء والتشغيل وراحة الركاب وسلامتهم. كما يضم مشروع النقل العام شبكة من 
وصيانة، وأنظمة نقل ذكية، على أرقى المواصفات

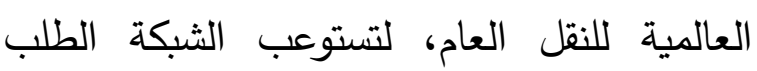

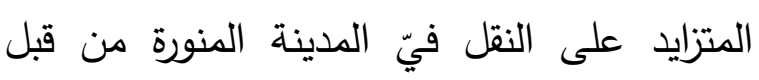

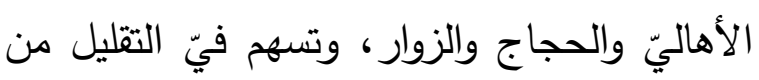

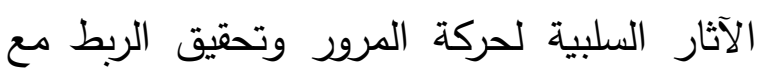

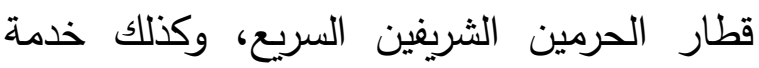
حركة الحجاج والمعتمرين عبر ميقات ذيّ الحليفة

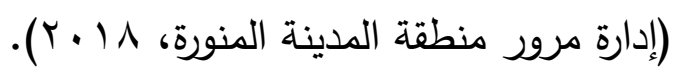

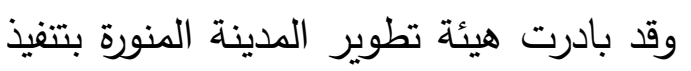
شبكة النقل العام بطرح مشروعين لوضع الركائز

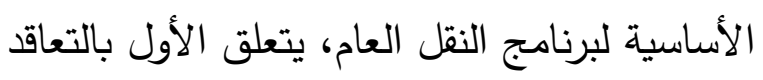

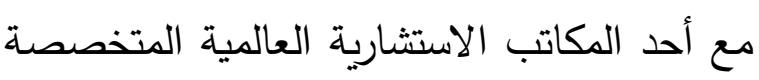
فيّ إدارة المشاريع العملاقة ومتابعة تصميمها وتتفيذها، وتمت ترسيه العقد على شركة لويس برجر الأمريكية، أما الثانيّ فيتضمن إعداد التصاميم المبئية لشبكة المترو فيّ المدينة المنورة، وقد تمت ترستيه على تحالف شركتيّ سيسترا وإيجس الفرنسيتين، وهما من أقوى تهات

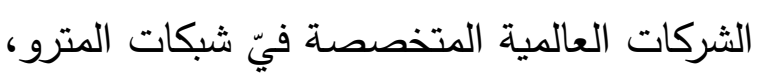
حيث يقوم بتوقيع عقدي المشروعين المذكورين

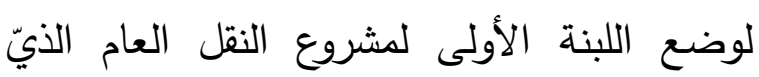

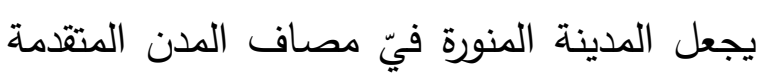

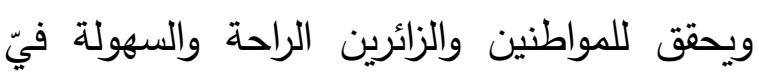
الانتقال الآمن باستخدام أحدث ما توصل إليه العلم والتقنية فيّ شبكات النقل العام. كما درست هيئة تطوير المدينة المنورة توفير خدمات النقل العام بنظام ( B O T) وهو المشروع لدئة

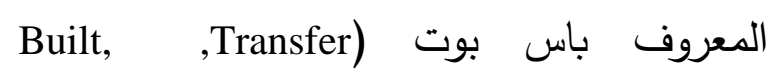

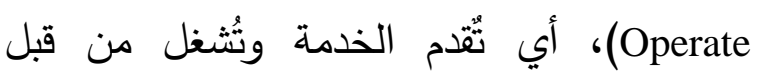

العديد من مواقف السيارات التيّ تخدم منظومة

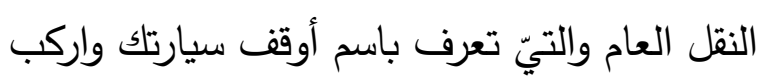
النقل العام Park and Ride. وحتى يمكن تحقيق التكامل التثغيليّ بين كافة مكونات منظومة النقل العام " الحافلات - قطار الحرمين والمترو - فئين الطرق" فسوف تتم الاستعانة بالنظم الذكية للنقل،

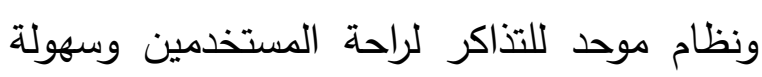

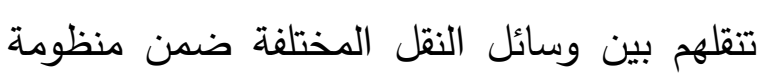
النقل العام. وحرصا على تكوين كادر وظيفيّ مؤهل من الفنيين والمتخصصين فيّ إدارة

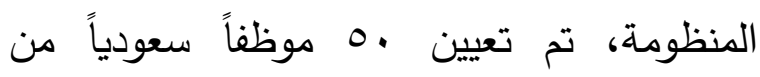
الثباب بهدف تأهيلهم وتدريبهم لضمان استيعابهم تصني للمتطلبات وقيامهم بواجبهم على الوجه الأكمل.

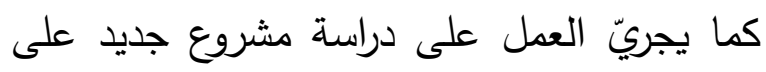
دوار طابة فيّ طريق الملك عبدالعزيز وإعادة تصميمه بالكامل بحيث يتماشى مع معنى مسار (المونيريل) وهو القطار المعلق بين محطة القطار

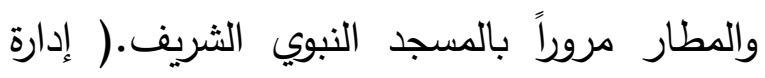
النقل والطرق فيّ المدينة المنورة، هيئة تطوير

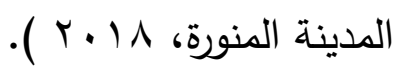

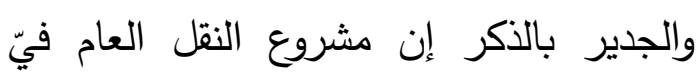
المدينة المنورة نقلة نوعية ستساهم فيّ انسيابية الحركة المرورية وفك الاختناقات، وتسهيل تنقل نقئل

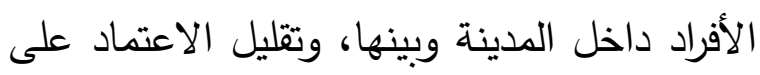
وسائل النقل الخاصة والحد من الحوادث الناتجة عنها، ورفع كفاءة شبكة الطرق وذلك من خلال تنفيذ مخطط تطوير شبكة النقل المتكاملة، وشبكة محطات المترو، وحافلات النقل وما يرتبط بهما

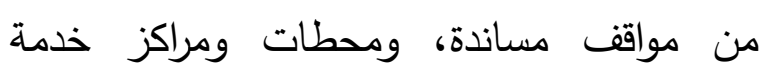


وبالرغم من الامتيازات المتعدة التيّ تمنحها المملكة لشركات النقل للجاج والمعتمرين والزوار والمسافرين، إلا إن القطاع الخاص ظل متردداً في بادئ الأمر لللخول في هذا الدجال لقله

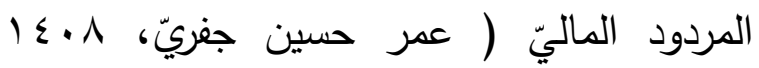

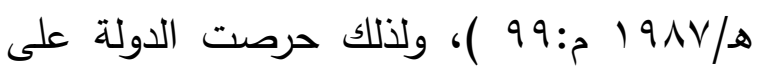

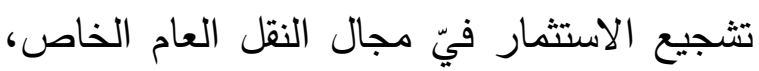
وتحفيز القطاع الخاص بتقديم الدعم الماليّ لشراء

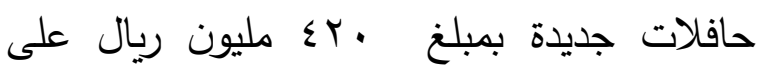
أقساط ميسرة لمدة 10 عام ،مما ساعد الثركات على شراء بآلاف حافلة جديدة لترتفع أعداد الشركات العاملة في النقابة العامة للسيارات إلى لى لداه

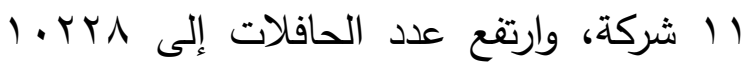

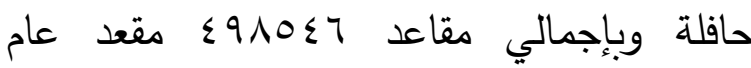
9 1 1 ا هـ، ثم ارتفع عدد الشركات إلى 11 شركة،

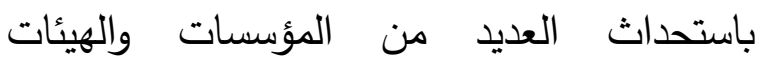

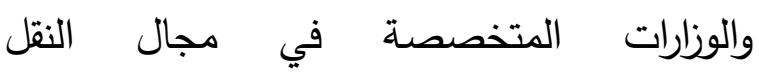
والمواصلات، وإنشاء أسطول لنقل الحجاج النقال

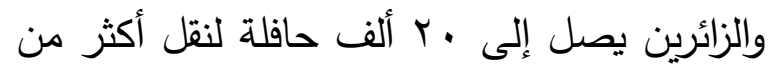
مليون و .. ألف راكب خلال موسم الحج فقط

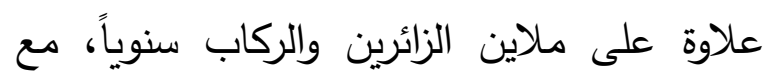
تبني شركات النقل معايير الجودة ولسلامة على لطين

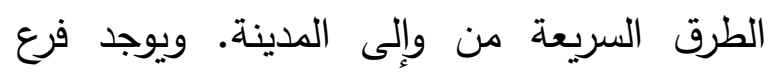
للنقابة فيّ المدينة المنورة للإشراف على شركات النقل.

- النقل العام الثخصيّ : تتمثل مركبات النقل العام الثخصيّ فيّ الحافلات الصغيرة،

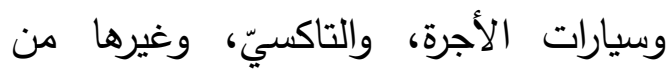
المركبات الصغيرة التيّ يشترك فيها أكثر من ونيرات من الحرة
مستثمر، و يستفيد منها لفترة محددة ليسترد أمواله مع تحقيق هامش ربح متفق عليه، وتعود بعد ذلك لكان لمصلحة الدولة، ومشروع المشاركة بين القطاعين العام والخاص، وقد تبين من الدراسات الخاصة ببعض المدن المختارة أن إيرادات النقل العام

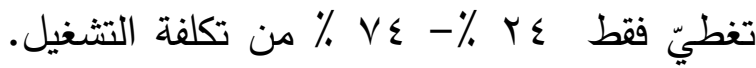
وتم أيضاً استعراض أمثلة لمشاريع النقل التي يتم لتعن تمويلها كلية من القطاع العام.( الهيئة العليا

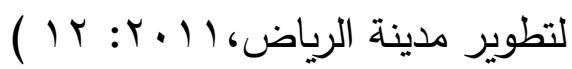
النقل العام الخاص: أنثئت النقابة العامة

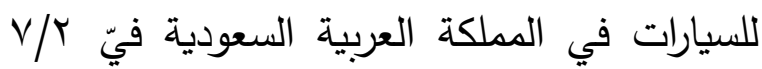

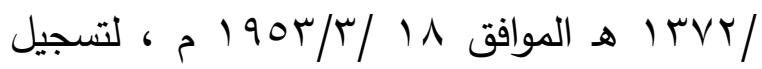
شركات القطاع الخاص العاملة فيّ مجال نقل الحجاج والزائرين أو المسافرين داخل المملكة أو

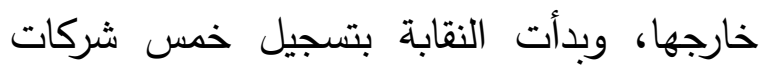

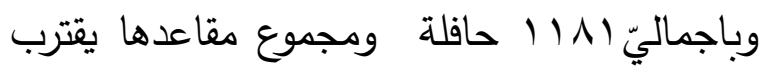
من VT ألف مقعد جدول ( جدول ( 0 ) الثركات المسجلة فيّ النقابة العامة لنقل الحجاج والمعتمرين والزوار عند تأسيس

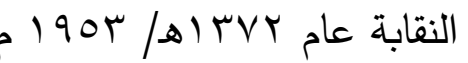

\begin{tabular}{|c|c|c|c|}
\hline المقاعد & عداد & اسم الشركة & b \\
\hline$\varepsilon r q 9$ & 94 & شركة باخشب باشا & 1 \\
\hline TVVV & $9 \leq$ & شركة المغربيّ & r \\
\hline$r \cdot r \varepsilon$ & 11. & شركة التوفيق & r \\
\hline V $7 \cdot 1$ & $r \vee \varepsilon$ & شركة عبدالعزيز الكعكيّ & $\varepsilon$ \\
\hline INIVT & 711 & الشركة العربية للسيارات & 0 \\
\hline 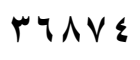 & 1111 & الاجماليّ & \\
\hline
\end{tabular}

الهصدر: (عبد الرحيم حمود الزهرانيّ، 9 1ـ1 هـ/999 م : 
المركبات التجارية بالأنظمة المرورية بالمدينة

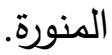

الفحص الآليّ للسلامة من جانب الطريق : ويتمثل فيّ الوصول إلكترونيًا بالتقنيات المتقدمة من جانب الطريق بفحص الأنظمة الضرورية للمركبة، ومستندات السلامة الخاصة بالثركات الناقلة والمركبات والسائقين، ومدى

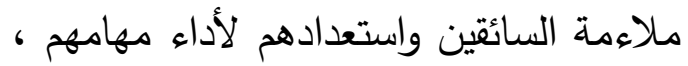
وكذلك مدى صلاحية رخص القيادة والمركبة والشحنة، وتبلغ السائق والثركة الناقلة، والجهات المنوط بها تطبيق الأنظمة عن أيّ وضع غير آمن. - الاستجابة لحوادث المواد الخطرة : وتطبق هذه التقنية لحصول على معلومات الحوادث الخطرة كتسربات المواد السريعة الاشتعال من مشتقات النفط والغاز، والتبليغ السريع لعمليات الطوارئ، مثل الحماية المدنيّة، لسرعة التعامل مع هذه الحوادث، ولهذه الخدمة أهمية كبيرة فيّ منطقة الدراسة نظراً لزيادة نقل المواد الخطرة داخل المدينة المنورة لتلبية متطلبات المركبات من الوقود، ومن نافلة القول إنه يوجد · rV محطة محروقات فيّ المدينة المنورة، وإمداد الصناعات المختلفة باحتياجاتها من مواد الطاقة .

- النظم المتقدمة للتحكم بالمركبة وسلامتها: وهـيّ نظـم متقدمــة للـتحكم بالمركبـة وسـلامتها وتتكون مـن الحساسـات والحاسـبات الآليـة، مـن أجل تحذير السائقين ومساعدتهم، ويكمن الهدف من وراء التحكم فيّ المركبة فيّ تحقيق مستويات
راكب.و توفر هذه المركبات خدمات النقل من الباب إلى الباب، و تغطية مناطق المدينة البعيدة بمسارات ثابتة إلى داخل المواقع والأحياء القليلة الكثافة السكانية وتظهر أهمية هذه الخدمة بصورة جلية فيّ تلبية حاجات تنقل النساء وخاصة المعلمات في المدينة

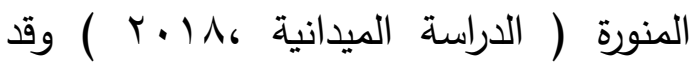
ساعد ذلك فيّ تقليل الاعتماد على السائق الخاص، و الحد من الازدحام المروريّ على شبكة الشوارع بالمدينة المنورة. ن - نظم عمليات المركبات التجاريـة : تطبق تقنيات أنظمة النقل الذكية لتحسين سلامة وكفاءة المركبات التجارية العاملة بمنطقة الدراسة، والمتمثلة فيّ الثاحنات والحافلات، وتحسين حركة الركاب و البضائع ، وخاصة الدولية، وتعتمد نظم عمليات المركبات التجارية على التقنيات المتقدمة والآلات الوظيفية الخاصـة بكل من : إدارة المرور، ومعلومات المتنقلين، وغيرها،وقد طبقت و تُمثل تطبيقات عمليات المركبات التجارية في خدمات المستقيدين التالية: - التخليص الإلكترونيّ المسبق للمركبات التجاريةة، وتتيح هذه الخدمة للمركبات التجارية المزودة بأجهزة الاستعلام الآليّ اللازمة للعبور عبر نقاط التفتيش، مثل محطات الوزن والحدود الدولية ، دون الاضطرار للتوقف إذا كانت أوراقها و مستنداتها وحمولاتها قانونية، وتطبق هذه الخدمة المفيدة فيّ منطقة المدينة المنورة عند محطات وزن الشاحنات ، ومراقبة التزام 
- تشغيل وسائل تثبيت الركاب قبل الاصطدام، و تطبق هذه التقنية على الأجهزة التي تتوقع حدوث اصطدام وشيك، وتقوم بتشغيل ميكانيكية الحفاظ على سلامة الركاب قبل الاصطدام، وذلك بناء على تفاصيل متعلقة بالمركبات والأجسام

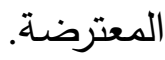

\section{التقنيات الحلديثة لتخطيط الطرق وعلاوثتها}

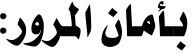

تشكل علامات تخطيط الطرق المرئية عنصراً رئيساً لسلامة وأمان لحركة النقل، حيث تسهم فيّ تزويد قائديّ المركبات بالمعلومات للتقليل والحد من حوادث الطرق، وذلك بتحسين الأمان للمرور على شبكة الطرق والحفاظ عليه. باتباع المبادئ الأساسية ومواصفات الأداء، ومراقبة الجودة، لعلامات تخطيط الطرق ومعلومات المرور المحسوسة بشكل بصريّ لرؤية الإشارات المرورية، ووسائل التحكم المروريّ، وبشكل دائم خلال الليل والنهار. وتتمثل أهم هذه التقنيات

$$
\text { فيما يليّ : }
$$

- تقنية حدود السرعة المتغيّرة، وتقنيات المراقبة

$$
\text { والتطبيق لحد السرعة المفرطة. }
$$

- التوجه لاستخدام أشرطة الدمدمة ذات النتوءات والعاكسات الفوسفورية لأكتاف الطرق السريعة والطرق الشريانية والشوارع الداخلية ولأكتاف، وذلك لما لها من تأثير على الحد من حوادث الخروج عن الطريق. وتطبيق أفضل النظم الحديثة لتحديد الطريق.
سلامة أعلى للمركبة وفيّ البنية التحتية، وتخفيف حدة الازدحام على شبكة الطرق الحضرية، ( (http://blog.translinedz.com/2013/05/blogوكذا تحقيق مستويات أفضل لإنتاجية الطرق السريعة بين المدن مما يؤديّ لإيجاد مفاهيم مبتكرة لخدمات النقل البريّ. وعلى العموم فان النظم المتقدمة للتحكم بالمركبة وسلامتها تساهم فيّ تحقيق ما يليّ: - تفاديّ الاصطدام الطوليّ باستشعار العوائق الثابتة، سواء أمام المركبة أو خلفها. - تفاديّ الاصطدام العرضيّ بتخفيض عدد التصادمات العرضية، بإعطاء تحذيرات من بن التصادم عند التغيير من حارة مرورية لأخرى، وعند البقع العمياء بجوار المركبات، وعند مغادرة حافة الطريق. واستخدام هذه التقنيات الحديثة يمنع التصادم ويحول دون وقوع الكثير من الحوادث المرورية الناتجة عن انحراف المركبات عن مسارها أو عن الطريق. - التحذير من التصادمات عند الدوارات و و التقاطعات والتحكم بها، و تلافيّ الاصطدامات عند التقاطعات التيّ تتكرر عندها التصادمات ، بسبب عدم وضوح أنظمة أحقية المرور عندها. - تحسين الرؤية من أجل تفاديّ الاصطدام وتقيد هذه الخدمة فيّ تحسين قدرة السائق على رؤية الأشياء الموجودة على الطريق وعلى جانبية، باستخدام أجهزة بالمركبة لاستشعار الأخطار، مثل الضباب والغبار وظاهرات إعاقة الرؤية، ومعالجة هذه المعلومات وعرضها لقائديّ المركبات للاستفادة منها. 
- توفير مواد مقاومة انزلاق المركبات على الطرق المنورة قد استفادت من تجارب مكة، وأبوظبيّ، أثناء سقوط الأمطار ضمن مكونات الرصف ودبي، وداكوتا فيّ حل المشكلات المرورية، مستخدمة نفس التطبيقات والتقنيات بهذه المدن. وفيّ عمليات الصيانة الدورية. وبدراسة هيكلية النقل الذكيّ وإسقاط التجارب العربية والعالمية جدول (T ) يتبين أن المدينة جدول (†) إسقاط التجارب العربية والعالمية على هيكلية النقل الذكيّ

\begin{tabular}{|c|c|c|c|c|c|c|}
\hline المنورة(0) & داكوتا(ع) & دبي & أبو ظبي(Y) & مكة (1) & \multicolumn{2}{|l|}{ 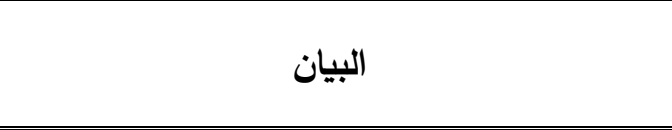 } \\
\hline$*$ & $*$ & * & $*$ & * & الازدحام المروري & \multirow{5}{*}{ المرورية المشلات } \\
\hline \multirow[t]{3}{*}{ * } & $*$ & $*$ & $*$ & * & الحوادث المرورية & \\
\hline & & & & & 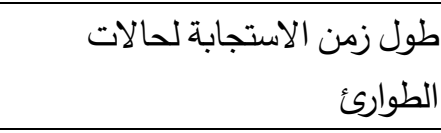 & \\
\hline & & & & $*$ & ارتفاع مستوى التلوث & \\
\hline$*$ & & & & * & الانتظار كفاية مواقف النقل واماكن & \\
\hline$*$ & * & $*$ & $*$ & $*$ & إدارة حركة المرور & \multirow{6}{*}{ تطبيقات نظام } \\
\hline$*$ & & $*$ & $*$ & $*$ & إدارة مواقف السيارات & \\
\hline$*$ & $*$ & $*$ & $*$ & $*$ & إدارة الطلب على النقل & \\
\hline * & * & * & * & * & إدارة مركبات الطوارئ & \\
\hline$*$ & $*$ & $*$ & $*$ & $*$ & الفحص الآلي الفني للمركبات & \\
\hline$*$ & $*$ & * & * & $*$ & تقديم معلومات عن الحالة الجوية & \\
\hline * & $*$ & $*$ & $*$ & $*$ & كاميرات مراقبة & \multirow{5}{*}{ المستخدمة التقيات } \\
\hline$*$ & $*$ & $*$ & * & $*$ & عدادات الكترونية & \\
\hline * & & & & $*$ & أجهزة استثعار & \\
\hline$*$ & * & $*$ & $*$ & $*$ & رادار لقياس السرعة & \\
\hline$*$ & $*$ & $*$ & * & $*$ & التقنيات الحديثة لتخطيط الطرق & \\
\hline$*$ & $*$ & $*$ & $*$ & $*$ & شبكات الاتصالات السلكية & \multirow{5}{*}{ المعلم نقل } \\
\hline$*$ & $*$ & $*$ & * & $*$ & إشارات الرسائل الآلية & \\
\hline$*$ & $*$ & $*$ & $*$ & $*$ & لوحات إرشادية الكترونية & \\
\hline * & $*$ & $*$ & * & $*$ & أكثاك المعلومات & \\
\hline$*$ & $*$ & $*$ & $*$ & $*$ & الموقع الالكتروني & \\
\hline
\end{tabular}

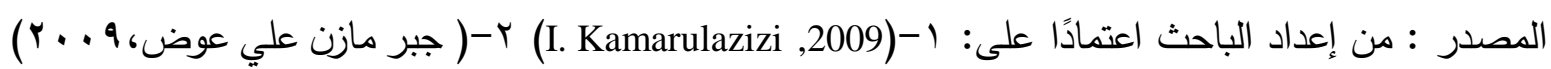

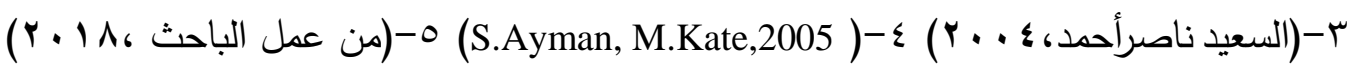


الحوادث المرورية بنسب تتراوح بين با \% \%-

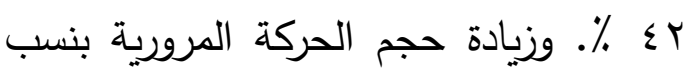
تتراوح من •1 \% - 1 1\%، وزيادة معدلات

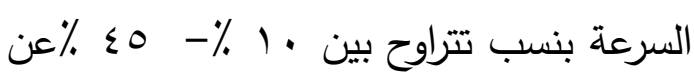

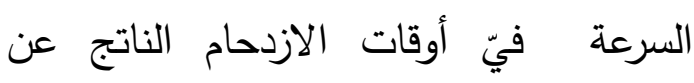

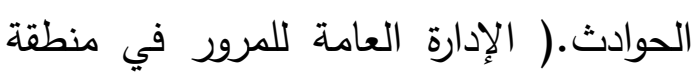

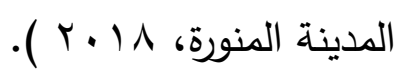

• انخفاض أعداد المصابين من الحوادث ل

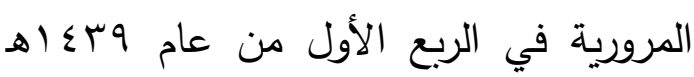

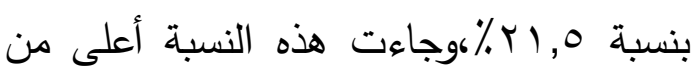

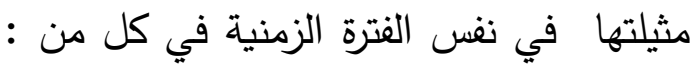

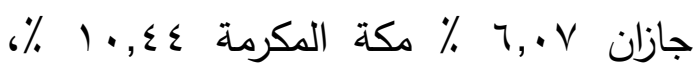

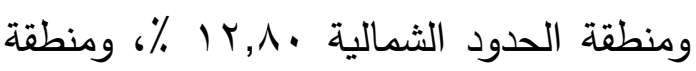

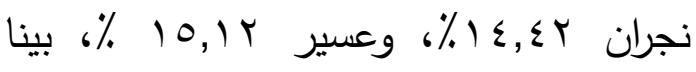

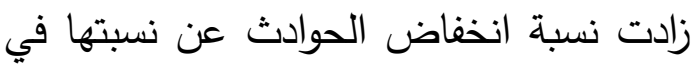

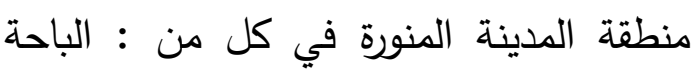

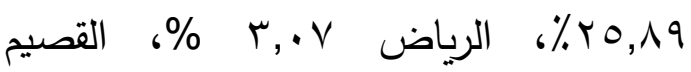

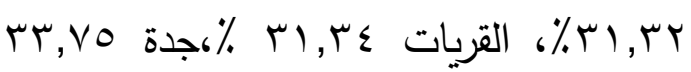

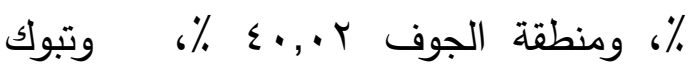
$\%$ or, $\varepsilon r$ • بينما سجلت بعض المناطق والمدن ارتفاعاً

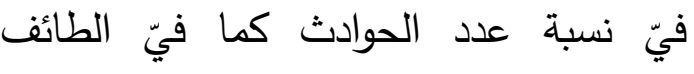


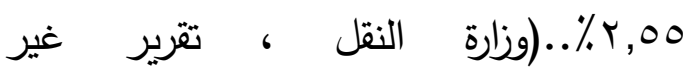

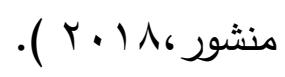

• أسهم تطبيق أنظمة السلامة والمستوفية للإجراءات الإلكترونية، والخاضعة لعمليات الفصص الآليّ إلى تقليل نسبة المصابين فيّ وليّ لئية

\section{تتـائج تطبيـق نظـــم النقـل الذكيـة في الملدينـة}

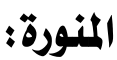

أظهرت نتائج الدراسة الميدانية وجود فوائد مباشرة وغير مباشرة نتجت عن تطبيق أنظمة النقل الذكيّ

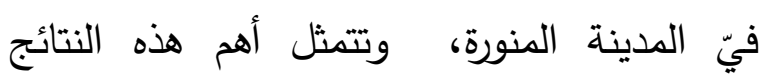
المباشرة فيما يليّ: • نتج عن تطبيق أنظمة ادارة حركة المرور لتئ

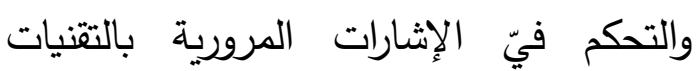
المتطورة تقليل فترات التوقف فيّ الإثارات المرورية، وبالتاليّ اختصار الفترة الزمنية

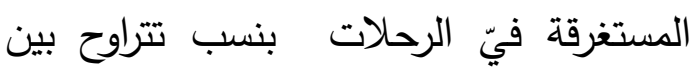

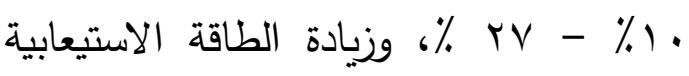

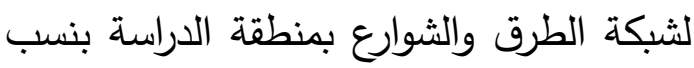

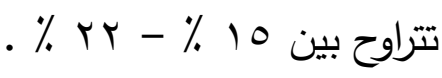
ماعدت أنظمة الإبلاغ عن الحوادث الطارئة

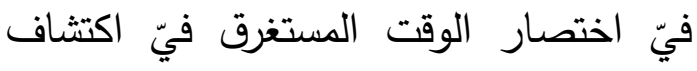
وقوع حادث على شبكة الطرق الإقليمية،

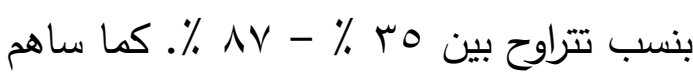
تخطيط الطرق المرئية لسلامة وأمان حركة النقل، واستخدام التقنيات الحديثة لتفاديّ التصادم، والالتزام بالمسار إلى الحد من الحن

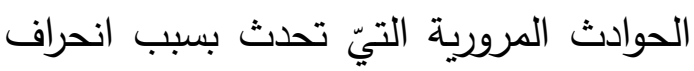
المركبات عن الطريق.

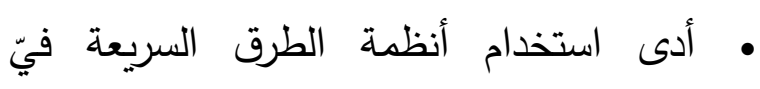

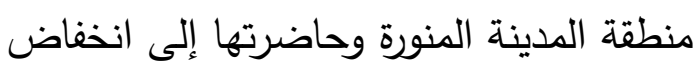

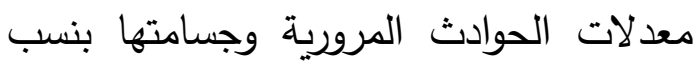

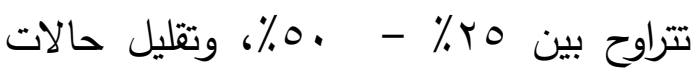

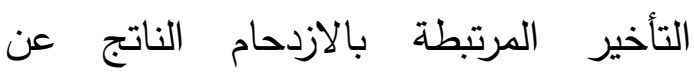


احترام المواعيد لدى حافلات النقل الحضريّي

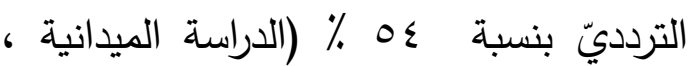

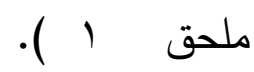
• • نتج عن تطبيق تقنيات أنظمة النقل الذكية

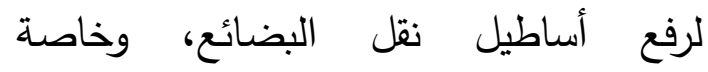
الدولية،إلى ارتفاع نسبة الإنتاجية فيّ مجال

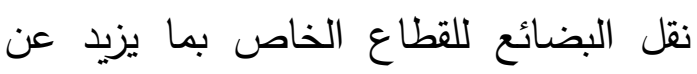

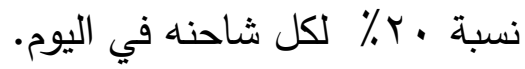
ومن نافلة القول إنه توجد فوائد غير مباشرة نتجت عن تطبيق أنظمة النقل الذكيّ بمنطقة الدراسة، تمثلت فيّ توفير تكاليف الرعاية الطبية، والعلاج لضحايا الحوادث المرورية، تصنية وتحسين مستوى السلامة والأمن، وتقليل الوفيات الناتجة عن الحوادث الجسيمة، وزيادة امكانية الوصول إلى الأماكن والعناوين غير المعروفة، إضافة إلى تسهيل الحصول على معلومات عن الى الى الأماكن المقصودة والخدمات المطلوبة .

\section{خامسـاً : أليـة تنفيـلذ اسـتراتيجية النقل الـذكيّ}

\section{وتحليات تطبيقها في الملدينة المنورة}

يتطلب تنفيذ استراتيجية النقل الذكيّ فيّ المدينة المنورة توافر مجموعة من التقنيات، ولتحديد التقنيات المطلوبة لابد من تحديد العناصر التقنية المتوافرة فيّ المدينة، ويبين الجدول( V ) V التاليّ

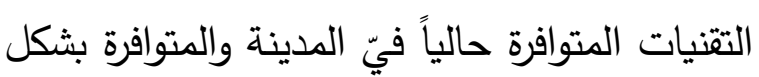
جزئيّ فضلاً عن التقنيات المطلوبة.
المدينة المنورة فيّ نفس الفترة الزمنية بنسبة

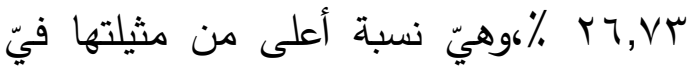
بعض مناطق المملكة مثل: تبوك بو, 90

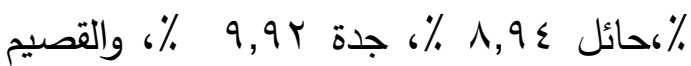

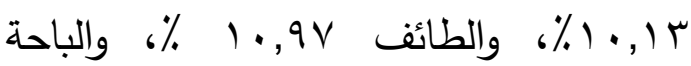

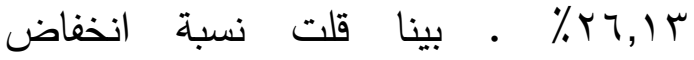
المصابين فيّ منطقة المدينة المنورة عن مثيلتها فيّ بعض مناطق المملكة حيث بلغت

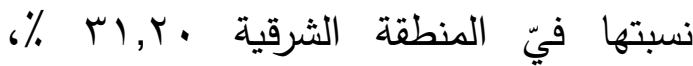

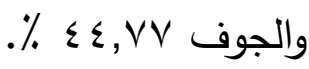
• سجلت بعض المناطق والمدن فيّ المملكة

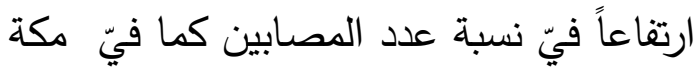

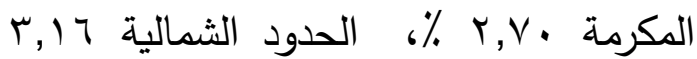

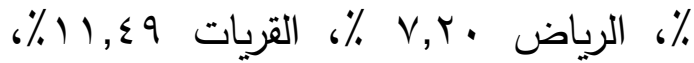

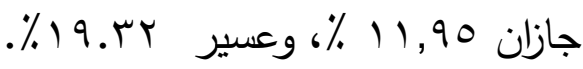
مكنت تطبيقات النقل الذكيّ من انخفاض معدل الوفيات الناتجة عن الحوادث المرورية

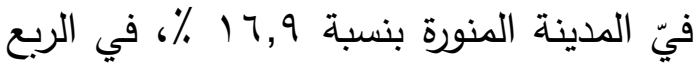

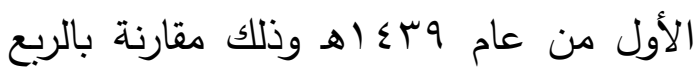

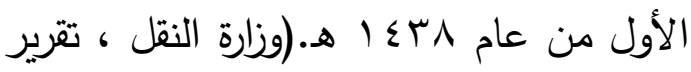

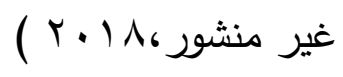

• أسهمت تطبيقات النقل الذكيّ فيّ المدينة المنورة من تحسين موثوقية النقل العام، لطائل واحترام المواعيد لدى وسائل النقل الجماعيّ ئي الحافلات والقطار ، وبالتاليّ تقليل مدة انتظار

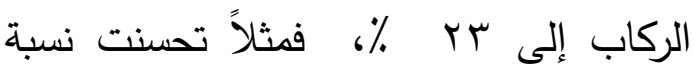


جدول ( V) تقنيات نظم النقل الذكية المستخدمة فيّ المدينة المنورة عام \1 • م م

\begin{tabular}{|c|c|c|c|c|}
\hline التقنيات & التقنيات & التقنيات & 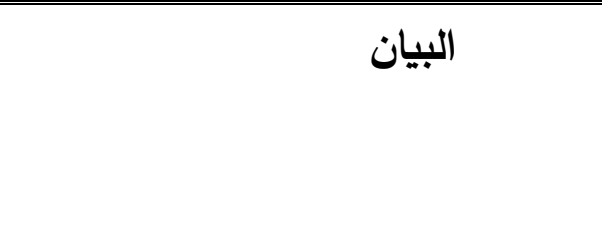 & \\
\hline & $*$ & & أجهزة استشعار & \multirow{5}{*}{ تقنيات تجميع } \\
\hline & & * & كاميرات مراقبة ثابتة & \\
\hline & & * & كاميرات مراقبة متحركة & \\
\hline & & * & كاميرات فيديو & \\
\hline & * & & عدادات إلكترونية & \\
\hline \multirow[t]{5}{*}{ * } & & & معدات وزن المركبة أثناء الحركة & \multirow{6}{*}{ تقنيات السيطرة } \\
\hline & & $*$ & شبكات الاتصالات السلكية واللاسلكية & \\
\hline & & $*$ & أكثاك المعلومات & \\
\hline & & * & لوحات إرشادية الكترونية & \\
\hline & $*$ & & إثارات الرسائل الآلية & \\
\hline \multirow[t]{2}{*}{$*$} & & & & \\
\hline & & $*$ & نظم المعلومات الجغرافية( GIS ) & تقنيات معالجة \\
\hline
\end{tabular}

المصد:من إعداد الباحث اعتمادًا على بيانات ادارة مرور المدينة المنورة، بيانات غير منشورة ^| ـ ب م يتبين من تحليل الجدول (v) أن جزءاً كبيراً منظومة النقل الذكيّ تتطلب تزويد باقيّ الأجزاء من شبكة النقل فيّ المدينة المنورة مُزود بكاميرات بهذه التقنيات. ومن خلال الدراسة النظرية لمفهوم مراقبة لحركة المرور وتصوير المخالفات كعدم النقل الذكي، وتطبيقاته ومتطلباته، ودراسة ربط أحزمة الأمان ،واستخدام الجوال أثثاء القيادة، التجارب العربية والعالمية، يقدم البحث منهجية ورادارات ثابتة ومتحركة لقياس السرعة، إلا أن لتطبيق النقل الذكيّ موضحة في الجدول (1 ). 


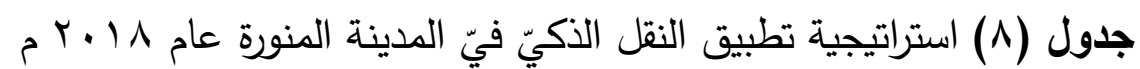

\begin{tabular}{|c|c|c|c|c|}
\hline الأنظمة المطلوب تنفيذها & الأنظمة المنفذة & تطبيقات نظام & 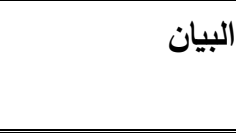 & \\
\hline - - تركيب إثارات التتبيه المروري - تخفيض مدة التتقل وتحسن الكفاءة التشغيلية & كاميرات تصوير إنظة إدارة المرور & إدارة حركة المرور & الازدحام المروريّ & \multirow{3}{*}{ 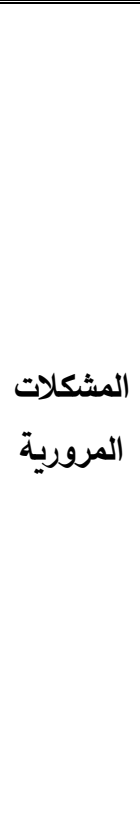 } \\
\hline 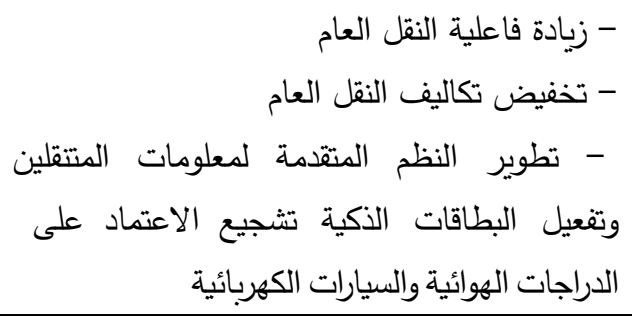 & نظام النقل الترددي & النظم المتقدمة & الطلب على النقل & \\
\hline 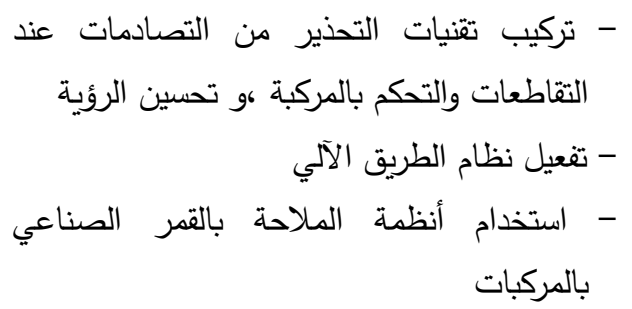 & الحوادث المرورية عن إبلاغ & النظمة السلامة & الحوادث المرورية & \\
\hline 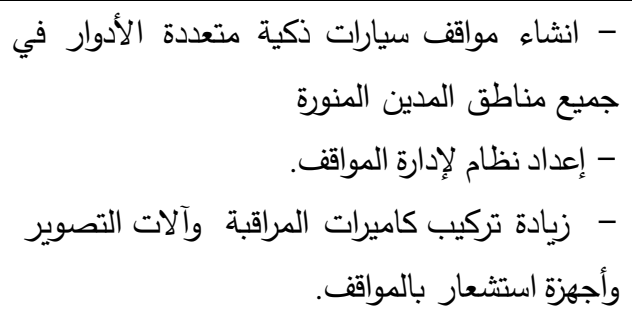 & فواقف سيارات ذكية & سيارات ذكية. & قالذا & علمام كفاية \\
\hline 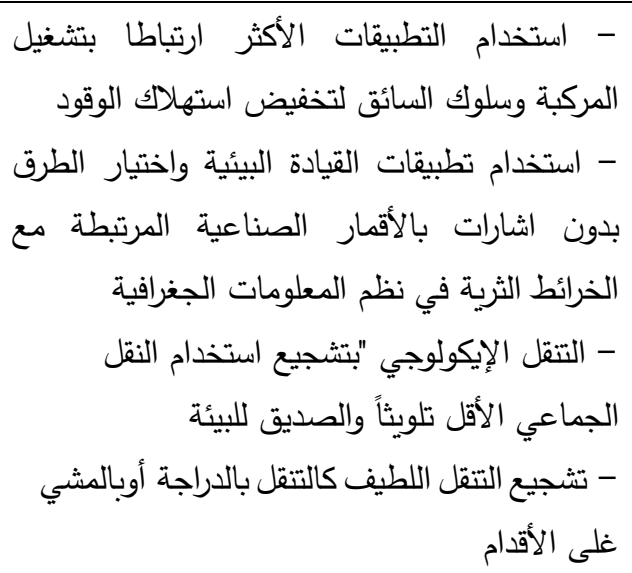 & & النقل النقاثل الذكية لتتليل & $\begin{array}{l}\text { التلوث } \\
\end{array}$ & مشكلات التلوث \\
\hline الى مركز العطليات أجهزة الرصد وأجهزة إيصال المعلومات & نظام للإبلاغ عن الحوادث المرورية & إل إدارة مركبات & الطوارئ الاغاثة في & الاستجابة \\
\hline
\end{tabular}

المصدر : من إعداد الباحث اعتمادًا على بيانات ادارة مرور المدينة المنورة وحماية البيئة ، المملكة العربية السعودية ،

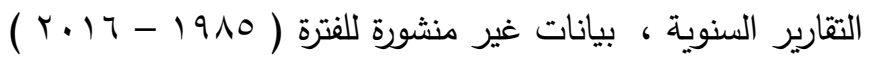


بعضها، وتتوزع مسؤوليات النقل بمنطقة الدراسة

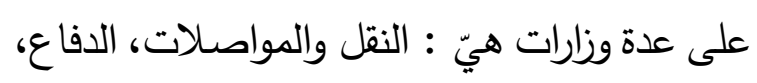
الداخلية ، الثؤون البلدية والقروية، وغيرها من وآن

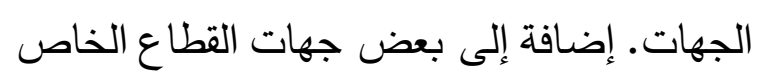

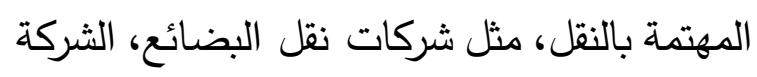

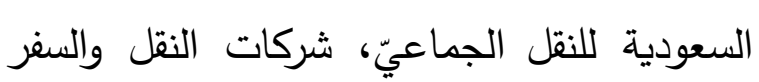
والسياحة، سيارات الأجرة ، ووكالات بيع السيارات وشركة الاتصالات ...وغيرها.

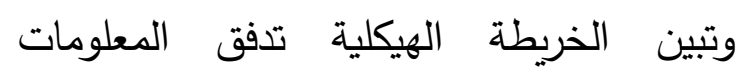
والتداخلات بين الجهات المعنية، وتطويرها تقنيًا بشكل مستمر لتكتسب دعم مطوريها، ومستخدميها من المتتقلين، وإدارات النقل ومشغلو مركبات النقل دمانل

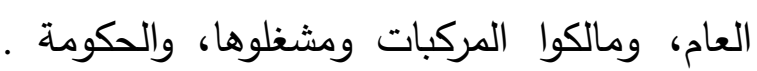

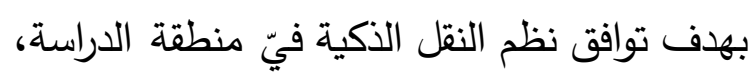

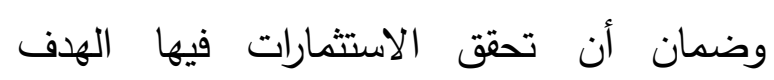

$$
\text { المطلوب. }
$$

وترتبط الخريطة الهيكلية لنظم النقل الذكية فيّ المدينة المنورة بالخريطة الوطنية للملكة العربية

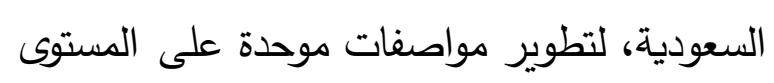

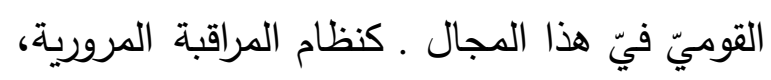

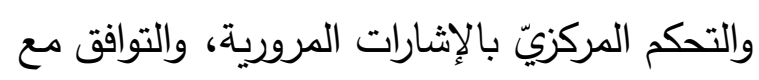
الأنظمة الأخرى ذات العلاقة فيّ الخريطة لتوفير

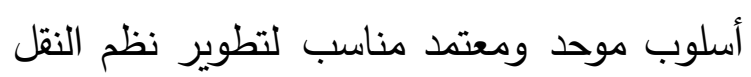
الذكية، وتكاملها عن طريق التخاطب الآليّ

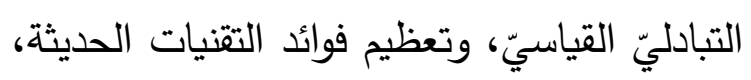

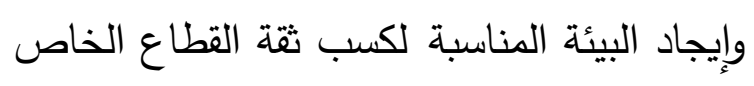

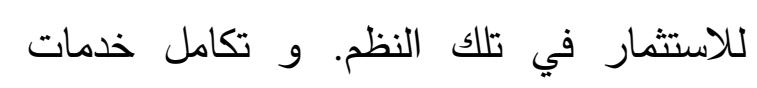
ومتطلبات الوزارات والجهات المعنية، وتكامل
و لنجاح تطبيق نظم النقل الذكية على مستوى المدينة المنورة يلزم تأسيس خارطة هيكلية موحدة

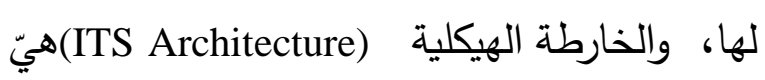
الإطار العام الذيّ يمكن من خلاله تطوير مختلف لفارطية

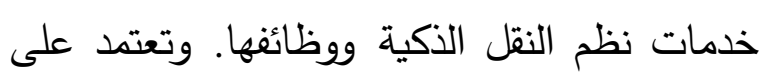
تعريف الإطار العام للنظام بناء على الأهداف أو الو متطلبات المستخدمين، مع تمييز الأنظمة الفرعية

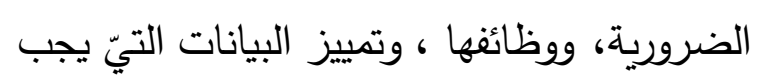
تدفقها بين تلك النظم، مما يوفر أساسًا منطقيًا لتصميم النظام. أيّ أنها تصف كيفية تفاعل

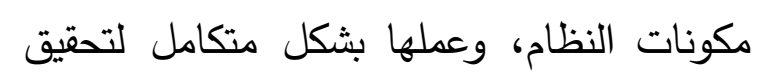

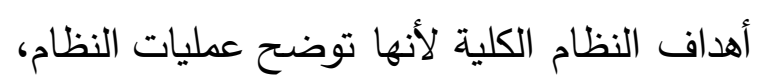
و دور كل عنصر فيه، و المعلومات المتداولة بين

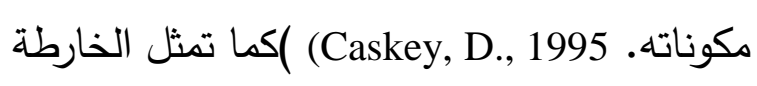
الهيكلية الإطار المشترك للتشغيل التبادليّ لنظم النقل الذكية الذيّ يعرّف ما يأتيّ:

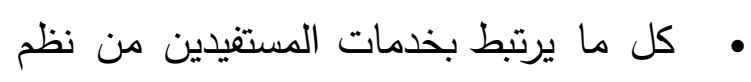
النقل الذكية( الخارطة الهيكلية المنطقية).

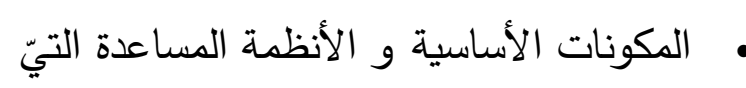
تقوم بتلك الوظائف(الخارطة الهيكلية الطبيعية). • نقل البيانات وتدفق المعلومات بين الأنظمة الفرعية الطبيعية ومعالجتها. • المتطلبات المتعلقة بنقل البيانات وتدفق المعلومات . - المنطات وتكمن القوة الأساسية للخريطة الهيكلية لنظام

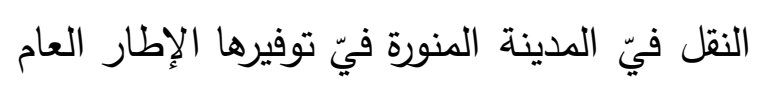

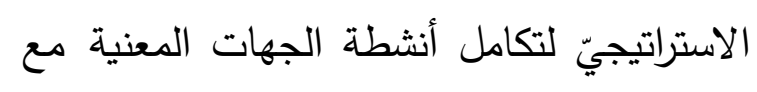




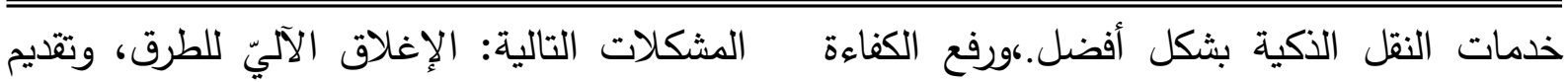
معلومات عن الحالة الجوية، والتطبيقات التيّ التيّات الإنتاجية فيّ مجال النقل بالاعتماد على منظومة لإنكل

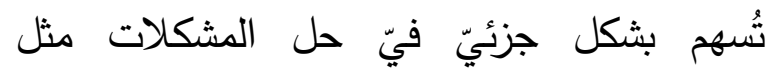
النقل الذكيّ.

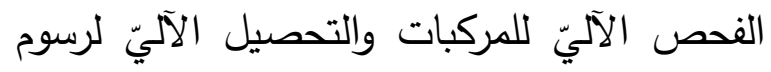

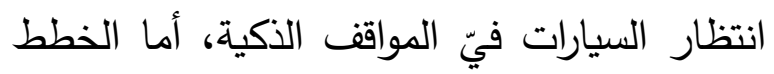

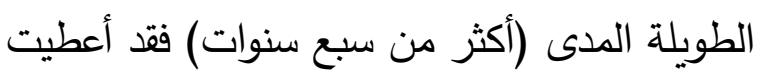

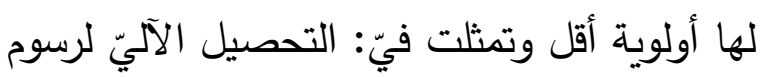
على الطرق السريعة، و وإن كان مشروع تحصيل

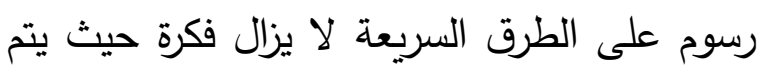

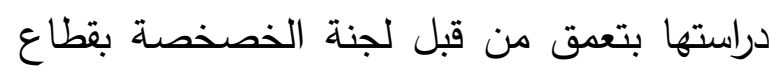

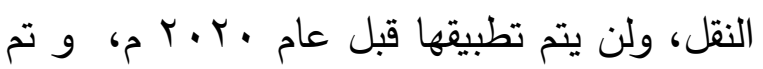

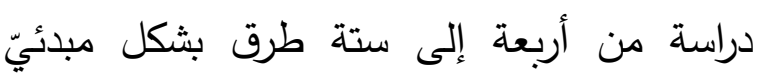

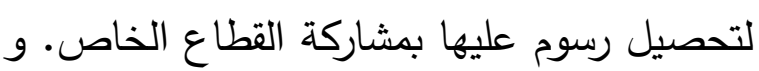
الغرض من هذه الرسوم هو رفع الكفاءة أكثر منه تحصيل إيرادات للدولة، حيث سيتم صرف جزء من هذه الرسوم على صيانة ورفع كفاءة هذه

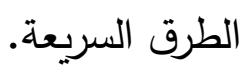
والجدير بالذكر أنه لا يمكن لوزارة المواصلات

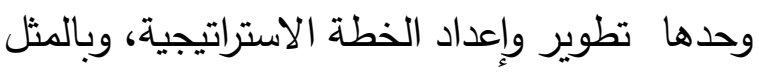
لا تستطيع الجهات الحكومية فقط، بل يجب تتسيق الجهود وتنظيمها و تعاون جميع الأطراف، وإشراك القطاع الخاص والمؤسسات الأكاديمية فيّ إعداد الخطة المعنية المشاركة ،واستحداث هيئة حكومية

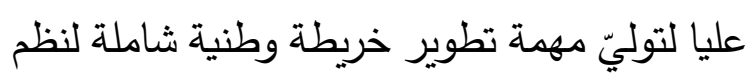
النقل على المستوى الوطنيّ. وذلك استتادا لتجارب

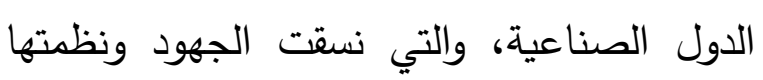
لإنثاء منظمات مهنية مستقلة مثل: المنظمة الأمريكية( ITS (ITS America و America Web Site: http://www.itsa.org/

وقد استنسخت المملكة العربية السعودية الخريطة الهيكلية القائمة والمطورة فيّ الولايات المتحدة

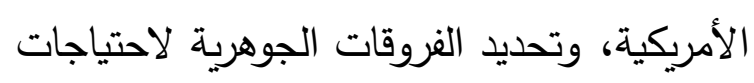
المملكة، و تعديلها وتكييفها لتلائم الاحتياجات والظروف المحلية، والتر كيز على المتطلبات الوظيفية وتوصيفها، ولذلك تم تطبيقها فيّ المدينة المنورة بعد معالجة المعوقات المتعلقة بمجال الاتصالات فيّ المملكة سواء من الناحية الفنية

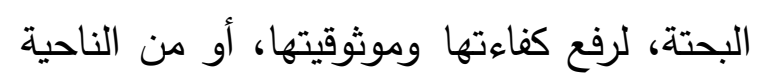
التنظيمية، لتلبية مختلف الاحتياجات الوظيفية لنظم النقل الذكية.(1997 Focus, ITS Focus 1TS (report on System Architecture, وبدأ تطوير الخريطة الهيكلية لنظم النقل الذكية فيّ منطقة الدراسة كجزء من الخطة الاستراتيجية الوطنية، تُعرف بالرؤية الوطنية نحو نظم النقل

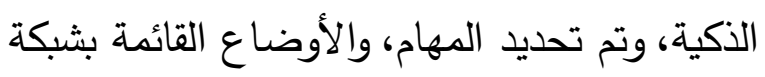
النقل، والغايات والأهداف، والغرص والتحديات،

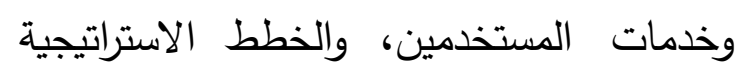
القصيرة والمتوسطة والطويلة الأجل .وقد حددت الألت

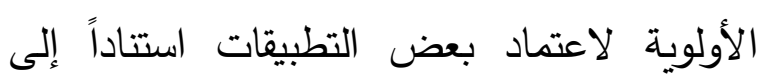

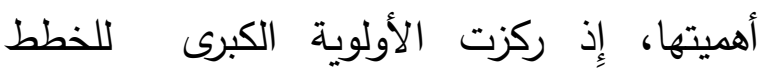
القصيرة ذات الددى (r سنوات ) فيّ التطبيقات التي تُسهم فيّ الحلول العاجلة مثل: مشكلات

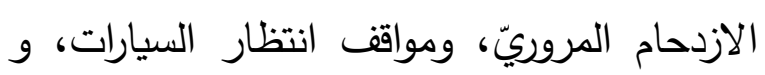

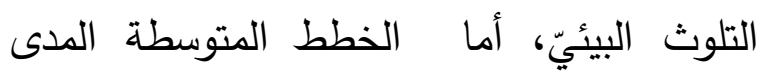

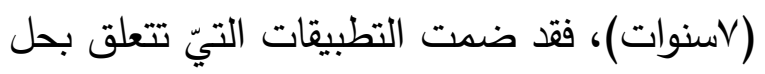


الاقتصاديّ فعلى المستوى التقيّ فيتمثل فيّ قلة خبرة الأفراد على التعامل مع تقنيات أنظمة النقل الذكية بالثكل الأمثل، ويمثل صعوبة التبادل الفوريّ للبيانات بين قائديّ المركبات بعضهم البعض من ناحية، وبينهم وبين البنى التحتية

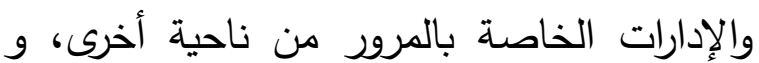
إمكانية الحصول على معلومات دقيقة عن الموقع تحدياً إضـافياً، فضلاً عن قلة الخبرة فيّ التعامل مع الأجهزة الحديثة المتنوعة الخصائص المستخدمة فيّ جمع وتحليل ومعالجة البرمجيات الحاسوبية التيّ تعالج بيانات أداء نظام النقل . كما يشكل الوقت اللازم لتنفيذ تطبيقات نظم النقل الاكيّ كثبكات الإنترنت وشبكات الاتصالات السلكية واللاسلكية التيّ تحمل تدفق البيانات، وشبكات أجهزة الاستشعار ومتطلبات البنية التحتية الكاملة ات ذاتلة التكلفة العالية لتركيب المعدات التقنية اللازمة تحدياً اقتصادياً. وأخيراً تحديات اجتماعية تتعلق بعدم قدرة مستخدميّ منظومة النقل كلهم على التعامل مع التقنيات. ويتطلب التغلب هذه التحديات وضع استراتيجية تضمن مجموعة من الإجراءات والبرامج الكفيلة بمعالجة وتجاوز تلك التحديات منها على سبيل المثال: تدريب الأفراد على استخدام التقنيات فيّ المراحل الأولى من تطبيقها فيّ منطقة الدراسة، لضمان كفاءتها وفعاليتها، و تخصيص الأموال اللازمة ومصادر التمويل لشراء التقنيات، و إعداد الأطر المتخصصة فيّ تجهيز البيانات وتبادلها، وتعميق ثقافة المرور والنقل لدى المجتمع المحلي.
الأوربية ( ERTICO (ITS Europe) ( ERTICO ،Web Site: http://www.ertico.com/ VERTIS (ITS Japan) (VERTIS) واليابانية Web Site: http://www.iijnet.or.jp/vertis/ ولذلك فمن الأهمية أن يكون فيّ المملكة جهة مركزية تكون مسؤولة عن تنسيق و تطوير التقنيات الذكية للنقل فيّ المملكة، وتشغيلها، وتكاملها، و متوافقة، ويمكن أن يتت التتسيق المباشر بين الأطراف المعنية لتطبيقات خدمات المستخدمين لنظم النقل الذكية، والتيّ يُعتزم إدخالها مثل: التخليص الإلكتروني للشاحنات عند محطات الوزن أثناء حركتها، و استخدام تقنيات التمييز الآليّ للمركبات المخالفة، وذلك كأحد تطبيقات نظم عمليات المركبات التجارية .ويتم التنسيق من قبل لجنة مشتركة من تلك الجهات، وتقويم متخذي القرار البدائل المختلفة طبقاُ للمعطيات السياسية والإدارية السائدة وطنيًا، وللظروف المحلية لكل منطقة. ومن نافلة القول أن وزارة المواصلات تبنت ونفذت بعض المشاريع التجريبية التيّ تقع تقريبًا بأكملها ضمن صـلاحياتها وتخضع لمسؤولياتها ولا تتطلب سوى تنسيق بسيط جداً مع مؤسسات وجهات أخرى .وقد ساعد هذه المشاريع التجرببية وزارة المواصلات فيّ تدريب وتعلم إمكانات نظم النقل الذكية، وحدودها، وصعوبات تشغيلها من خلال القيام بتنفيذها فعلً .( سعد بن عبد الرحمن

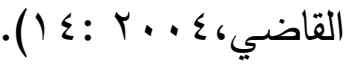

\section{تحليـات تطبيق نظم النقل الذكية :}

يواجه تطبيق أنظمة النقل الذكية فيّ المدينة المنورة عدة تحديات منها، التقنيّ، والاجتماعيّ. و 
أنها ستضاعف من فاعلية النقل العام وجذب الخاتقة الركاب له، وفتح المجال أمام فرص العمل لفاعل والاستثمار، والمساهمة فيّ التقليل من الحوادث

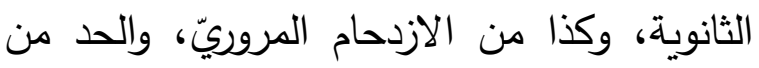
استهلاك الوقود وتلويث البيئة نتيجة للسيطرة على الإنى الازدحام و البحث عن أفضل الطرق لتقليل الانبعاثات من قطاع النقل فيّ المدينة بنسب قد الطبل تصل إلى .0 \% أيضاً تقليل انبعاثات الغازات

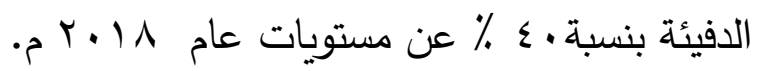

ا 1

- ساهمت تقنية أنظمة النقل الذكية بالمدينة المنورة، واستراتيجية تطبيقها الجديدة والمستحدثة فيّ تطوير قطاع النقل، وظهر ذلك جلياً فيّ تحسين خدمات النقل وسيولة الحركة المرورية، و السيطرة على الازدحام المروريّ، والتقليل من النين

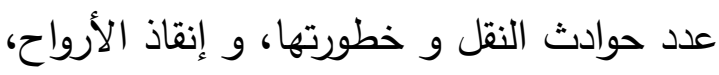
وتوفير الوقت والمال، والحد من استهلاك الوقود

$$
\text { وتلوث البيئة. }
$$

- ساعد تطبيق تقنية نظم النقل الذكية بمنطقة

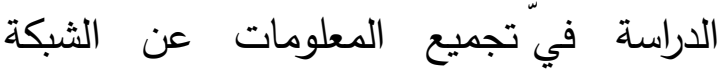
النقلية، واستخدامها المطور ليساعد مستخدميّها

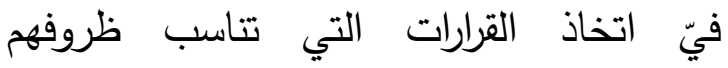

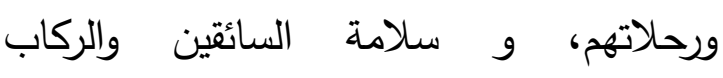
والمركبات، لذلك فان التقنيات الخاصة بالنظام الذكيّ قدمت أماناً اكبر لمستخدمي الطريق فيّ لمان

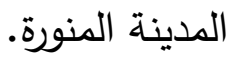
- إعادة تتظيم النقل فيّ المدينة المنورة، بهدف تحديث نظام النقل وحركة التنقل وتحسينهما، و

عالج البحث مفهوم نظم النقل الذكيّ، وأنظمة التعامل الذكية التيّ تجمع العديد من التقنيات الحديثة، لإدارة نظم النقل والتتقل فيّ المدينة المنورة بكفاءة وبفاعلية عالية، وبمستوى أمان

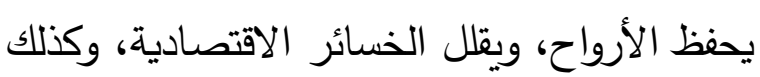
يضمن نظام نقل مستدام يحافظ على البيئة ويقنن

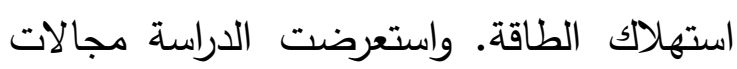
التطبيق الخمس الأساسية لنظم النقل الذكية، وهيّ النيتي

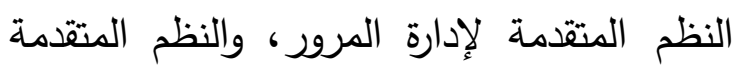

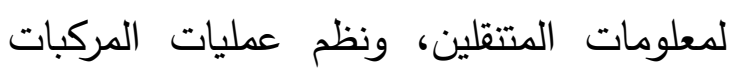
التجارية، والنظم المتقدمة للنقل العام، والنظم المتقدمة للتحكم بالمركبة وسلامتها، مع مناقثة ولنة أهمية كل منها، ومدى ملاءمتها لواقع المدينة

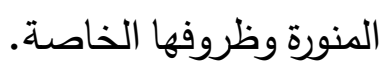
و سعت المدينة المنورة لتطبيق النقل الذكيّ بهدف ايجاد حلول لمشكلات النقل الحضريّ الذي

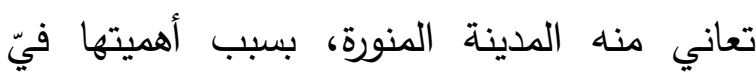
مجال السياحة الدينية، وأسهمت نظم النقل الذكية والتيّ تمثل التطور الطبيعيّ للبنية التحتية للنقل

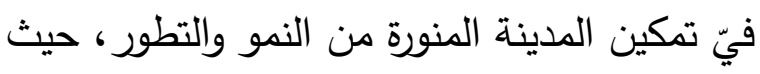
يُعد استمرار وضع الاستراتيجيات الذكية باستخدام

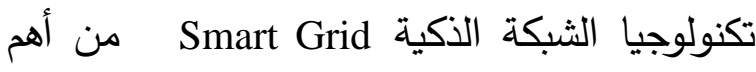

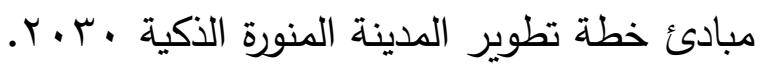

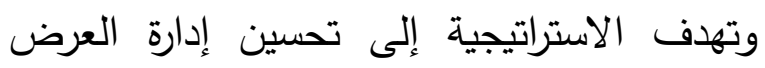

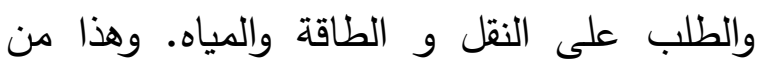
شأنه أن يحفّز على استخدام البيانات والتكنولوجيا

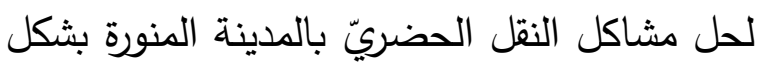
فعال. وإنقاذ الأرواح وتوفير الوقت والمال، كما لئل 
المتزحات

لتطوير منظومة النقل الذكيّ فيّ المدينة المنورة، ورفع كفاءة البنية التحتية للشبكة النقلية، و زيادة دورها فيّ عملية التتمية الشاملة والمستدامة، و تقليل الهدر الاقتصاديّ على المستوى الحكوميّ و المجتمعيّ و الشخصيّ، يجب اقرار الانظمة التقنية و التشغيلية و الادارية و القانونية و غيرها لإنجاح المنظومة عن طريق دراسة وتطبيق المقرحات التالية: - إكمال الأطر القانونية لنظام النقل الذكيّ وتطبيقها بصرامة فيّ المدينة المنورة . - الاهتمام ببرامج وحملات التوعية بأهمية نظام النقل الذكيّ. - تطوير وتفعيل نظام النقل الذكيّ طويل المدى مرن ومتكامل مع الرؤية للنقل . تبني رغبات المستخدمين للنقل لمعرفة أراءهم وتوجهاتهم لتحسين الخدمة . توجيه وتمويل الإدارة العامة للمرور والجهات ذات العلاقة لتوفير نظم المعلومات والإدارة الذكية للنقل . تدريب وابتعاث كوادر فنية متخصصة في الإدارة الذكية وهندسة المرور . تشغيل اشارات المرور الذكية عند دوارات: السلام ، القبلتين ، العنبرية لتنظيم حركة النقل لأن ثقافة الدوار ليست مطبقة، ولا أحد ينفذها بالشكل الصحيح على أرض الواقع. - لزيادة انسيابية حركة السير والحركة المرورية بالمدينة المنورة جعلها حركة واحدة متصلة
خفض حركة النقل و المرور والازدحام وخاصة فيّ وسط المدينة . - اتخاذ الإجراءات التيّ تساعد على تخفيف المشكلات المرورية مثل: تعزيز استخدام حافلات النقل العام، وتتظيم محاور مرورية متعددة لتخفيف الغزارة المرورية، وإنشاء مواقف انتظار تحت الأرض وفوقها في مناطق مختلفة من المدينة، وتطبيق نظام المواقف المأجورة فيّ بعض الثوارع المركزية. - ولحل مشكلة الحوادث المرورية وتقليص آثارها السلبية، فقد اعتمدت ادارة مرور منطقة المدينة نظاماً مرورياً حديثاً يعتمد على التنسيق بين تقنيات متقدمة ومرتبطة مباشرة مع أنظمة معلومات عن حركة المرور، ومع أجهزة مراقبة وتحكم مرورية، وأنظمة اتصالات وحواسيب، وقاعدة معلومات يديرها جهاز فني متخصص. - إعداد مشروع التخطيط الإقليميّ للمدينة المنورة واقتراح تشييد وصلات طرق جديدة، وفصل التيارات المرورية عند بعض التقاطعات، و و صياغة استراتيجية للنقل المدينيّ، UTS . - أثبتت تطبيقات أنظمة النقل الذكيّ فيّ المدينة المنورة فاعليتها في تخفيض حوادث الطرق وخطورتها، و تخفيض الوقت المستغرق في رحلات السفر، و تخفيض الآثار السلبية للبيئة الناتجة عن العوادم والانبعاثات الضارة من محركات المركبات، زيادة الفاعلية لسعة الطرق بدون الحاجة لإنشاء طرق جديدة. 
النقل العام، و اقتراح خطة استراتيجية للنقل العام بوسائل مختلفة، واقتراح الحلول القصيرة والبعيدة المدى لتنفيذ استراتيجية النقل العام، لخدمة السكان وغيرهم من الفئات، وتوفير وسائل النقل العام التي تسمح للركاب بالتوجه إلى مركز المدينة، وترك مركباتهم فيّ مواقف في الأطراف الخارجية للمدينة. وضع الخطط التشغيلية للنظام المقترح بوسائله المختلفة، والسعي إلى تحقيق التوازن والتكامل مع خدمات النقل الأخرى، بما يتلاءم مع البيئة الحضرية وللوصول إلى الأهداف

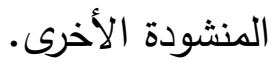
تطوير المنطقة المركزية فيّ المدينة المنورة بإعداد دراسة لتطوير النقل العام، و تحديد محاور رئيسة تتركز حول الحرم ومركز المدينة - أخذ الوقت الكافي لتطبيق سياسات النقل الحضريّ المترابطة، ووضع مراحل لتطبيق برنامج القطارات الخفيفة والحافلات السريعة، وإعطاء الوقت للسكان (ولأصحاب المحلات التجارية والمستثرين) لكيّ يتعودوا على النقل العام والتأكد من اهتمام السكان بالنقل العام. تخفيف حدة الازدحام فيّ شبكة الطرق السريعة الحضرية بمنطقة الدراسة، وكذا تحقيق مستويات أفضل لإنتاجية الطرق بين المدينة وباقيّ المدن مما يؤديّ لإيجاد مفاهيم مبتكرة لخدمات النقل الحضريّ . الاستفادة دن نظام المعلومات الجغرافية وتقنية إدارة المعلومات لإعطاء أوقات حقيقية عن
ببعضها اذا نجعلها انسيابية فيّ جهة وضغطها ضغطاً فيّ الجهة الثانية. - إنشاء هيئة للنقل تتمتع بالاستقلال الماليّ والإداريّ تسمى "هيئة النقل العام " يكون مقرها الرئيس فيّ مدينة الرياض، ولها فرع أو مكتب بالمدينة المنورة لتنظيم خدمات النقل العام للركاب داخل المدينة، و بينها وبين المدن، والإشراف عليه، وتوفيره بالمستوى الجيد والتكلفة المناسبة، وتشجيع الاستثمار فيه بما يتفق مع أهداف التتمية الاقتصادية والاجتماعية فيّ منطقة الدراسة . وتختص الهيئة بتتفيذ خطط النقل العام على مستوى المملكة، والتأكد من توافر التمويل لأنشطة النقل العام من مصادره المختلفة، وتحديد شبكة خطوط النقل العام ومساراتها، ومواقع مرافقها، ووضع مواصفات وسائل النقل العام ومنح التراخيص والتصاريح واقتراح آلية لتظيم أجور النقل العام، وتوفير الظروف الملائمة لجذب الاستثمارات فيّ هذا المجال. - إعداد المخطط الشامل للنقل العام فيّ المدينة

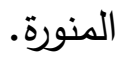
- التنسيق مع أمارة المدينة والأمانة والجهات ذات العلاقة الأخرى كوزارات: النقل، الداخلية، الثؤون البلدية والقروية، المالية والاقتصاد، التخطيط و القطاع الخاص وإعداد نطاق خدمات النقل الذكي لتحقيق متطلبات المدينة والاتفاق على أسلوب تمويله ومتابعته. - تقويم خدمات النقل العام الحالية داخل المدينة ، و تقدير الطلب الحاليّ والمستقبليّ لخدمات 


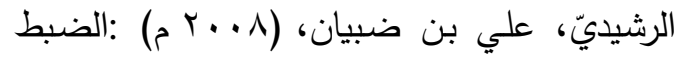

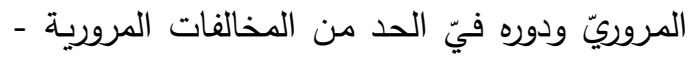
نموذجاً المملكة العربية السعودية "، دراسة غير منشورة

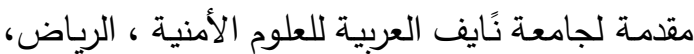

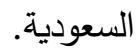

(0) قستيّ ، طارق بن مصطفى، (9 . . r م) : "تقنيات

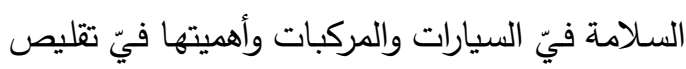

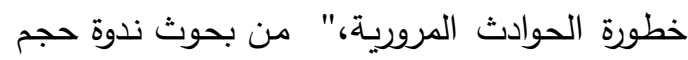
حوادث المرور فيّ الوطن العربي وسبل معالجتها " جامعة نايف العربية للعلوم الأمنية، الرياض، السعودية.

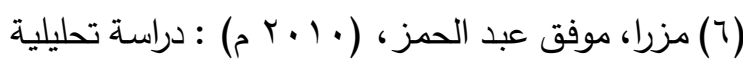
لوجستية فيّ تطوير وتحسين الخدمات - تطوير النقل عزيل الخاص بالعراق ."رسالة ماجستير غير منشورة مقدمة

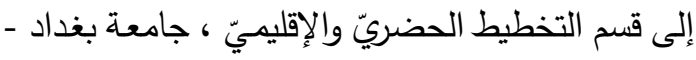

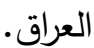

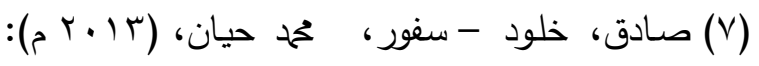
المدن الذكية ودورها فيّ إيجاد حلول للمشكلات

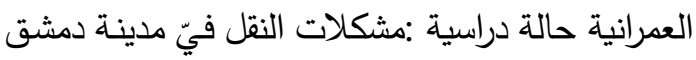
بحث منشور فيّ مجلة جامعة دمشق للعلوم الهندسية،

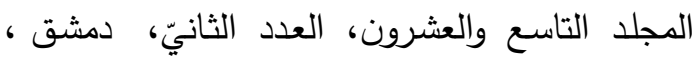

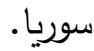

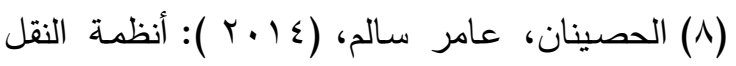

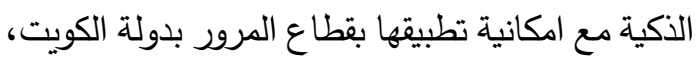

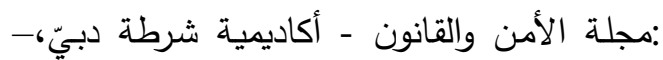
المجلد،بr،العدد، الامارات العربية المتحدة.

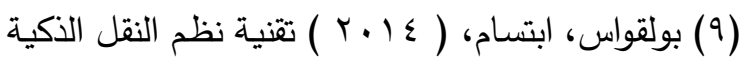
كاستراتيجية لتطوير قطاع النقل، مجلة رؤى اقتصادية

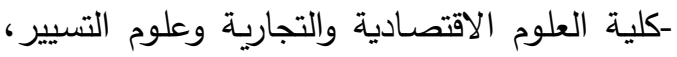
المجلد الأول، العدد 7، جامعة الوادي، الجزائر .

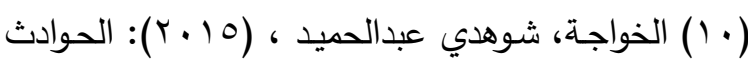
المرورية على شبكة الطرق فيّ المدينة المنورة دراسة الماته جغرافيــة باســتخدام نظــــم المعلومـــات الجغرافيـــة (GIS) السادس والخمسون، يناير، المنصورة.
الرحلات، وهيّ آليات تطبق لمعرفة مواقع (ع) الاختناقات ليتم توجيه السائقين وللإسراع فيّ حل الاختناقات ولإشعار السائقين عن طريق 11 (1)، و لوحات إعلانية وشاشات رقمية على - الطريق من أجل دعم توفير السلامة ITS ضرورة توافر أنظمة نقل منخفضة القدرة للأنظمة

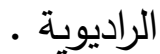
تدريب وتأهيل الكوادر الفنية الوطنية على ألى العمل فّي مجال أنظمه النقل الذكية، مع الاستفادة من الخبرات الأكاديمية الأجنبية فيّ

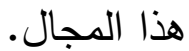

\section{الهـــــامش:}

(1) الزهرانسيّ، عبد الـرحيم بـن حمـود، ( ع . . بم): دور

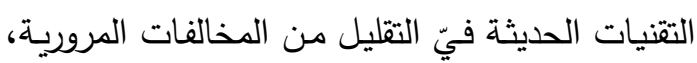

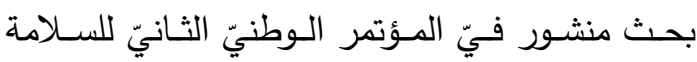
المروريــة المخالفــات المروريــة: الأســباب والآثـار

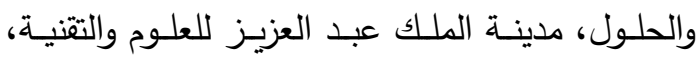

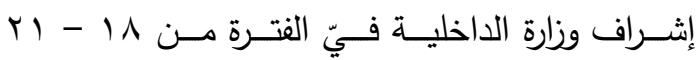

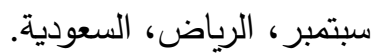

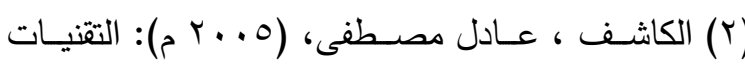

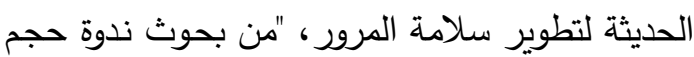

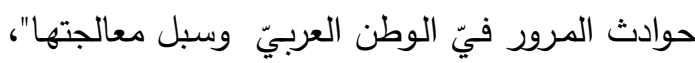

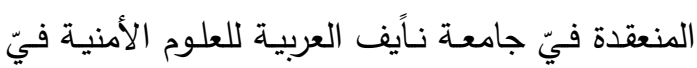
الفترة من اY - rr نوفمبر، الرياض، السعودية.

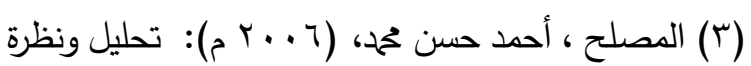
مستقبلية قصيرة الأمد لمخطط المواصـلات فيّ مدينة جنين "، رسالة ماجستير غير منشورة ـ مقدمة إلى قسم هندسة الطرق والمواصلات بكلية الدراسات العليا ، جامعة النجاح الوطنية ،نًابلس، فلسطين. 
مدينـة الريـاض، تقويم اسـتخدام وسـائط النقل المصادروالمراجع : المجاج العام ذات السعة العالية ، الفرص والتحديات، أولاً: باللفة العربية : الــروس المسـتفادة مـن تجربــة فـيّ الثـرق

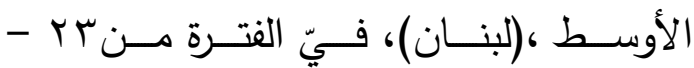
هrأكتوبر ، الرياض.

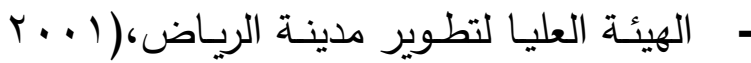
م): نحو تطوير نظام نقل عام آمن وفعال فيّ مدينـة الريـاض، تقـويم تمويـلـ وتثـغيل وإدارة

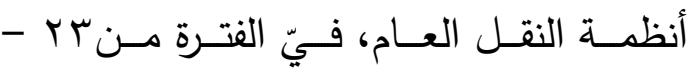
ه广أكتوبر ، الرياض.

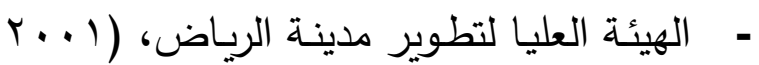
م):نحو تطوير نظام نقل عام آمن وفعال فيّ مدينـة الريـاض، أنظمـة النقل العام، فيّ الفترة من سץ - مبأكتوبر ، الرياض.

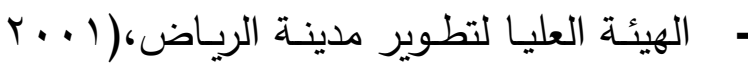
م): نحو تطوير نظام نقل عام آمن وفعال فيّ مدينة الرياض، المتطلبات المؤسسية والإداريـة لتطـوير وتثـغيل أنظمــة النقـل العـام، نظـرة

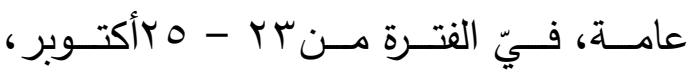

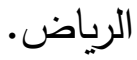
- جامعة الملك عبد العزيز،(ع ا • م م): التخطيط العمرانيّ و الاستراتيجيّ و الإدارة الاستراتيجية للمدن، الإصدار 10 ، مركز الإنتاج الإعلامي،.جدة. - جبر مـازن عليّ عوض، الظريـف جمال،(9. . بrم ): النقل الذكيّ فيّ بيئة حضرية سريعة النمو فيّ مدينة أبو ظبيّ كمثال تطبيقيّ، دائرة الشؤون البلدية، بلدية أبو ظبيّ.

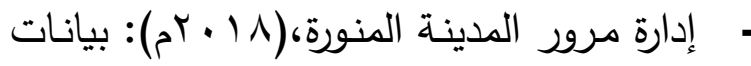
غير منشورة، المدينة المنورة.

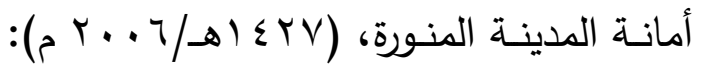

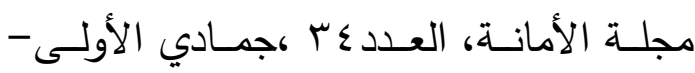
جمادي الثانية ، المدينة المنورة. - الرئاسـة العامــة لشـؤون المسـجد النبـوي، إدارة الأنظمة والثؤون القانونية، (1 ا • r م): بيانات غير منشورة، المدينة المنورة.

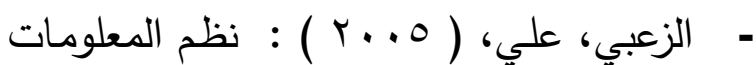

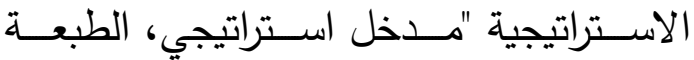
الأولى، عمان، دار وائل للنشر، الأردن. - السعيد ناصـر أحمد،(ع . . ب): شبكة الطرق ونظـام المـرور - تجربـة بلديـة دبي، ندوة إدارة وتطوير الخدمات البلدية والمرافق العامـة فيّ المدن العربية، المعهد العربي لإنمـاء المدن، الخرطوم ، جمهورية السودان.

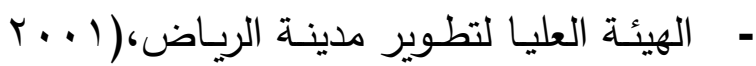
م): نحو تطوير نظام نقل عام آمن وفعال فيّ مدينـة الريـاض، التحديات والفرص المتاحـة، فيّ الفترة من بr - ه بأكتوبر ، الرياض.

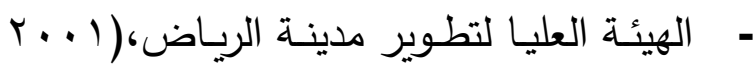
م): نحو تطوير نظام نقل عام آمن وفعال فيّ مدينــة الريـاض، ورشــة عمـل ،تجربــة مدينــة

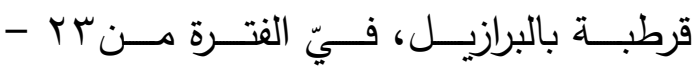
ه بأكتوبر ، الرياض.

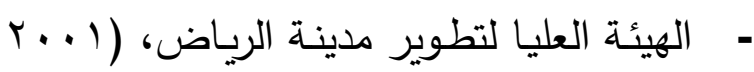
م):نحو تطوير نظام نقل عام آمن وفعال فيّ 
عبدالرحيم حمود الزهرانيّ،(9 (19 1999 199 م):وقـائع نقـل الحجـاج والحاجـة إلى تطـوره، ندوة النقل البريّ بين الماضيّ والحاضر ، كلية الهندسة، جامعة الملك عبدالعزيز، ذو الحجة، جدة. عبد الله بن عبد الرحمن المقبل ،(0. . . F م) : أنظمة النقل الذكيّ فيّ المملكة العربية السعودية 6الرياض.

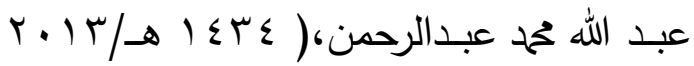
م): تقيـيم خـدمات نقـل الـزوار إلـى المدينــة المنورة دراسـة ميدانية سبـ إنه هـ، معهد خادم الحـرمين الثــريفين لأبحـاث الحــج والعمـرة، جامعة أم القرى، مكة المكرمة. عمـر حسـين جفـريّي،( ^ . ع ا هـ/ 1911 () ): النقابة العامة للسيارات وشركات نقل الحجاج، تاريخ ونطور ، ندوة النقل الثالثة للحج، وزارة

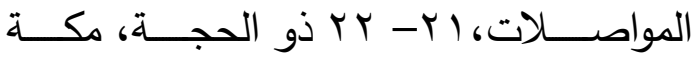

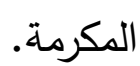

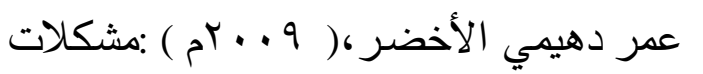
المرور وسبل معالجتها ،" التجارب العربية والدولية في تتظيم المرور "من بحوث الندوة المقدمة إلى مركز الدراسـات والبحوث بجامعة نًايف العربية للعلوم الأمنية المنعقدة في الفترة

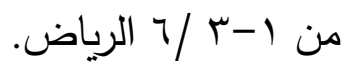

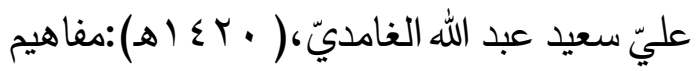
أساسية فيّ علم المرور، الطبعة الأولى،

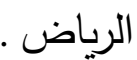

- حامد موسى الخطيب ، (0. - بrم ): الاتجاه العـام لتوزيــع الملوحسـة فـيّ الميــاه الجوفيــة السطحية بالمدينة المنورة، مجلة مركز بحوث ودراسـات المدينـة المنورة، العدد ب ا ، المدينـة المنورة.

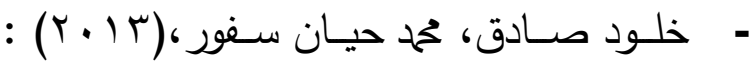

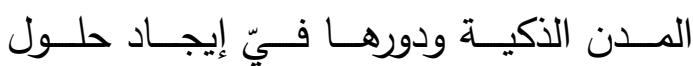
للمشكلات العمرانيـة حالـة دراسـية: مشكلات النقل في مدينـة دمشق، مجلة جامعـة دمشق

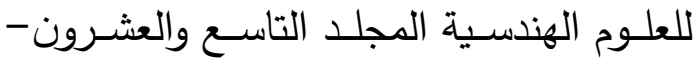

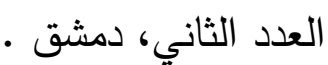

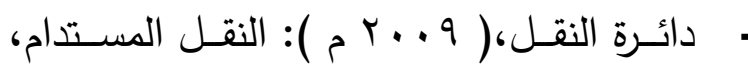
تقرير الاستدامة لدائرة النقل فيّ أبوظبي لعام

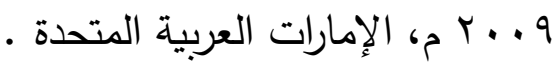

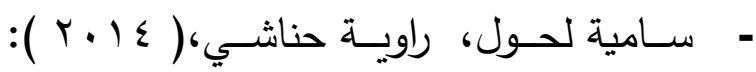
مساهمة نظم النقل الذكيّ فيّ الحد من التلوث البيئي " مجلة اسيوط للدراسـات البيئية، العدد

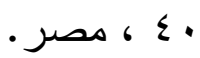

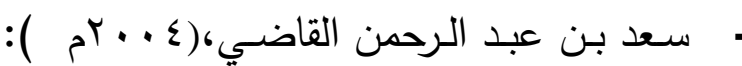
نظـم النقـل الذكيـة أهــم مواضـيعها وفـرص تطبيقها في المملكة العربيـة السـعودية، كليـة الهندسة، جامعة الملك سعود، الرياض.

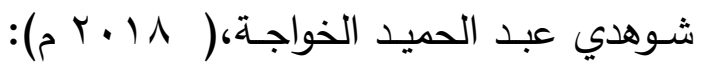
انتـاج ميـاه الثـرب واسـتهلاكها فيّ المدينـة المنـورة :دراســة فـيّ الجغرافيـا الاقتصـادية، رسـائل جغرافيـة ، مجلـة الجمعيـة الجغرافيـة

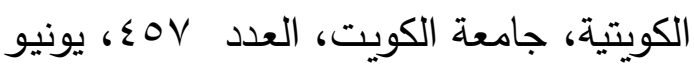




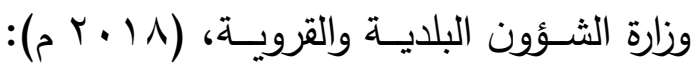

الادارة العامــة للتخطــيط، المملكــة العربيــة السعودية، الرياض. الاض.

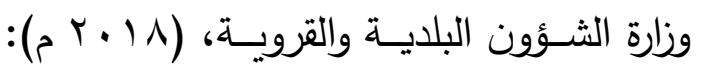

التقريـر الثـامل لمؤشـرات المرصـد الحضـريّ

للمدينــة المنـورة، المملكـة العربيـة السـعودية، المدينة المنورة، السعودية.

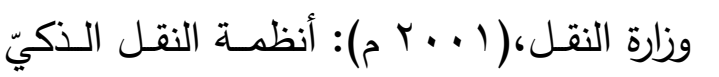
فـيّ تــونس ، أهــداف النقـل الـــكيّ ، إدارة التنظيم والإعلامية، وزارة النقل، تونس.

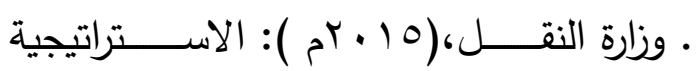
الوطنيـة للنقل، منتدى الريـاض الاقتصـاديّ نحو تتميـة اقتصـادية مستدامة، دراسـة تطوير النقــل داخـل المــدن فـيّ المملكــة العربيــة السعودية، الدورة الخامسة، الرياض.

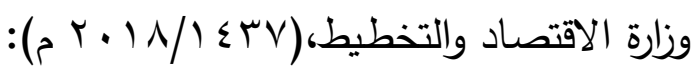

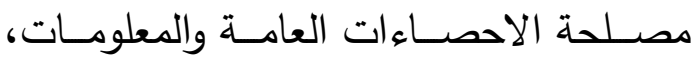
المؤشرات الدوليـة للسكان والمسـاكن ،الكتاب

$$
\text { الإحصائيّ السنويّ العام، الرياض. }
$$

- Applications and Requirements,( 2011): European M. C. Luis, W. Klaus, Smart Cities Technology Platform,.

- Bart van Arem,( 2006): INTELLIGENT TRANSPORTATION SYSTEMS, "IEEE ITS SOCIETY NEWSLETTER" Vol. 8, No. 1, March.

- Caskey, D. and P. Heermann, (1995):White Paper on The National ITS System Architecture: Transit Issues and Recommendations. The Volpe National Transportation Systems Center, Cambridge, MA, USA, October.

- Caragliu, A; Del Bo, C. \& Nijkamp, P (2009). "Smart Cities in Europe". Serie Research Memoranda 0048 (VU University Amsterdam, Faculty of

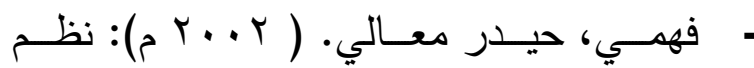

المعلومـات: مدخل لتحقيق الميـزة التنافسية، الدار الجامعية للنشر، الإسكندرية.

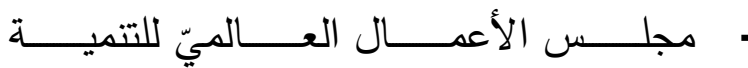

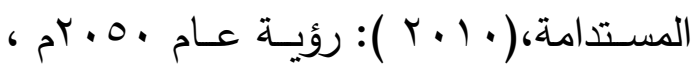
فبراير ، سويسرا.

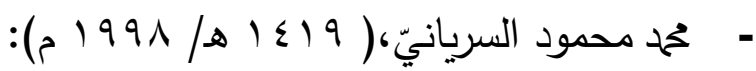
المدينـة المنورة دراسـة في التطور الحضـريّ ،

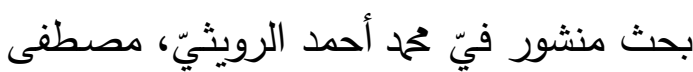
خوجليّ سلسلة بحوث المدينـة المنـورة البيئة والإنســان، نـادي المدينــة الأدبــيّ، المدينــة

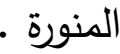

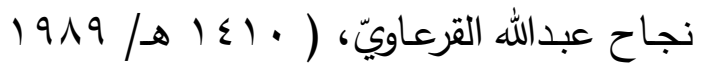
م) شـبكة الطـرق البريـة فيّ المدينـة المنـورة، نادي المدينة الأدبيّ، المدينة المنورة .

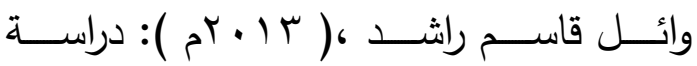
اقتصادية لمشكلة الازدحام المروريّ فيّ مدينة البصــرة، مجلــة دراســات البصــرة، الســـة السابعة، العدد س (،العراق.

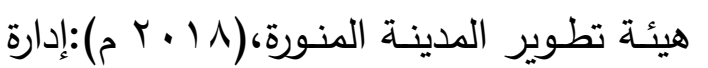
النقـل والطـرق فـيّ المدينــة المنـورة، المدينـة

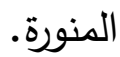

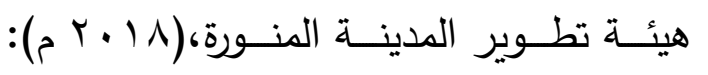
ملخـص المخطـط الثـامل، البوابـة الوطنيـة للتعـاملات الالكترونيـة الحكوميـة ، ملخـص

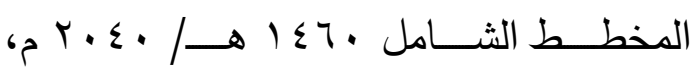
المدينة المنورة. 
- Matsah,M.I.\& Hossain,D.,(1993):Ground Conditions in AL-Madinah ALMunawarah,Saudi Arabia,JKAU:Earth science,6,pp.47-7

- North Dakota Department of Transportation , Intelligent Transportation Systems (ITS). Statewide Plan ,"Final Report", Advanced Traffic Analysis Center Upper Great

- Pardo, T., \& Taewoo, N. (2011), Conceptualizing smart city with dimensions of technology, people, and institutions, the12th Annual International Conference on Digital Government Research New York, ACM., pp. 282-291

- Plains Transportation Institute North Dakota State University Fargo, (2011): North Dakota, October.

Shibata, Jun and Robert French, (2010):“A Comparison of Intelligent Transportation Systems :Progress Around the World Through". ITS America, June.

- Stratigea Anastasia, E.A. (2015): Tools and Technologies for Planning the Development of Smart Cities, Journal of Urban Technology, v. 22.

- Washburn, D. (2010): Helping CIOs Understand "Smart City" Initiatives, Defining the Smart City, Its Drivers, and the Role of the CIO: Cambridge, MA, Forrester Research, Inc., Vartanian

\section{ثالثاً : مواقع بشبكة المعلومات الدولية:}

www.techno-science.net Système de

transport intelligent-

http://www.itstunisie.tn/index.php -

-ITS America Web Site: http://www.itsa.org www.dilax.fr/comptage-de-personnes -

WwW.thisbigcity.net

- http://blog.translinedz.com/2013/05/blog

- http://www.itsa.org/

- http://www.ertico.com/

http://www.iijnet.or.jp/vertis/ -

www.cirrelt.ca/DocumentsTravail /.pdf -

وزارة النقل. Www.mot.gov.sa. تم الاطلاع عليه

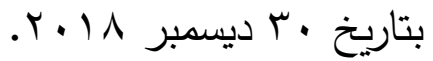

Economics Business Administration and Econometrics.

- Dameri, R.P. (2013), Searching for smart city definition: a comprehensive proposal, International Journal of Computers \& Technology, v. 11.

- European Telecommunications Standards Institute,( 2009): "Intelligent Transport Systems" (ITS Basic Set of Applications Vehicular Communications; Definitions) "Technical Report", ETSITR 102638 V1.1.1.

-E.Stephen, Explaining International IT Application Leadership: Intelligent Transportation Systems, The Information Technology\& Innovation Foundation, 2010.

-Giffinger, R. , C. Fertner, H. Kramar, R. Kalasek N. , ( 2007 ): Pichler-Milanovic and E. Meijers, Smart Cities - Ranking of European Medium-Sized Cities, Research Report, Vienna: University of http://wwwTechnology, Vienna, Austria smart-

cities.eu/download/smart_cities_final report.pdf

- hany samy abu el ela , (2016): monitoring some smart city geographical characteristics of medina in saudi arabia roum. géogr./rom. journ. geogr., 60, (2), p. 183-201, 2016, bucureşti

- Hollands, R.G. (2008), Will the real smart city please stand up? Intelligent, progressive or entrepreneurial?, City, v. 12 , pp. 303-320

- ITS Focus, ITS Focus report on System Architecture,( 1997) : Evaluation of the US National ITS Architecture and Recommendations for the U.K. ITS Focus Task Force on System Architecture, UK, May.

- I. Kamarulazizi,(2009): Intelligent City An Enable For A First Class Hajj Service, Intelligent Cities Conference, Umm AlQura University, Makah/Saudi Arabia.

- Joseph, T. (2014): Smart city analysis using spatial data and predicting the sustainability, International Journal of Computer and Technology(IJCTT), v. 12. 


\section{ملحق ( 1 ) بسم الله الرحمن الرحيم}

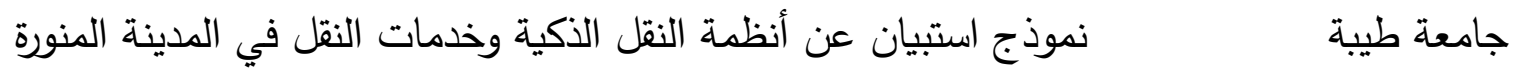
(يرجى التفضل بتحري الدقة عند الإجابة

كلية الآداب والعلوم الإنسانية

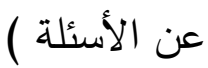

مكان الراصد بمنطقة المدينة المنورة:

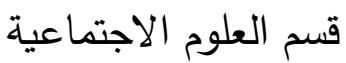

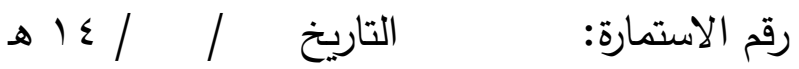

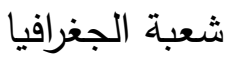

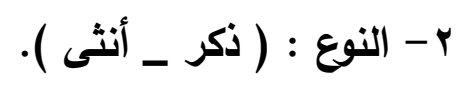

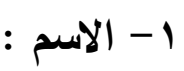

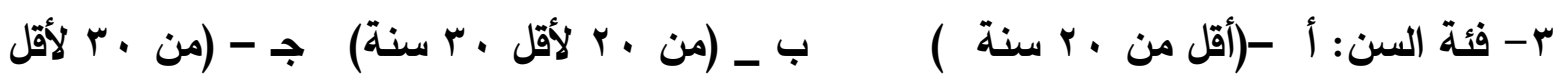

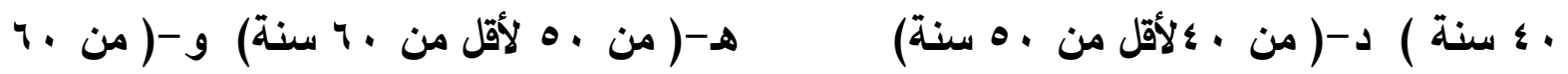

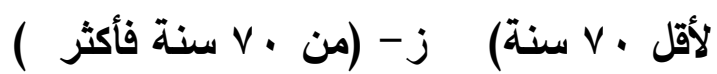

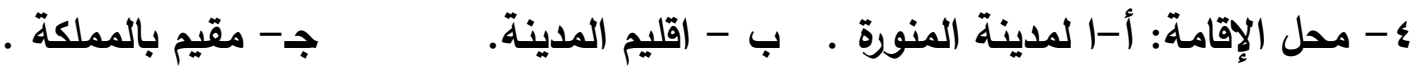
د- مائر من خارج المملكة

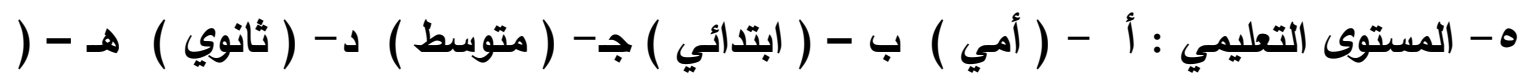
دبلوم ) و - ( جامعي ) ز - ( فوق جامعي ).

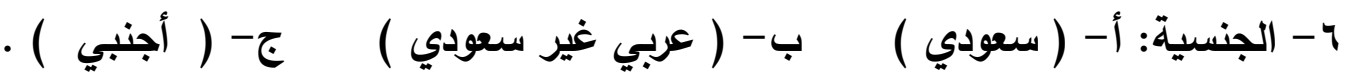

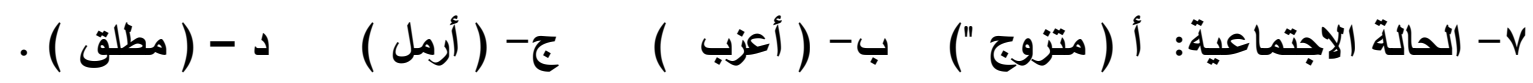

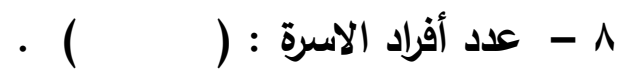

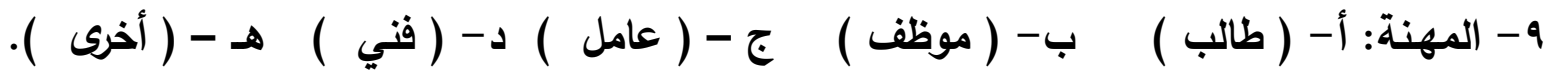

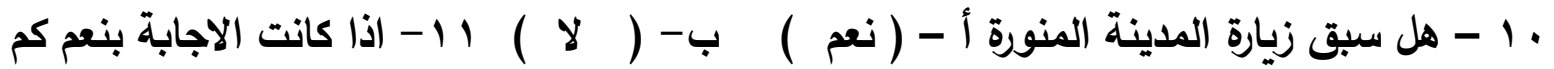
عدد مرات الزيارة . عليق

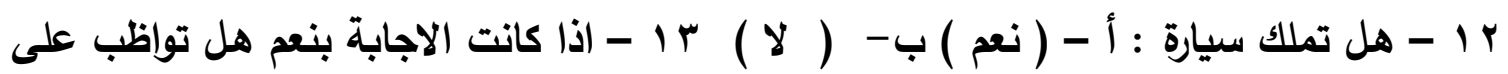

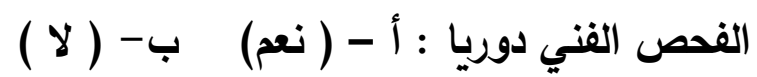

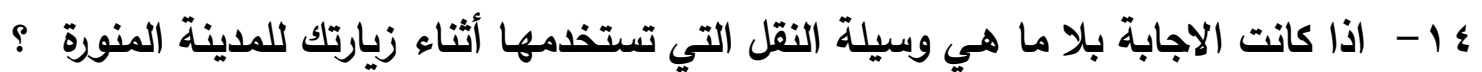

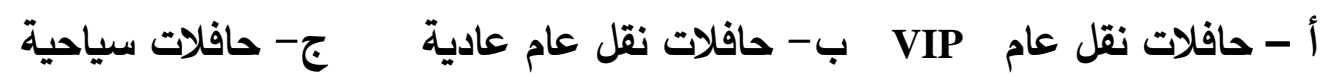
و - وسيلة نقل أخرى داحيه

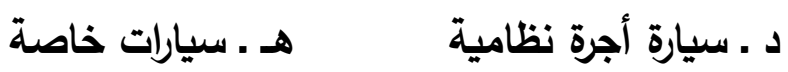

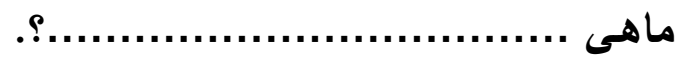
؛ ا - اذا كنت تملك سيارة : هل تقودها بنفسك ؟ : أ - ( نعم ) ب- ( لا ) ) 
10 - ما رأيك في شبكات الطرق والثوارع فيّ المدينة المنورة ؟ أ- ( ممتازة ) ب - ( فوق )

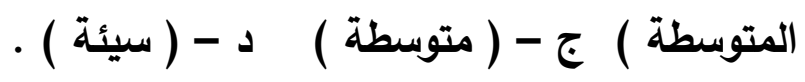

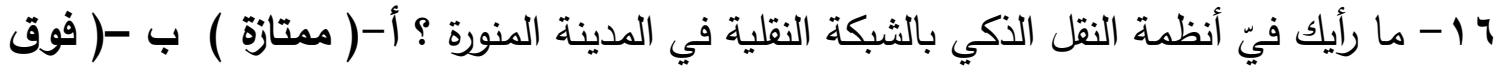

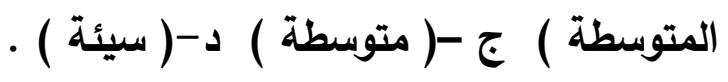

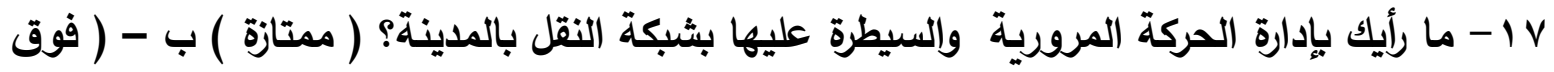

$$
\text { المتوسطة ) ج - ( متوسطة ) د -(سيئة ). }
$$

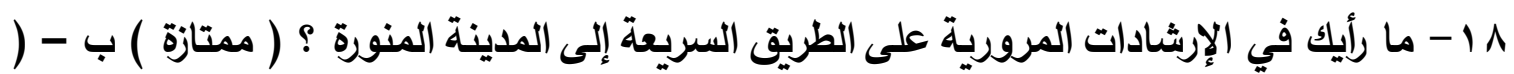
فوق المتوسطة ) ج - ( متوسطة ) د -(سيئة ).

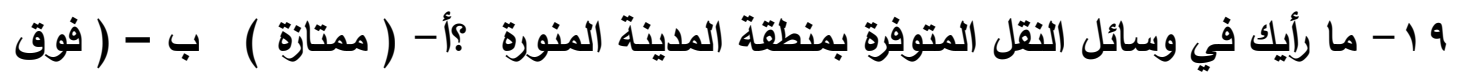

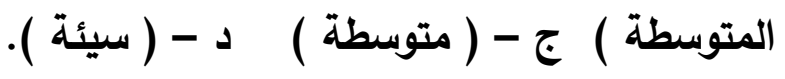

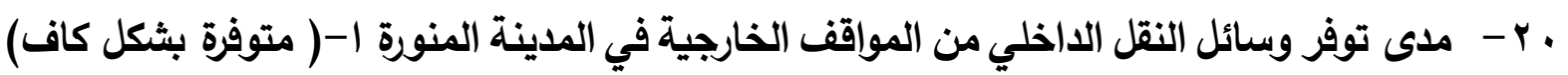

$$
\text { ب - (جيدة جدا) ج - ( جيدة ) د - (ضعيفة ). }
$$

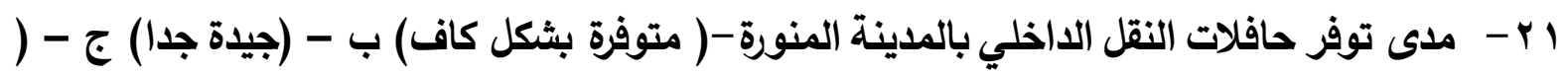

$$
\text { جيدة ) د - (ضعيفة ). }
$$

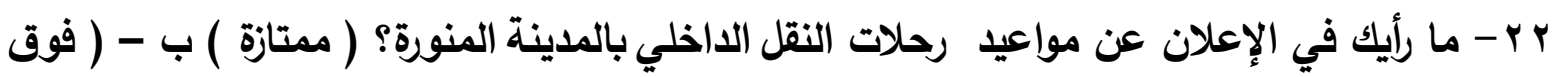

$$
\text { المتوسطة ) ج - ( متوسطة ) د -(سيئة ). }
$$

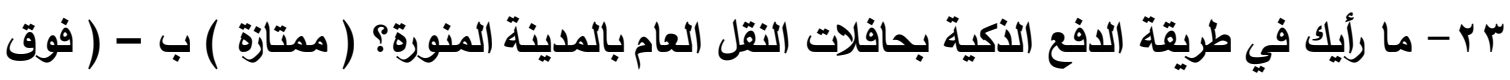

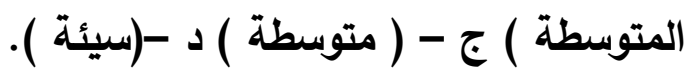

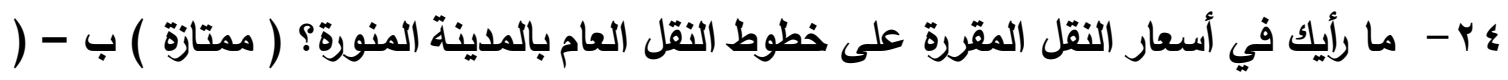

$$
\text { فوق المتوسطة ) ج - ( متوسطة ) د - (سيئة ). }
$$

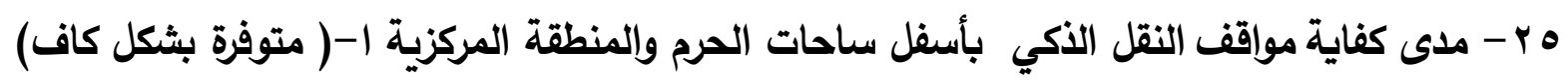

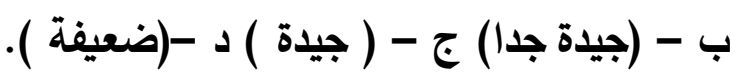

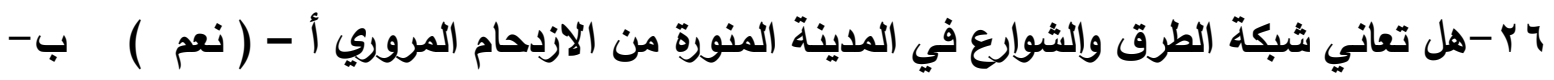

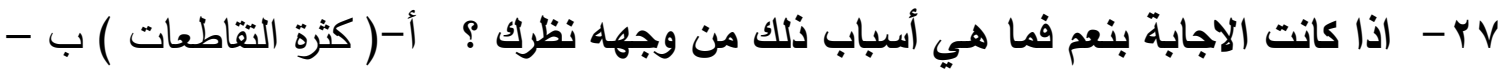

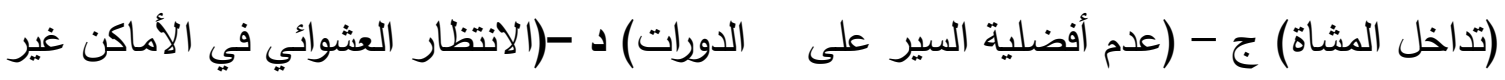
المخصصة للانتظار).هـ (عدم وجد تنظيم كاف للنقل الداخلي ) و -( تركز الخدمات على جانبي

الثوارع ) 
ه/ شوهلدي عبدا لحميل عبد القادر الخواجه

المدن الذكية ودورهل في علاج مشكلات النقل الحضري - حالة المدينة المنورة.

^ץ - هل تساعد أنظمة إدارة الطرق ونشر بيانات المسافر فيّ تقليل تأخير الرحلات ؟ أ - ( نعم )

-

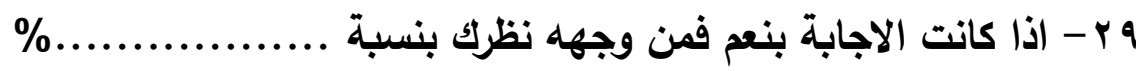

• r - هل تساعد أنظمة النقل الأكية والسلامة المرورية على تقليل الحوادث وتخفض من وقت الرحلة

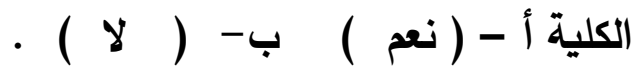

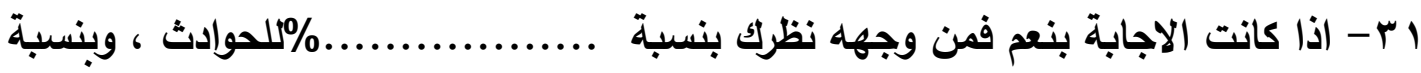

\% لوقت الرحلات.

ץ r-ما أهم المقترحات التي تراها لتحسين الحركة المرورية ورفع كفاءة حركة النقل في المدينة

المنورة

أ- تحديث كافة الإرشادات المرورية ب - زيادة انسيابية الحركة المرورية ج - تخصيص طرق

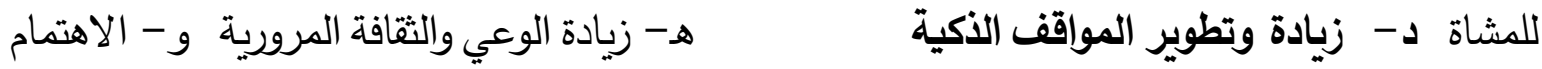

بخدمات النقل لذوي الاحتياجات الخاصة والثيبة - تنظيم أسعار النقل

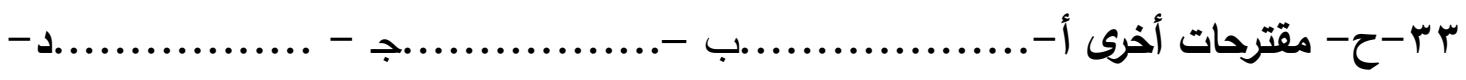

شكراً على حسن تعاونكم

$\leqslant 10$ 
ملحق (r)
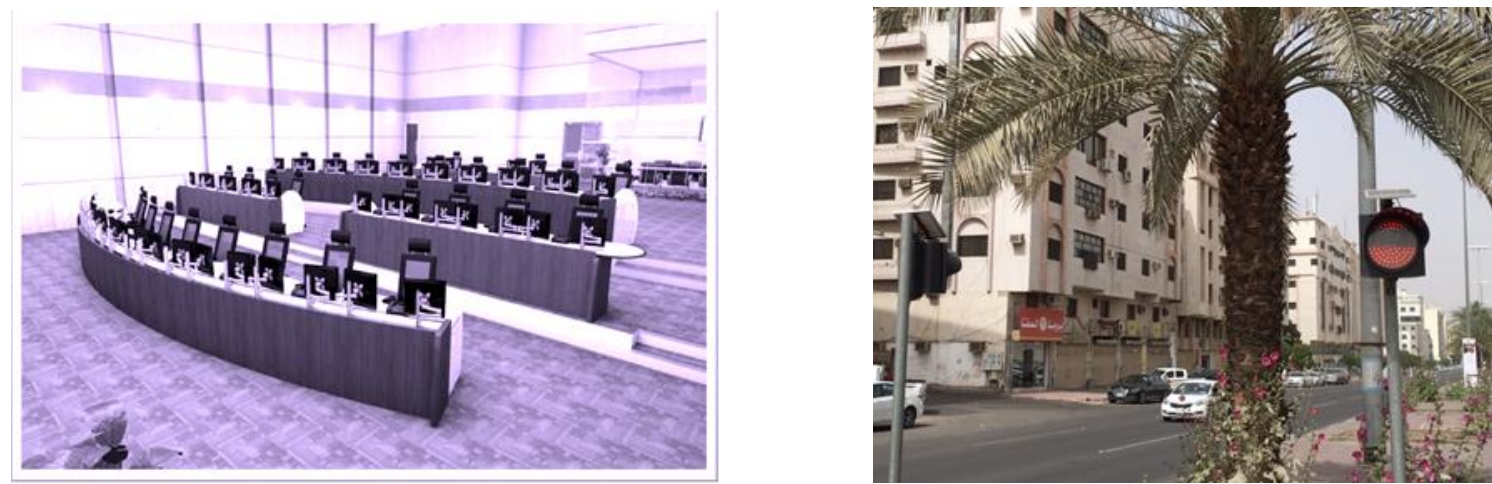

صورة (1) استخدام الإنارة الذكية فيّ الإثارات لترشيد الطاقة صورة (r) مركز السيطرة والتحكم
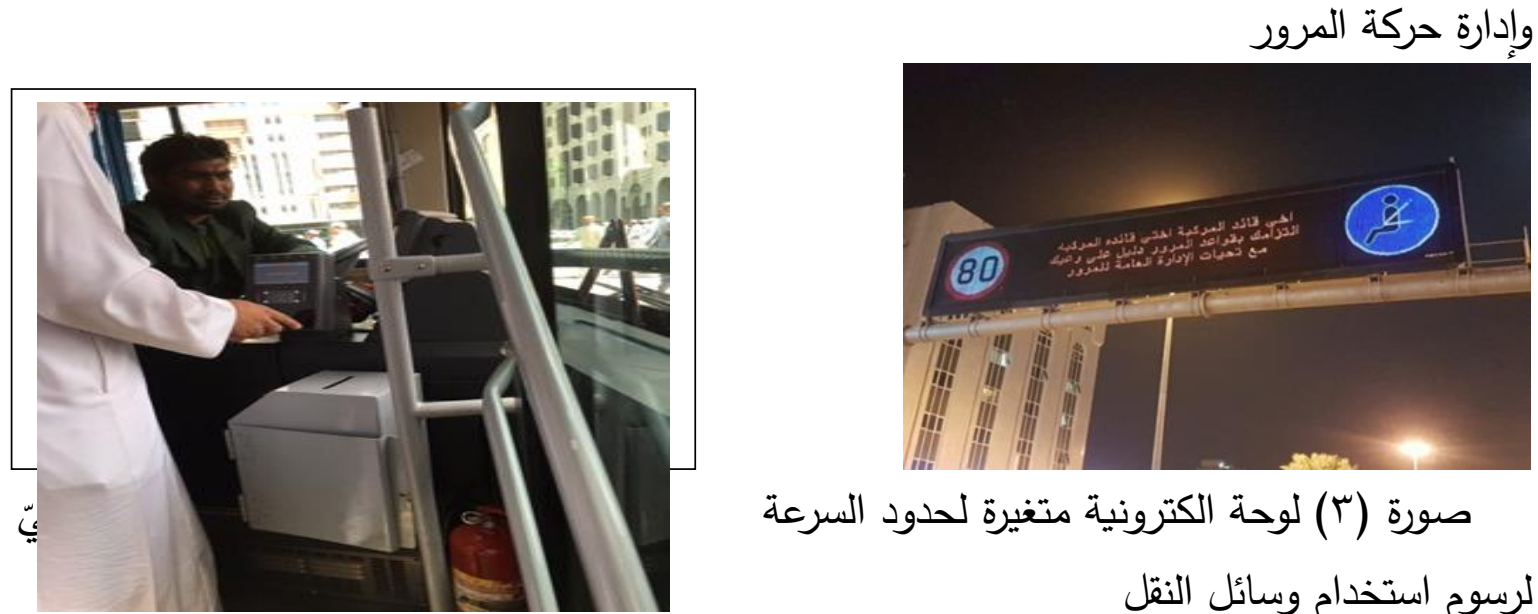

صورة (r) لوحة الكترونية متغيرة لحدود السرعة

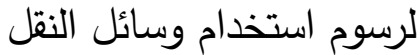
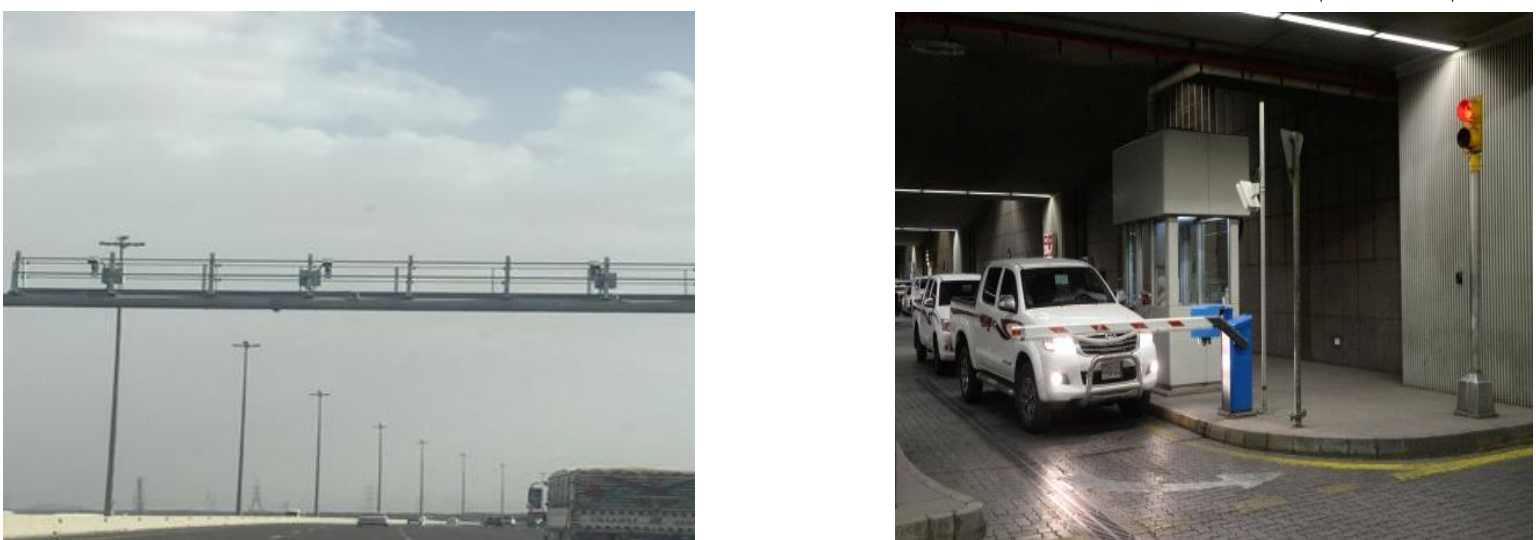

صورة ( ا) أنظمة ضبط مخالفات عدم ربط

صورة (0) بوابات التعريفة الإلكترونية للمواقف الذكية حزام الأمان، واستخدام الجوال أثناء القيادة 


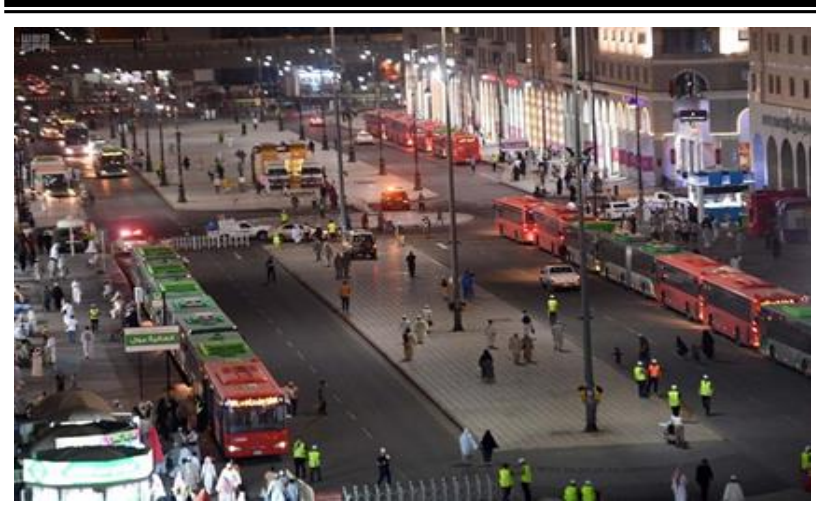

صورة ( V ) أنظمة ضبط مخالفات قطع الاشارة وهي حمراء صورة ( A ) حافلات النقل العام الترددي
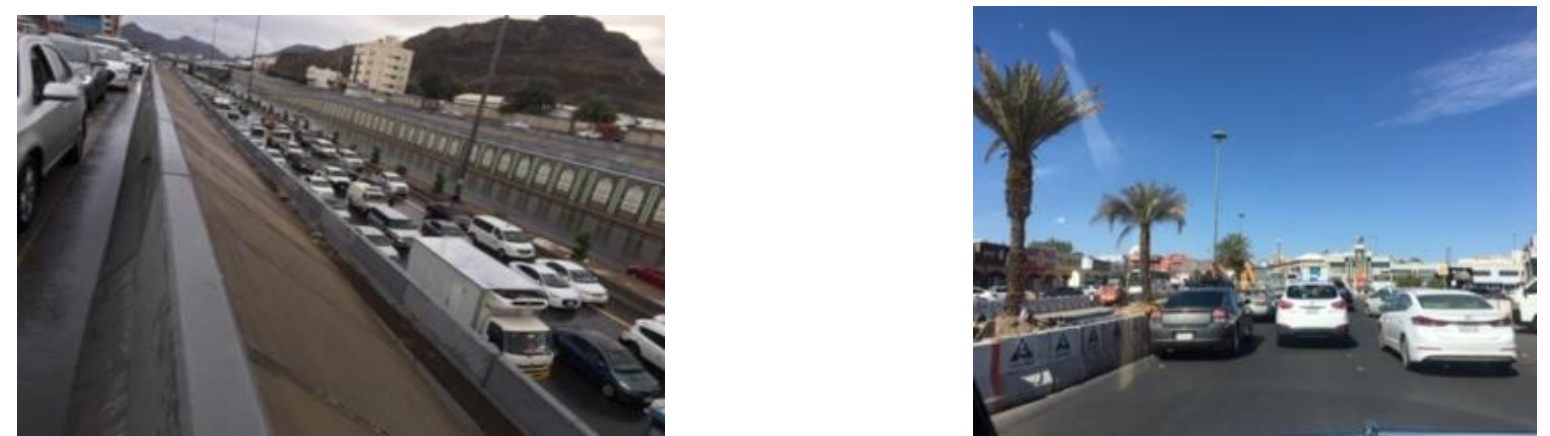

صورة (9 ) حفريات المياه والكهرباء وأثرها في المشاكل المرورية صورة ( • ()ازدحام شوارع المدينة المنورة فيّ مواسم الحج والعمرة
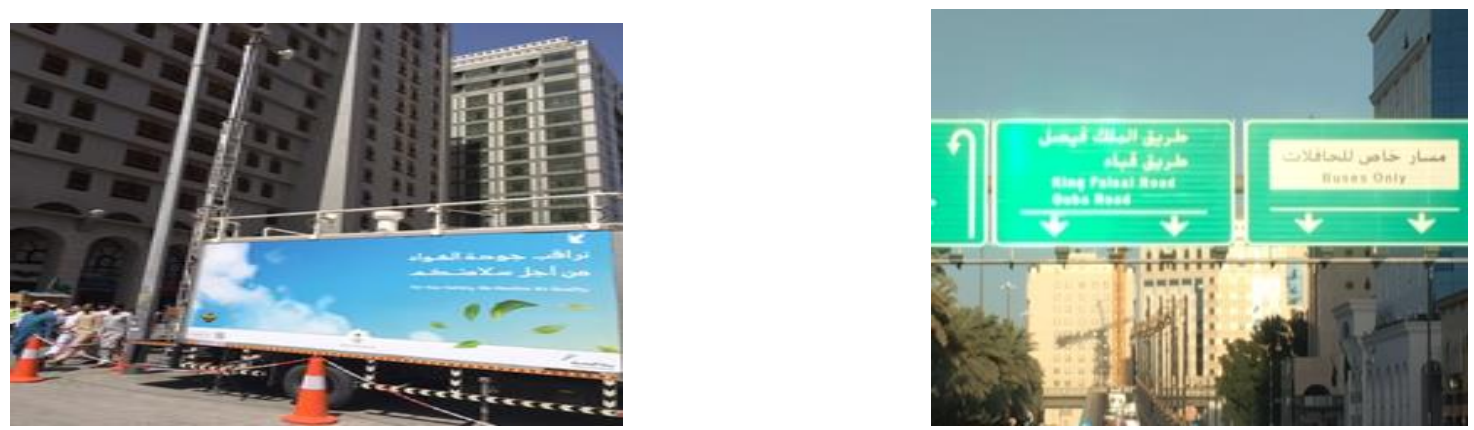

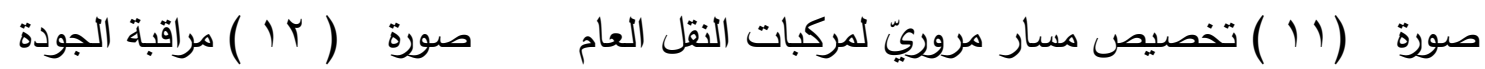
العامة للهواء وإدارتها 

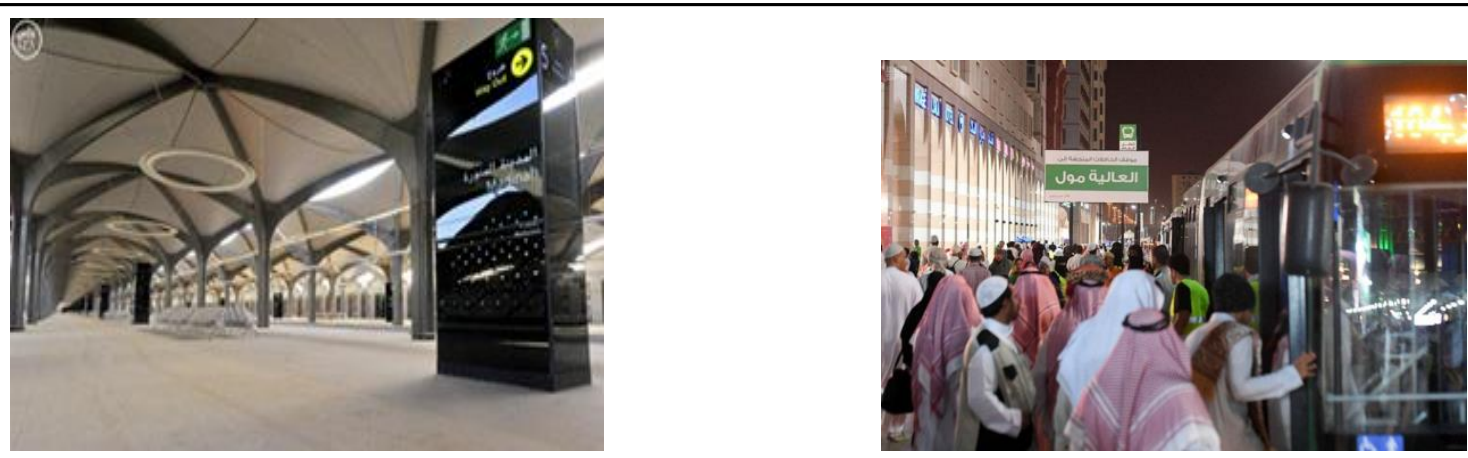

صورة ( ب ()لحافلات النقل العام التردديّ من وإلى الحرم صورة ( ع ( ) محطة سكك حديد المدينة المنورة
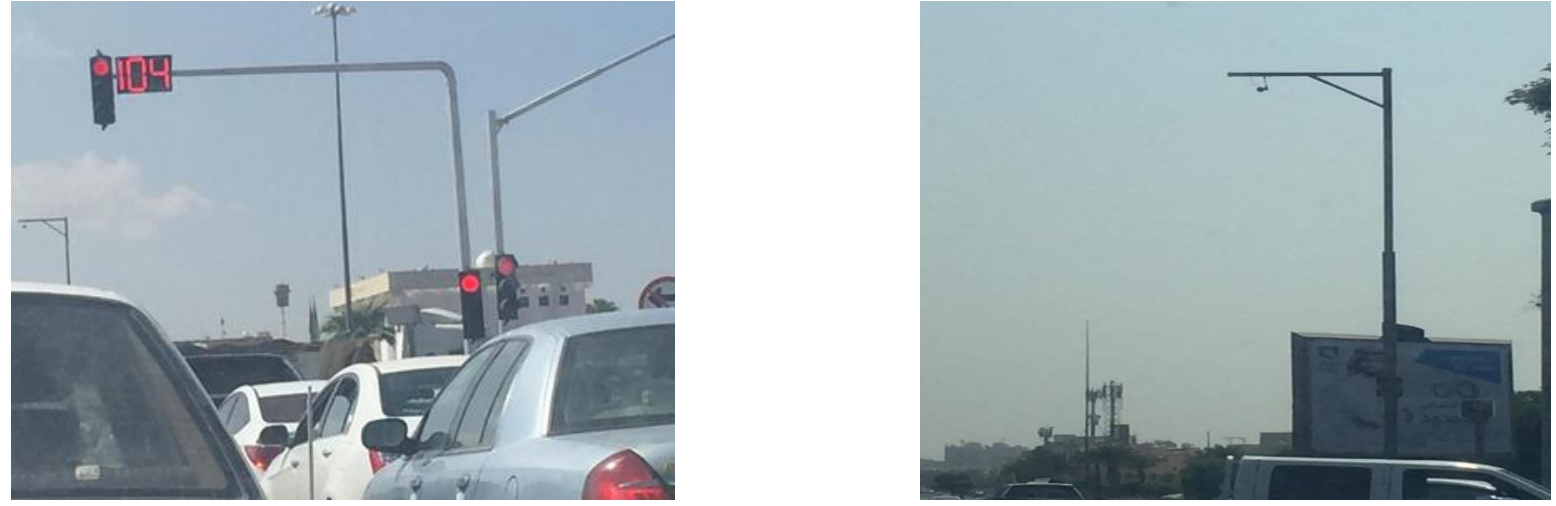

صورة (7 1 ) توقيت ديناميكيّ لدورات الإشارات الضوئية و

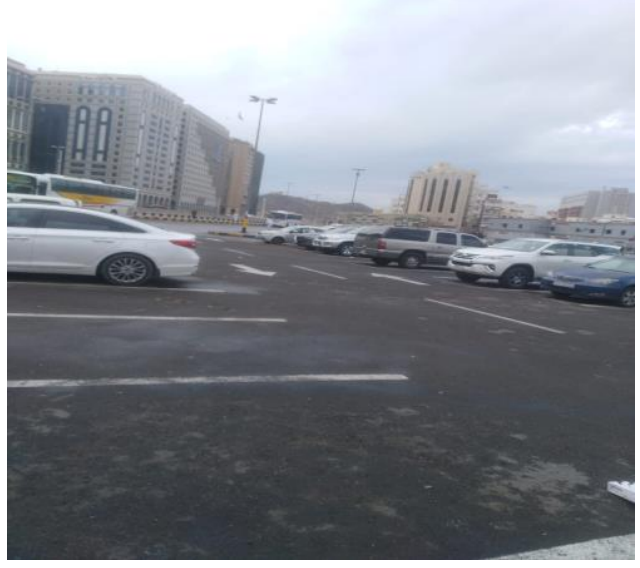

صورة ( 1 1 ) المواقف الذكية المنشرة بالمنطقة

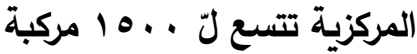

صورة ( م 1) كاميرات فيديو لمراقبة حركة المرور إدارة الأحداث المرورية

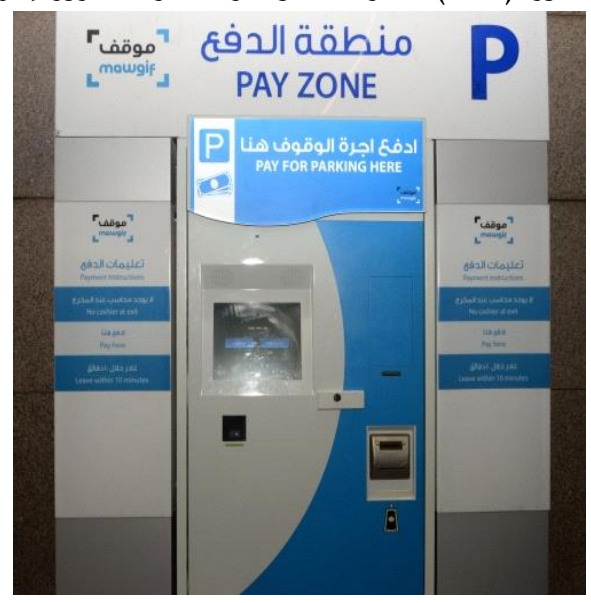

صورة ( V ) مواقف النقل الذكية المزودة بأنظمة الدفع الذكية 

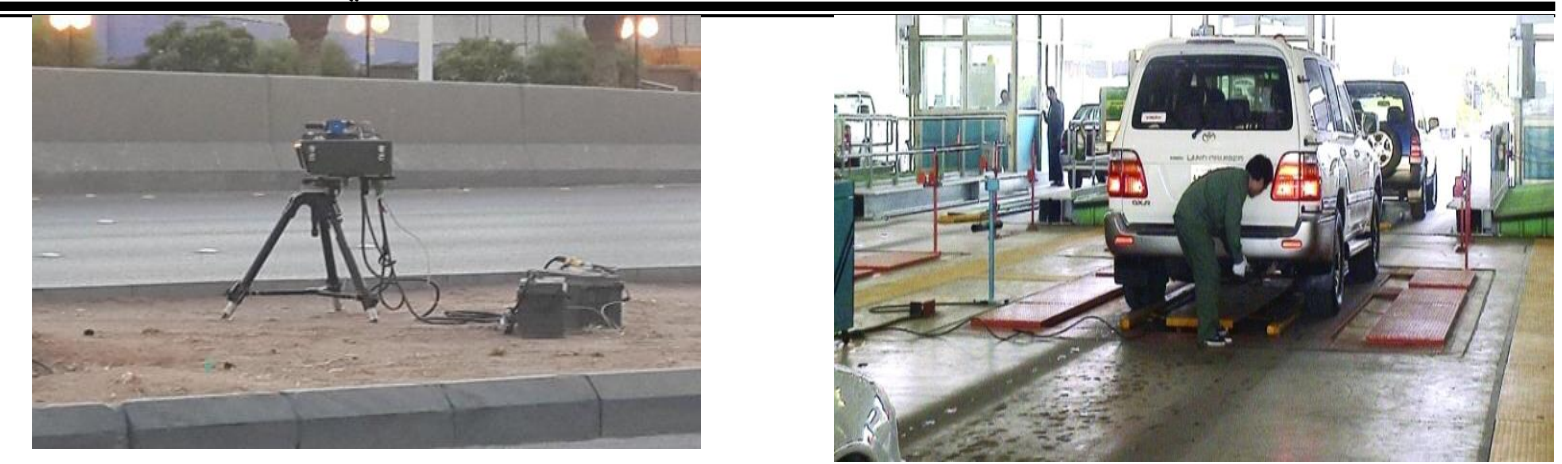

صورة (·r) بنظام ساهر أو كاميرات قطع الإثارات المرورية

صورة (9 19) قياس الكربون فيّ محركات المركبة
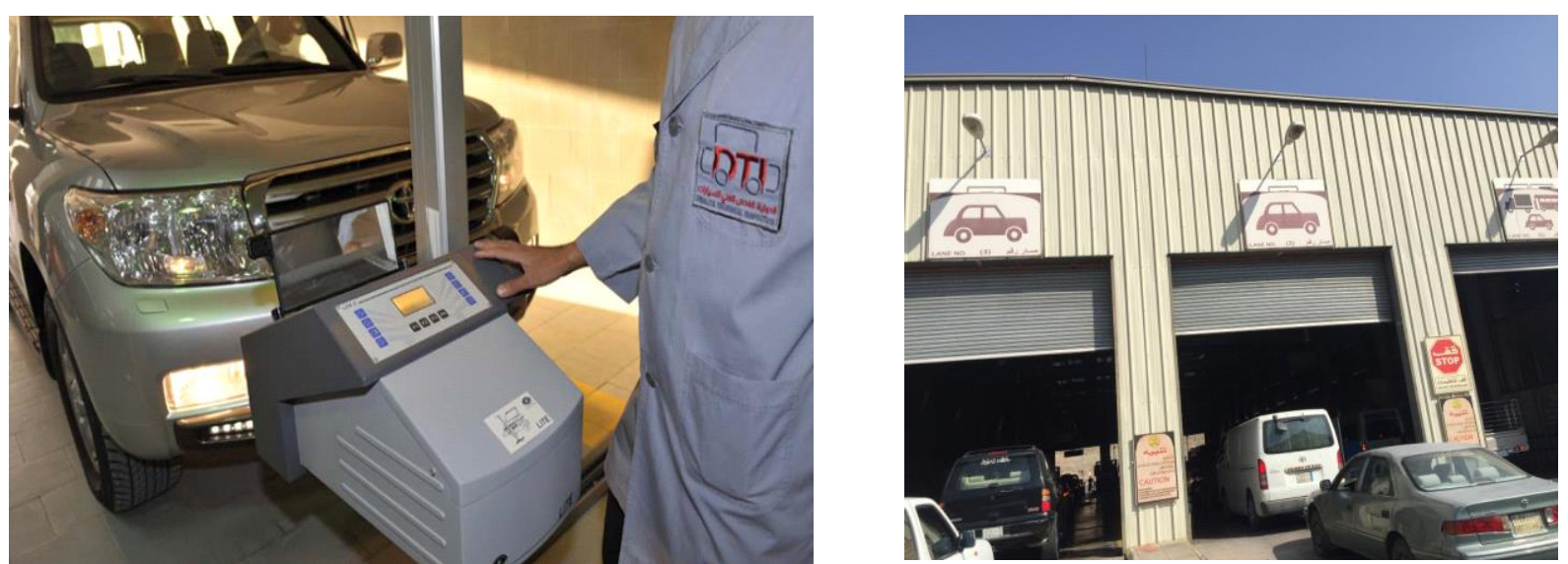

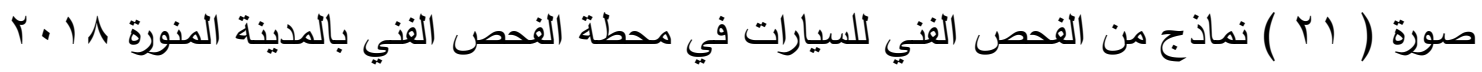

